NATIONAL LABORATORY

MANAGED BY UT-BATTELLE

FOR THE DEPARTMENT OF ENERGY

\title{
Application of Wear-Resistant, NanoComposite Coatings Produced from Iron-Based Glassy Powders
}

\section{$04 / 08 / 2013$}

Prepared by

William H. Peter \& Ryan Dehoff

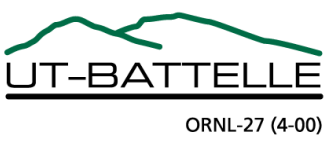




\section{DOCUMENT AVAILABILITY}

Reports produced after January 1, 1996, are generally available free via the U.S. Department of Energy (DOE) Information Bridge.

Web site http://www.osti.gov/bridge

Reports produced before January 1, 1996, may be purchased by members of the public from the following source.

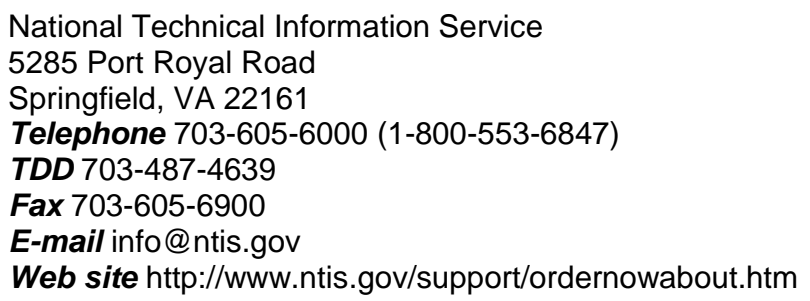

Reports are available to DOE employees, DOE contractors, Energy Technology Data Exchange (ETDE) representatives, and International Nuclear Information System (INIS) representatives from the following source.

Office of Scientific and Technical Information

P.O. Box 62

Oak Ridge, TN 37831

Telephone 865-576-8401

Fax 865-576-5728

E-mail reports@osti.gov

Web site http://www.osti.gov/contact.html

This report was prepared as an account of work sponsored by an agency of the United States Government. Neither the United States Government nor any agency thereof, nor any of their employees, makes any warranty, express or implied, or assumes any legal liability or responsibility for the accuracy, completeness, or usefulness of any information, apparatus, product, or process disclosed, or represents that its use would not infringe privately owned rights. Reference herein to any specific commercial product, process, or service by trade name, trademark, manufacturer, or otherwise, does not necessarily constitute or imply its endorsement, recommendation, or favoring by the United States Government or any agency thereof. The views and opinions of authors expressed herein do not necessarily state or reflect those of the United States Government or any agency thereof. 
ORNL/TM-2013/134

Materials Science and Technology Division

Final Technical Report

\section{APPLICATION OF WEAR-RESISTANT, NANOCOMPOSITE COATINGS PRODUCED FROM IRON-BASED GLASSY POWDERS}

DOE Award Number: CPS Agreement No. 19441

Project Period: July 2008 - May 2012

Primary Investigators:

Dr. William Peter, Dr. Ryan Dehoff, Dr. Peter Blau, Dr. Yukinori Yamamoto, Dr. Wei Chen, Dr.

Adrian Sabau, and Andrew Klarner

Oak Ridge National Laboratory

1 Bethel Valley Rd, Oak Ridge, Tennessee 37831

Industrial Participants:

David Novatnak, Lou Lherbier, Greg DelCorsio, Carpenter Powder

Lou Aprigliano, Consultant, Strategic Analysis

Mr. Carl Van Hoozier and Jeff Moffett, Vulcan Materials Company

Date Published: 04/08/2013

Prepared by

OAK RIDGE NATIONAL LABORATORY

Oak Ridge, Tennessee 37831-6283

managed by

UT-BATTELLE, LLC

for the U.S. DEPARTMENT OF ENERGY

under contract DE-AC05-00OR22725 


\section{ACKNOWLEDGMENT}

This report is based upon work supported by the U. S. Department of Energy, Advanced Manufacturing Office (AMO) as CPS Agreement number 19441.

The authors would like to acknowledge Mr. David Harper for coordination of the tasks in the materials processing laboratory, Mr. Kevin Harper and Mr. Larry Lowe for performing laser deposition of samples, coupons, and components, Mr. Jackie Mayotte for optical metallography and hardness measurements, Ms. Rita Ayers for her help as administrative support including the formatting the report, and Dr. Chad Duty and Hiram Rogers, for their review of the report.

Furthermore, the authors would like to thank the management and guidance of Dr. Gideon Varga formerly of DOE's Industrial Technologies Program Office (now the Advanced Manufacturing Office) and Dr. Joseph Renk of the NETL, Dr. Craig Blue (Program Manager of Advanced Manufacturing at ORNL), and Dr. Alan Liby (Deputy Program Manager of Advanced Manufacturing at ORNL). The team would also like to express appreciation to Jennifer Palmer for her contributions in media and highlight development. Lastly, we would like to thank Jeff Moffett and Carl Van Hoozier for their participation in the project and allowing for coated paddles to be tested at the Vulcan rock quarry. 


\section{Contents}

ACKNOWLEDGMENT ............................................................................................................ V

LIST OF ACRONYMS.................................................................................................................

LIST OF FIGURES.......................................................................................................................

LIST OF TABLES.............................................................................................................................. XV

EXECTIVE SUMMARY ....................................................................................................... XVII

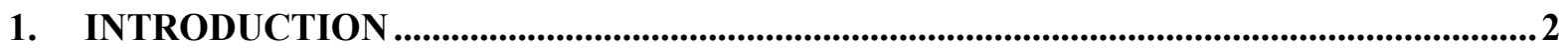

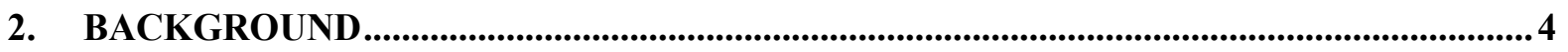

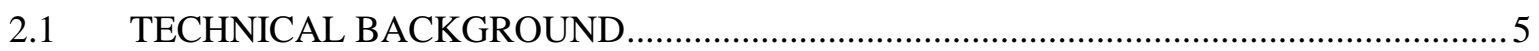

2.1.1 Nanostructured Materials ............................................................................................

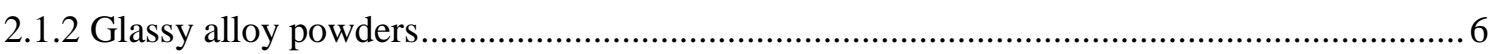

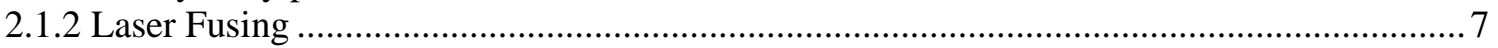

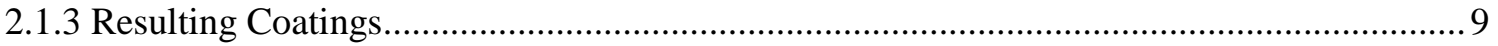

2.1.4 Powder metallurgy consolidation .................................................................................. 9

2.2 RESPONSIVENESS TO ORIGINAL RESEARCH CALL AND FOCUS AREAS ...........10

2.3 POTENTIAL ENERGY AND COST BENEFITS OF WEAR RESISTANT COATINGS

AND STEEL COMPONENTS ………………………………………………………..... 10

2.4 POTENTIAL MARKETS FOR NANOCOMPOSITE COATINGS ……………………......11

3. RESULTS AND DISCUSSION ...............................................................................................

3.1 DESIGN AND EVALUATION OF AMORPHOUS METAL POWDERS ........................12

3.1.1 Powder Production Design and R\&D Atomization........................................................... 12

3.1.2 Commercial Size Atomization of Powders …………………………………………....15

3.1.3 Powder Characterization ..................................................................................... 16

3.2 LASER FUSING AND BULK PROCESSING OF NANOCOMPOSITE …………….......24

3.2.1. Deposition Of -325 Mesh Powder Using A 4 Kw Nd:YAG Laser ....................................2

3.2.2. Deposition of +325 Mesh Powder Using POM Deposition System: ..................................31

3.2.3. Modeling of Laser Deposition...................................................................................... 34

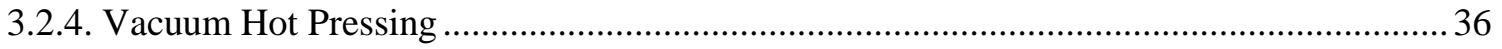

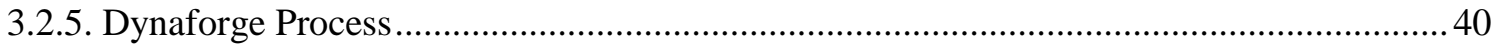

3.2.6. Hot Isostatic Pressing (HIP) …………………………………………………….... 42

3.3 ABRASIVE WEAR AND OTHER MECHANICAL PROPERTIES ..................................51

3.4 FIELD EVALUATION OF NANOCOMPOSITE COATINGS …………………………....60

4. COMMERCIALIZATION..................................................................................................6.6.

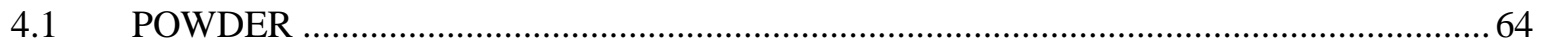

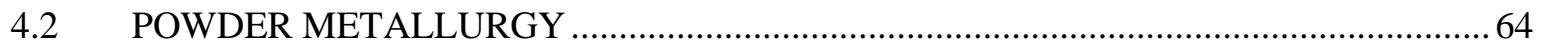

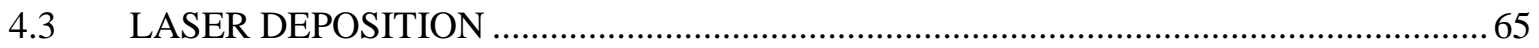

5. CONCLUSIONS........................................................................................................6

6. RECOMMENDATIONS ……………….............................................................................6

7. REFERENCES / BIBLIOGRAPHY ............................................................................................69 


\section{LIST OF ACRONYMS}

AMO: Advanced Manufacturing Office

ASTM: American Society for Testing and Materials

BSE: Back-Scattered Electron

CIP: Cold Isostatic Press

CMBC: Complex metal boron-carbide

CSM: $\quad$ Colorado School of Mines

DARPA: The Defense Advanced Research Projects Agency

DOD: Department of Defense

DOE: Department of Energy

EDS: $\quad$ Energy Dispersive X-ray Spectroscopy or Spectroscope

HIP: Hot Isostatic Press

HPCRM: High performance corrosion resistant material

$\mathrm{kmt}$ thousand metric tons

ksi: thousand pounds per square inch

kW: Kilowatt

ICP: Inductively Coupled Plasma

ITP: Industrial Technologies Program

MMC: $\quad$ Metal Matrix Composite

Nd:YAG: $\quad$ Neodymium-doped Yttrium Aluminum Garnet

OCRWM: Office of Civilian Radioactive Waste Management

OEM: Original Equipment Manufacturer

OM: Optical Microscopy or Microscope

ORNL: $\quad$ Oak Ridge National Laboratory

PIF: Pneumatic Isostatic Forge

PM: Powder Metallurgy

SAM: Structurally Amorphous Metal

SEM: Scanning Electron Microscopy or Microscope

TBM: Tunnel Boring Machine

TD: Theoretical Density

US or U.S.: $\quad$ United States

VHP: Vacuum Hot Pressing 


\section{LIST OF FIGURES}

FIGURE 1. SEM IMAGE OF NANOCRYSTALLINE BULK SAMPLE EXHIBITING NANO TO SUBMICRON CARBIDE AND BORIDE PRECIPITATES.

FIGURE 2. TUNNEL BORING MACHINE USED TO CONSTRUCT THE TUNNEL AT YUCCA MOUNTAIN (LEFT). NANOCOMPOSITE COATINGS TESTED ON DISC CUTTER AT THE COLORADO SCHOOL OF MINES LINEAR CUTTING MACHINE (RIGHT). 4

FIGURE 3. SCHEMATIC OF THE VARIATION OF HARDNESS H WITH GRAIN SIZE D. [SOURCE: H. CONRAD AND J. NARAYAN, SCRIPT. MET. 42, 1025 (2000), FIGURE 1].........................................6

FIGURE 4. GAS ATOMIZATION OF GLASSY POWDER. A) GAS ATOMIZATION FURNACE, B) GLASSY POWDER IN FRONT OF COATED DISC CUTTER, C) CROSS SECTION OF ETCHED SINGLE POWDER PARTICLE SHOWING GLASSY NATURE (LACK OF CRYSTAL STRUCTURE).

FIGURE 5. ORIGINAL LASER PROCESSING SETUP FOR APPLYING LASER COATINGS TO DISC

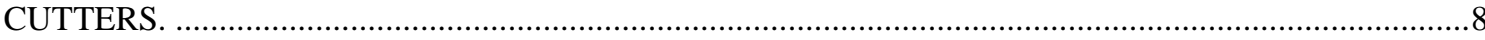

FIGURE 6. POM DMDTM LASER DEPOSITION SYSTEM FOR COATING COMPLEX COMPONENTS AND A CLOSE UP OF THE POWDER DELIVERY TO SUBSTRATE

FIGURE 7. CLOSE UP OF FINISHED COATING AND MICROSTRUCTURE. ..............................................

FIGURE 8: BSE IMAGE OF ALLOY 1 IN THE +325 MESH SIZE RANGE (LEFT) AND -325 MESH SIZE RANGE (RIGHT).

FIGURE 9: BSE IMAGE OF ALLOY 2 POWDER IN THE +325 MESH SIZE RANGE (LEFT) AND -325 MESH SIZE RANGE (RIGHT)

FIGURE 10: INCREASE MAGNIFICATION BSE IMAGES OF ALLOY 1 IN THE +325 MESH SIZE

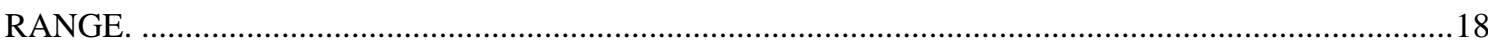

FIGURE 11: INCREASED MAGNIFICATION BSE IMAGES OF ALLOY 2 IN THE +325 MESH SIZE

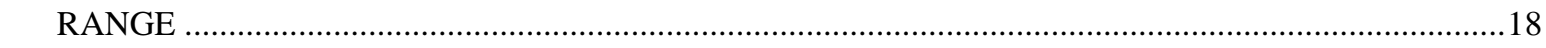

FIGURE 12: INCREASED MAGNIFICATION BSE IMAGE OF ALLOY 4 IN THE +325 MESH RANGE. 19

FIGURE 13: HIGHER MAGNIFICATION BSE IMAGE OF ALLOY 1 IN THE -325 MESH RANGE ..........20

FIGURE 14: HIGH MAGNIFICATION BSE IMAGE OF ALLOY 2 WITH SIZE DISTRIBUTION AT -325

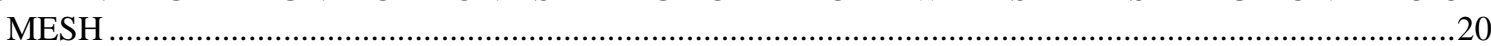

FIGURE 15: XRD SCANS FOR ALLOY 1-4 FOR -325 AND +325 MESH SIZE RANGE.............................22

FIGURE 16: SEM IMAGES OF -325 MESH SIZE RANGE POWDER OF ALLOY 3 SHOWING SMALL CRYSTALLINE PARTICLES. PARTICLES UNDER $10 \mu \mathrm{M}$ APPEAR TO BE AMORPHOUS...........23

FIGURE 17: XRD PHASE ANALYSIS FOR ALLOY 1 IN THE +325 MESH SIZE RANGE.......................23

FIGURE 18: A CLOSE UP OF THE LOWER 2 THETA REGION OF THE DIFFRACTION PATTERNS OF

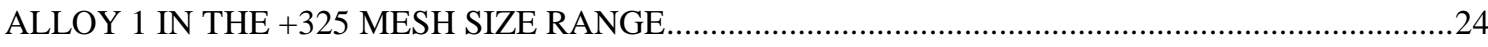

FIGURE 19: COATED COUPON UTILIZED IN LASER FUSING WITH THE 4 KW ND:YAG LASER

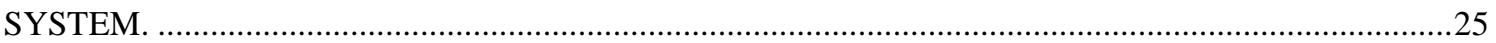

FIGURE 20: 4 KW ND:YAG LASER SYSTEM UTILIZED TO FUSE COATINGS ONTO COUPONS. THE GANTRY SYSTEM FOR THE LASER IS COMPUTER CONTROLLED. ..........................................26

FIGURE 21: IMAGE OF THE LASER FUSING PROCESS UTILIZING THE 4 KW ND: YAG LASER

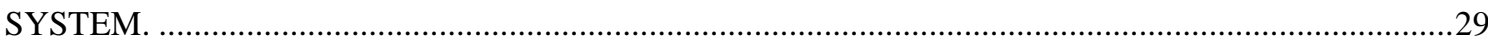

FIGURE 22: EXAMPLE IMAGES SHOWING THE COATING ON THE SUBSTRATE MATERIAL AFTER LASER FUSING WITH THE 4 KW ND:YAG SYSTEM. A) ALLOY 5 ON H13, 2500W, 1500 MM/MIN B) ALLOY 5 ON 4340, 2200W, 1000 MM/MIN C) ALLOY 1 ON 4340, 3500W, 1500 MM/MIN D) ALLOY 7 ON H13, $2500 \mathrm{~W}, 1500 \mathrm{MM} / \mathrm{MIN}$

FIGURE 23: IMAGE TAKEN DURING THE FUSING PROCESS IN BETWEEN MELT LINES SHOWING

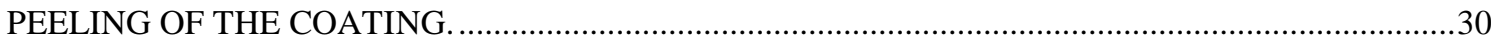

FIGURE 24: OPTICAL MICROGRAPHS OF ALLOY 1 LASER FUSED WITH THE 4 KW ND:YAG

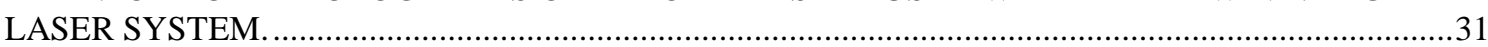

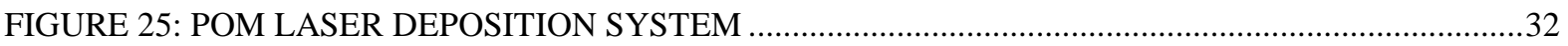

FIGURE 26: ALLOY 1 FUSED COATING FABRICATED USING THE POM LASER DEPOSITION SYSTEM. 
FIGURE 27: THE DISTRIBUTION OF THE TEMPERATURE 0.2 SECONDS AFTER THE ONSET OF LASER TRANSLATION USING A SURFACE EMISSIVITY OF 0.43. THE LENGTH SCALE IS

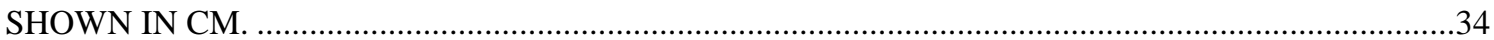

FIGURE 28: TEMPERATURE EVOLUTION ALONG THE X-AXIS FROM THE SAMPLE EDGE FOR A SURFACE EMISSIVITY OF 0.43. THE LENGTH OF THE LOCATIONS ARE INDICATED IN MM.

FIGURE 29: MEASURED REFLECTIVITY OF SAMPLES AS A FUNCTION OF LASER WAVELENGTH

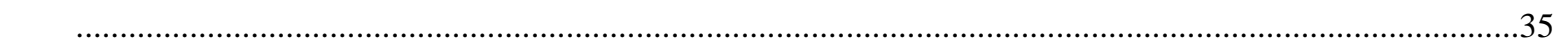

FIGURE 30: TEMPERATURE EVOLUTION ALONG THE X-AXIS FROM THE SAMPLE EDGE FOR A SURFACE EMISSIVITY OF 0.653. THE LENGTHS FOR THE LOCATIONS ARE INDICATED IN MM.

FIGURE 31: VHP EXAMPLES OF ALLOY 1 USING BOTH 0.5" AND 1.0" GRAPHITE DIE. ...................37

FIGURE 32: BSE IMAGES OF VHP ALLOY $2+325$ MESH POWDER. SOME POROSITY WAS

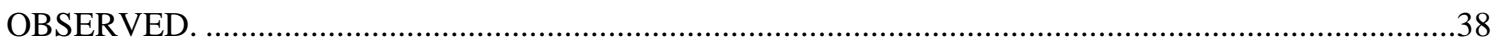

FIGURE 33: ALLOY 8 VACUUM HOT PRESSED FROM +325 MESH POWDER AT 900C AND 4KSI FOR 1 HOUR.

URE 34: ALLOY 2 (LEFT) AND ALLOY 3 (RIGHT) VACUUM HOT PRESSED FROM -325 MESH

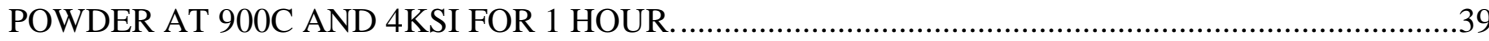

FIGURE 35: ALLOY 8 (LEFT) AND ALLOY 7 (RIGHT) VACUUM HOT PRESSED FROM -325 MESH POWDER AT 900C AND 4KSI FOR 8 HOURS.

FIGURE 36: DYNAFOGED SAMPLES OF ALLOY 1-5 SECTIONED USING EDM. EVIDENCE OF CRACKING WAS OBSERVED IN ALLOY 1, ALLOY 2 AND ALLOY 4. ALLOY 4 SHOWED SIGNIFICANT CRACKING SUCH THAT A WEAR SAMPLE COULD NOT BE PRODUCED FOR TESTING.

FIGURE 37: OPTICAL MICROSTRUCTURE (TOP LEFT) AND BSE IMAGES OF ALLOY 2 (-40 MESH) AFTER DYNAFORGE AT 1950F. SIGNIFICANT CRACKING WAS OBSERVED IN THE SAMPLE.

FIGURE 38: HIP SAMPLES FROM ALLOY 1-10 AT 1950F AND 2125F ……..........................................43

FIGURE 39: ALLOY NC3 POWDER IN THE -325 MESH SIZE RANGE AFTER HIP AT 1950F SHOWN AT VARIOUS MAGNIFICATIONS USING OPTICAL (TOP) AND BSE IMAGING (BOTTOM), ......44

FIGURE 40: INCREASED MAGNIFICATION OF BSE IMAGES OF ALLOY 3 POWDER IN THE SIZE

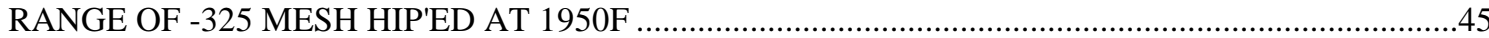

FIGURE 41:EDS MAPPING SHOWING ELEMENTAL DISTRIBUTION ON -325 MESH POWDER OF ALLOY 3 HIP'ED AT 1950F

FIGURE 42: -325 MESH ALLOY 5 POWDER CONSOLIDATED VIA HIP AT 1950F USING OPTICAL IMAGING (TOP) AND BSE IMAGING (BOTTOM).

FIGURE 43: INCREASED MAGNIFICATION BSE IMAGES OF -325 MESH POWDER OF ALLOY 5 HIP'ED AT 1950F

FIGURE 44: BSE IMAGES OF -325 MESH ALLOY 8 POWDER HIP'ED AT 1950F...

FIGURE 45: BSE IMAGES OF ALLOY 1 (TOP), ALLOY 2 (MIDDLE) AND ALLOY 3 (BOTTOM). SAMPLES WERE FABRICATED FROM -325 MESH POWDER HIP'ED AT 2125F....

FIGURE 46: BSE IMAGE OF ALLOY 4 (TOP), ALLOY 5 (MIDDLE) AND ALLOY 6 (BOTTOM). SAMPLES WERE FABRICATED FROM -325 MESH POWDER HIP'ED AT 2125F .........................50

FIGURE 47: BSE IMAGES OF ALLOY 7 (TOP), ALLOY 8 (MIDDLE) AND ALLOY 10 (BOTTOM). SAMPLES WERE FABRICATED FROM -325 MESH POWDER HIP'ED AT 2125F..........................51

FIGURE 48: CLOSE-UP OF THE LOOP ABRASION APPARATUS SHOWING THE TOP PULLEY AND ABRASIVE STRIP. THE TEST SPECIMEN IS A FLAT RECTANGULAR PIECE 3MM THICK, CLAMPED JUST ABOVE THE PULLEY.

FIGURE 49: MICROINDENTATION ARRAY ON DYNAFORGED NC9 (+325 MESH) SAMPLE. THE SIZE OF THE INDENT IS MEASURED CORNER TO CORNER TO ACHIEVE AN ASSOCIATED HARDNESS VALUE.

FIGURE 50: EXAMPLE STRESS-STRAIN COMPRESSION CURVE FOR ALLOY 6 FABRICATED FROM -325 MESH POWDER USING HIP AT 2125F.

FIGURE 51: EXAMPLE STRESS-STRAIN COMPRESSION CURVE FOR ALLOY 1 FABRICATED FROM -325 MESH POWDER USING HIP AT 2125F. 
FIGURE 52: TESTED TENSILE SAMPLES USING THE SS3 TENSILE GEOMETRY. SAMPLES HAD A TENDENCY TO NOT BREAK IN THE GAUGE SECTION OF THE SAMPLE.

FIGURE 53. VULCAN MATERIALS DIXIE LEE ROCK QUARRY (LEFT), FINE AGGREGATE ROCK MIXING MACHINE (CENTER), AND A WORN MIXING PADDLE (RIGHT).

FIGURE 54. LASER FUSING SETUP OF THE MIXING PADDLE IN THE POM LASER (LEFT). VARIOUS LASER FUSING TRIALS FOR 7 POWDERS ON PADDLE.

FIGURE 55. HARDNESS PROFILES OF THE CHROMIUM STEEL CAST PADDLE COMPARED TO THE HARDNESS PROFILES OF THE NANOCOMPOSITE COATINGS DEPOSITED ON THE PADDLE.

FIGURE 56. LASER FUSED NANOCOMPOSITE COATING ON MIXING PADDLES SHOWING FRONT FACE (LEFT) AND SIDES (RIGHT).

FIGURE 57. ANNUAL INSPECTION OF PADDLES (LEFT). THE NANOCOMPOSITE COATINGS WERE STILL INTACT AND APPEARED TO BE IN GOOD SHAPE (CENTER). THE UNCOATED PADDLE INSTALLED AT THE SAME TIME EXHIBITED VISUAL SIGNS OF LIGHT ABRASION, BUT WERE IN GOOD CONDITION (RIGHT).

FIGURE 58. CONSOLIDATION OF MULTIPLE SIZES FROM 1/2” DIAMETER TO 2" DIAMETER.........64

FIGURE 59: MACHINED BIT FROM NC1 COMPOSITION.

FIGURE 60. CONICAL TOOL BEFORE AND AFTER LASER COATING WITH ALLOY 8. COATING OF THE SHOULDER OF THE CONICAL TOOL RESULTS IN INCREASED WEAR PERFORMANCE AND MAINTAINS THE INTEGRITY OF THE WC/CO INSERT. THE COATING DID NOT EFFECT OR CRACK THE INSERT DURING THE DEPOSITION PROCESS.....

FIGURE 61. NANOCOMPOSITES TEAM WON AN R\&D 100 AWARD ENTITLED "NANOSHIELD” FOR THE DEVELOPMENT LASER FUSING OF AMORPHOUS POWDERS TO FABRICATE “SUPER HARD INEXPENSIVE LASER DEPOSITED” NANOCOMPOSITE COATINGS. 


\section{LIST OF TABLES}

TABLE 1: ALLOY COMPOSITIONS DETERMINED FOR ATOMIZATION BASED ON THE SAM 2X5 AND SAM 1651 COMPOSITIONS SHOWN IN BOTH ATOMIC AND WEIGHT PERCENT. A BRIEF DESCRIPTION OF EACH ALLOY RELATIVE TO THE INITIAL COMPOSITIONS IS INCLUDED.

TABLE 2: TARGET COMPOSITION AND ACTUAL COMPOSITION OF FABRICATED POWDER

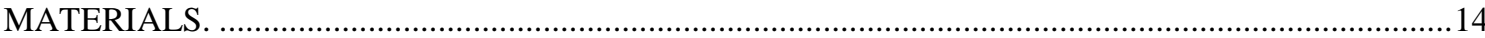

TABLE 3: PARTICLE SIZE DISTRIBUTION AS A FUNCTION OF WEIGHT FOR ALLOYS 6-10...........15

TABLE 4: TARGET COMPOSITION AND RESULTING CHEMICAL ANALYSIS OF THE LARGE-

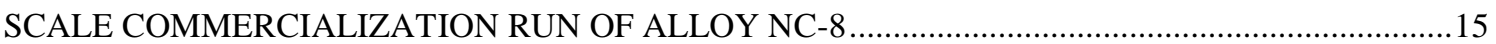

TABLE 5: YIELD WEIGHT AND PERCENTAGE OF LARGE SCALE COMMERCIALIZATION RUN.

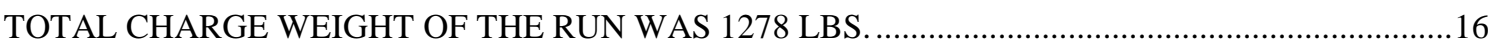

TABLE 6: EXPERIMENTAL CONDITIONS OF THE X-RAY MEASUREMENTS WITH THE 4-CIRCLE

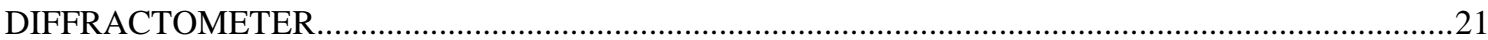

TABLE 7: XRD PHASE ANALYSIS FOR ALLOY 1 IN THE +325 MESH SIZE RANGE...........................21

TABLE 8: LASER PROCESSING PARAMETERS UTILIZED TO FUSE ALLOY 1-10 USING THE 4 KW

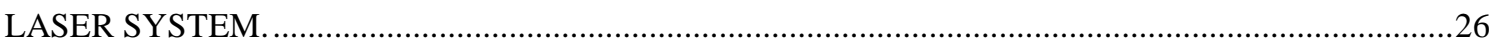

TABLE 9: POM LASER DEPOSITION PROCESSING PARAMETER MATRIX CONDUCTED ON ALL 10 ALLOYS.

TABLE 10: CALCULATED COOLING RATES FROM THE IMPROVED MODEL FOR LASER FUSING

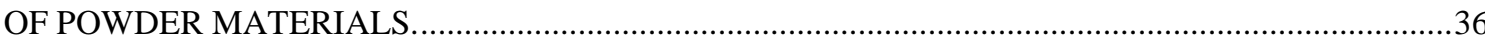

TABLE 11: CALCULATED LIQUID POOL HEIGHT AS A FUNCTION OF PREHEAT AND SURFACE

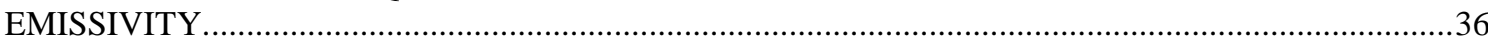

TABLE 12: VHP PARAMETERS USED FOR CONSOLIDATION. TIME SHOWS THE DURATION THE SAMPLE WAS HELD AT A TEMPERATURE.

TABLE 13: ALLOYS AND LABELS FOR THE HIP'ED SAMPLES...........................................................43

TABLE 14: ABRASIVE LOOP WEAR TESTING FOR NC SAMPLES IN VARIOUS PROCESSED CONDITIONS. WEAR FACTOR IS UNITLESS WITH THE MAGNITUDE INDICATING RESISTANCE TO ABRASIVE WEAR. LOWER NUMBER INDICATES IMPROVED WEAR RESISTANCE.

TABLE 15: HARDNESS REPORT GENERATED USING THE BUEHLER OMNIMET MHT MACHINE FOR NC9 DYNAFORGED FROM +325 MESH POWDER. .56

TABLE 16: MICROHARDNESS INDENTATION RESULTS FOR BULK CONSOLIDATED MATERIALS USING VHP, HIP AND DYNAFORGE.

TABLE 17: TABULATED RESULTS OF COMPRESSION TESTING ON SAMPLES HIP'ED AT 2125F. SAMPLE 9 WAS NOT TESTED DUE TO MELTING AT 2125F DURING THE HIP CYCLE...............59

TABLE 18: TENSILE PROPERTIES OF BULK SAMPLES FABRICATED FROM HIP AT VARIOUS CONDITIONS. 


\section{EXECTIVE SUMMARY}

The innovative iron-based amorphous alloy powders and the high heating and cooling rates associated with infrared and laser technologies at ORNL allow for the production of nanostructured coatings and bulk nano-crystalline materials via devitrification. The ability to engineer mechanically-superior formations, and "dial-in" desired nano-structures is possible. Previous work demonstrated in-field testing of laser fused nanocrystalline coatings on full-sized disc cutters used on tunnel boring machines, which resulted in a $20 \%$ or better improvement in wear resistance in the most aggressive of wear conditions. The current project demonstrated that standard, high yield, low-cost, scalable processes are available for incorporating nano-sized, complex metal boron-carbides (CMBCs) into metal matrix coatings and the ability to produce nanocomposites in bulk form for heavy machinery applications.

ORNL worked with commercial suppliers to obtain amorphous and nanocrystalline iron based powders. Ten new alloys were developed and fabricated using gas atomization practices. Each atomization run was approximately $250 \mathrm{lbs}$. net material. Depending on chemical composition of the material and powder size range, the powder was either fully amorphous or partially devitrified with nano to submicron grain structure. Yield criteria improved with the modifications of chemistry. All ten coatings were successfully fused to tool steel coupons (H13 and 4140). Based on initial laboratory test results, the atomized powders were laser fused as thin coatings to industrial components supplied by an industrial partner (Vulcan Materials Company). A second objective was to consolidate the amorphous powders via powder metallurgy technologies to fabricate bulk nanocomposites. Three consolidation methodologies were evaluated including hot isostatic pressing, vacuum hot pressing, and Carpenter's proprietary process, Dynaforging. Two of the three consolidation technologies resulted in fully dense bulk material. The various processing technologies each had unique results for microstructure, wear, and resulting mechanical properties. Mechanical tests included abrasive wear loop tests, hardness profiling, and compression testing. Thermodynamics and kinetics based solidification thermal analysis methods were modified for the new materials.

Based on the results of laboratory testing of the ten initially designed alloys, one alloy, designated NC8 was chosen to demonstrate a large-scale gas atomization run. The resulting industrial production run by Carpenter produced over 1,000 pounds of powder. Hot isostatically pressed NC8 powder samples in bulk form exhibited wear rates in laboratory tests an order of magnitude less than current high chromium cast steels currently used in the application of fine aggregate rock mixing paddles. Rock mixing paddles were selected for field evaluation by Vulcan Materials and ORNL due to the ability to visually inspect the coatings during field evaluation, the abrasive wear and impact degradation that is observed in this application, and the lower risk to equipment and down time. 400 um to 600 um-thick coatings of NC8 powder were successfully fused to six rock mixing paddles and were installed for testing at the Vulcan's Dixie Lee rock quarry. The coated paddles were tested in the field for over two years. On average, less than 1 millimeter of wear occurred to the paddles. The coating was still present on each of the three faces originally fused (large face and two sides).

Approximately half the coating was still visible on the largest face of the paddles fused. Due to the extremely low wear of the paddles over the two-year evaluation, no differences in wear rate of coated and uncoated paddles were observed. Thicker coatings on more wear prone applications are suggested for any future evaluations. Additional evaluations by third parties are currently ongoing since the completion of this project. New areas of interest include down-hole applications, construction equipment, and potential for coating of dies. The development of the laser fused coatings and preliminary results in tunnel boring applications received an R\&D100 Award in 2012. 
xviii 



\section{INTRODUCTION}

The ability to control the insertion of complex metal boron-carbides (CMBCs) in metal matrices at nanometer scales is a novel method for creating unique and attractive engineering coatings and bulk components. Specifically, metals have been shown to get harder and stronger as the matrix and precipitate grain sizes move into the nanoscale regime $[1,2,3,4,5,6,7]$. Wear-resistant coatings with nano-sized boron-carbide precipitates and a refined metal matrix have tremendous potential in a number of applications. In many of these applications, the coatings would be fused to tool steels or low carbon steels where the wear-resistant, hard coatings would be a good match with the toughness of the substrate.

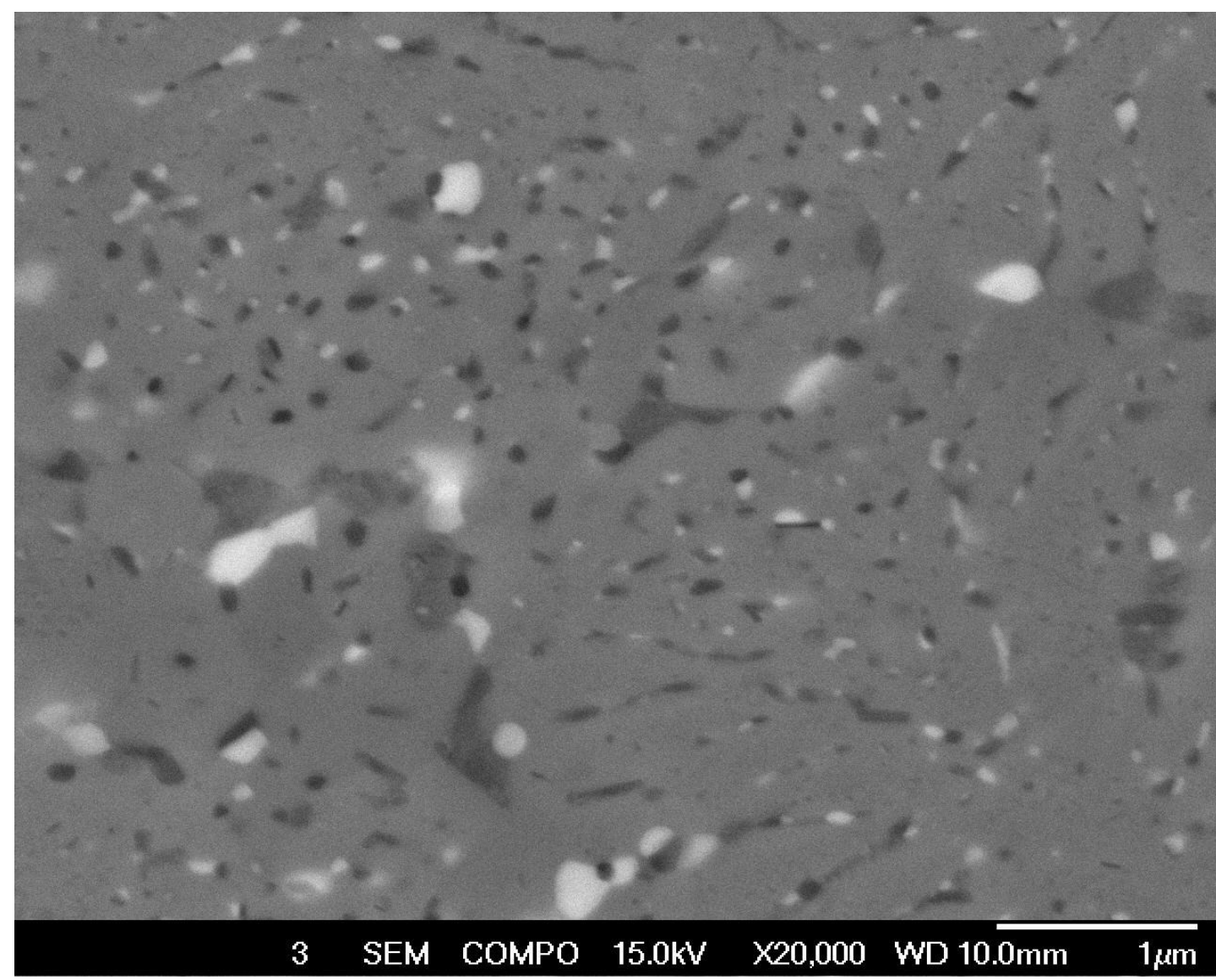

Figure 1. SEM image of nanocrystalline bulk sample exhibiting nano to submicron carbide and boride precipitates.

The primary objective of the project was to develop laser processing of amorphous and nanocrystalline powders as a nano-manufacturing process for the incorporation of nano-sized, CMBCs for use as a wear resistant coating for steel substrates. A secondary objective was to consolidate the powders via powder metallurgy practices to form bulk nanocomposite components with an example microstructure of a bulk consolidated nanocomposite material shown in Figure 1. Both objectives were addressed by developing the manufacturing technology for producing Fe-based amorphous and nanocrystalline powders with high carbon and boron contents, and controlling precipitation of nano-sized CMBCs into a fine grained metal matrix. By developing powders with relatively low critical cooling rates of devitrification, carbon and boron do not experience large segregation from the iron matrix, as is often characterized in conventional steel castings of high carbon content. 
Nano-sized CMBCs in a metal matrix have shown to be a very tough, hard and wear resistant coating. CMBCs are intermetallic mixtures of carbon and boron, with tungsten, molybdenum and chromium, individually or in different permutations. It is not possible to conventionally mix these CMBCs into molten steel without dissolution before solidification. It has been found that by de-vitrifying ironbased amorphous metal powders a metal matrix composite (MMC) of CMBCs can result with control in determining the optimum particle size for ceramic particles and the optimum grain size for the metal matrix based on thermal histories. It is believed that the best properties in these MMCs can be obtained if the CMBCs are precipitated from the amorphous metal with particle sizes on the order of 50 to $100 \mathrm{~nm}$ scale. These materials have been shown to have excellent wear resistance, up to an order of magnitude over conventional tool steels, and with Vicker's hardness values up to 1,800 $\mathrm{kgf} / \mathrm{mmÇ}$.

This effort was headed by the DOE National Laboratory, Oak Ridge National Laboratory (ORNL). The industrial partner for the project was Carpenter Powder Products. Furthermore, additional industrial participation took place in the form of field trials, supply of components, and potential applications. Vulcan Materials Company is a potential industrial end user that facilitated the performance of field trials at the Dixie Lee Quarry Site in Concord, TN. Carpenter Powder Products provided the largest percentage of cost share contributions (monetary and/or in-kind contributions) with greater than $20 \%$ of the total budget. The project was performed over four years with two of those years designated to field trials. 


\section{BACKGROUND}

The development of the current nanocomposite technical approach was initiated in the development of structurally amorphous Fe-based alloys as part of the Defense Advanced Research Projects Agency's (DARPA) Structurally Amorphous Material (SAM) program. Several Fe-based chemistries were evaluated for good glass forming properties, and the ability to remain amorphous at relatively low critical cooling rates. Laser fusing of the original chemistries to H13 steel substrates developed by the High Performance Corrosion Resistance Materials (HPCRM) team was initiated by the DOE's Office of Civilian Radioactive Waste Management (OCRWM) for evaluating new coating technologies to improve the overall lifetime of disc cutters in tunnel boring operations for Yucca Mountain. Fe-based amorphous powder precursors with high boron and carbon content were fused to H13 disc cutters; these high hardness and high wear resistant coatings were the first to survive full scale, field testing without spalling and were shown to substantially increase the lifetime (more than $20 \%$ ) in field boring evaluations. Tunnel boring is only one area of application for these new advanced coatings. The coatings fuse well to other steel substrates, making them ideal candidates for many high wear applications where steels are used, such as auger bits, mining picks, track shoes, grading equipment, printing dies, blades, and machining tools. In addition, the original powder chemistries were chosen due to their ability to remain amorphous, and were not designed for controlled devitrification and the optimization of laser-fused properties or atomization yields.

The objective of this project was to focus on the development of high yield, low-cost, scalable processes that can incorporate nano-sized, complex metal boron-carbides (CMBCs) into metal matrix coatings for wear prone applications. ORNL teamed with Carpenter Powder Products (supplier of amorphous iron based powders) to produce industrial quantities of amorphous based powders and with Vulcan Materials Company (industrial equipment operators) to conduct field evaluations of the nano-structured coatings on full-size components. The following technical background will describe the technical approach used in this project, and the theory behind nano-grain structures, and potential energy savings in improving wear resistance.

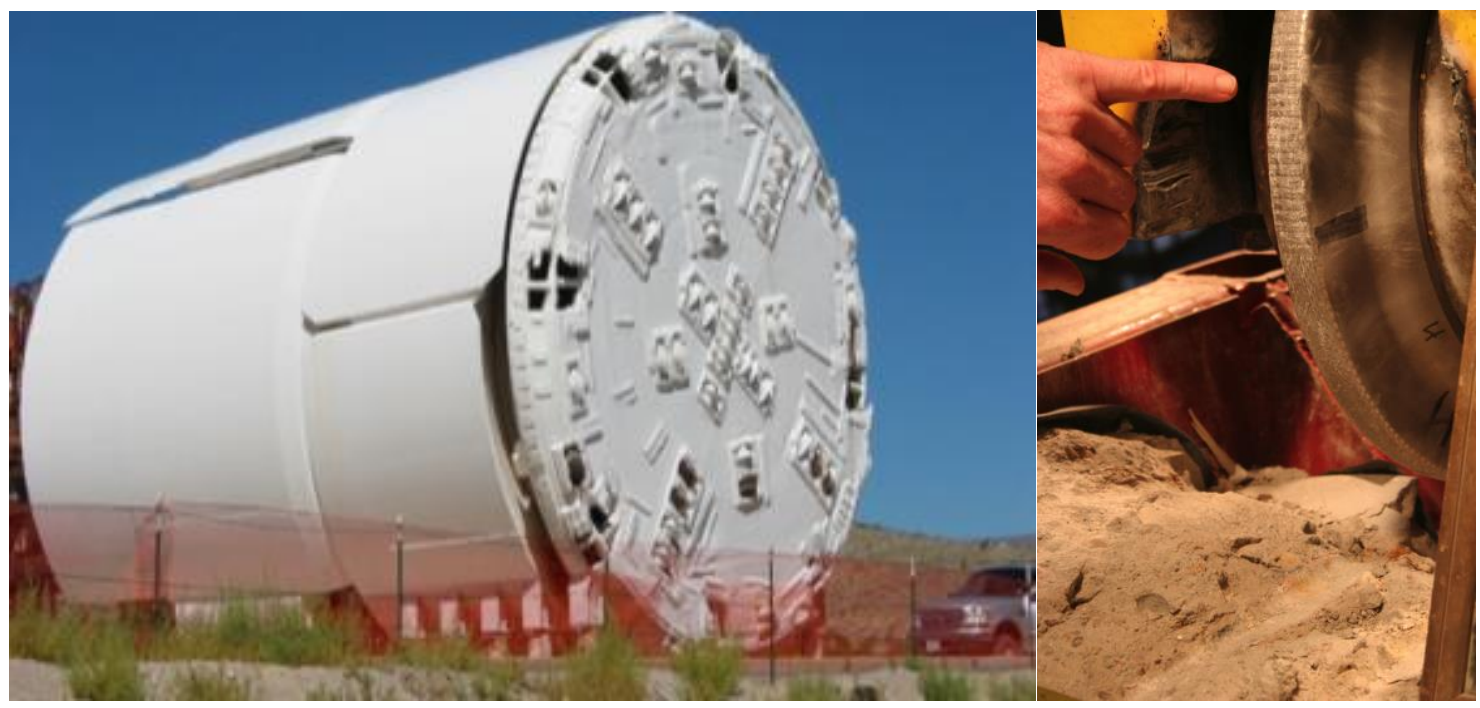

Figure 2. Tunnel boring machine used to construct the tunnel at Yucca Mountain (Left). Nanocomposite Coatings Tested on Disc Cutter at the Colorado School of Mines Linear Cutting Machine (Right). 


\subsection{TECHNICAL BACKGROUND}

Nanocrystalline materials have unique mechanical properties. However, developing bulk metallurgical nanostructures has historically been challenging, requiring either extremely high cooling rates or the introduction of heavy deformation processes. ORNL has approached the development of nanostructures by utilization of devitrification process of amorphous based materials. This requires good glass forming ability such as those demonstrated on Fe-based alloys that have the potential to be amorphous at room temperature through moderate cooling rates. Gas atomization of these alloys provides powders with sufficient cooling rates to largely remain amorphous. The powders can then be consolidated by solidstate consolidation where time at temperature can be controlled or by laser fusing where heat input can be systematically adjusted. By controlling time at temperature, the devitrification and time for diffusion can be controlled with the result of varying sized grain structures and precipitates. The following sections will first discuss the advantages of nanostructured materials, and then discuss the various technologies involved with this approach.

\subsubsection{Nanostructured Materials}

Though nanocrystalline materials have shown much promise and growth in the electrical, optical, and magnetic industries, little research has been performed to determine the role bulk nanocrystalline materials could have in the next generation of structural materials. Nanocrystalline materials are materials with crystals or grains of the 10 to $100 \mathrm{~nm}$ scale. The ability to control the microstructure of alloys and ceramics at nanometer scales is a novel method to creating unique and attractive engineering materials. Specifically, metals have been shown to get harder and stronger as the grain size moves into the nanoscale regime, and thin-film ceramic materials have exhibited an increase in ductility as the grain size approaches $10 \mathrm{~nm}[1,2,3,4,5,6,7]$.

Development of nanostructured materials has resulted in decreased sintering temperatures, increased yield strengths and hardness of ductile materials, improved catalytic properties and novel electrical, optical and magnetic properties of a variety of conventional materials $[3,4,5,6,7]$. The enhanced sintering behavior has been attributed to high driving forces and short diffusion distances [3]. The increased strength and hardness in metals can be correlated to grain confinement. Dislocations are less frequent as nano-sized grains are smaller $[2,8]$. The stresses required to generate a dislocation at a Frank-Read source becomes greater since the shear stress is inversely proportional to the distance between two pinning points [8]. In nano-size grain materials, the distance between pinning points becomes so small that the required stress reaches theoretical values of a defect-free grain; this causes a more energetic mechanism to become necessary to influence deformation [8]. In addition, the elastic strain accommodation that is a result of cluster consolidation may also be a contributing factor in increased strength [9]. Enhanced stain rate sensitivity and the resulting increased ductility has been attributed to increased grain boundary sliding, in addition, to the contributions of porosity, ultra-fine grain size and short range diffusion distances [10,11]. As the relative dimension of nanostructured materials decreases, the surface area increases allowing more surface active sites and thus attributing to the observed higher catalytic activity [12]. It has been suggested that the size of constituent domains that fall below the critical length scales, the volume and proposed purity of the grain boundary phase and the large fractions of ions that reside in the interface control the electrical, optical and magnetic properties [13]. In addition, nanocrystalline films and coatings also have important applications for improving the surface and performance of metallic and ceramic materials [14].

In microcrystalline ceramics and alloys that are currently used in ultra-hard applications, the conventional Hall-Petch relationship is observed in the mechanical properties [1,2,3,4,5]. The intrinsic defect size of materials is dependent on the average grain size. Grain boundaries naturally act as barriers for defect movements. As grains become sufficiently small, flaws become restricted, and defect movements such as 
dislocations become difficult. New mechanisms must then play a role in deformation, such as grain boundary sliding, grain rotation, and shear banding [3]. At this point the Hall-Petch relationship begins to break down, and the contemporary deformation mechanisms change the fracture mechanisms as observed in conventional materials.

In alloys, the Hall-Petch relationship can break down below $100 \mathrm{~nm}[3,4,5]$. Generally, nanocrystalline metals continue to increase in hardness and strength as the grain size is reduced $[1,2,3,4,5]$. In fact, stresses would have to be near the theoretical shear stress in order to activate a dislocation in the smallest group of atoms to make up a grain $[3,4,5]$. However, as the grain becomes sufficiently small, fracture can occur from preexistent flaws in the alloy and material becomes less sensitive to a decrease in the grain size [3]. Depending on the alloy or metal, a negative slope of hardness compared to grain size or no dependence on grain size can occur when the grain size of metals is reduced below a critical size in the range of 10 to $50 \mathrm{~nm}$ [15] as shown in Figure 3. Therefore, the strength of nanocrystalline alloys never reach the stress required to shear atomic planes. As a general rule, most materials in the nanoscale regime are 4 to 5 times harder than in the microscale regime.

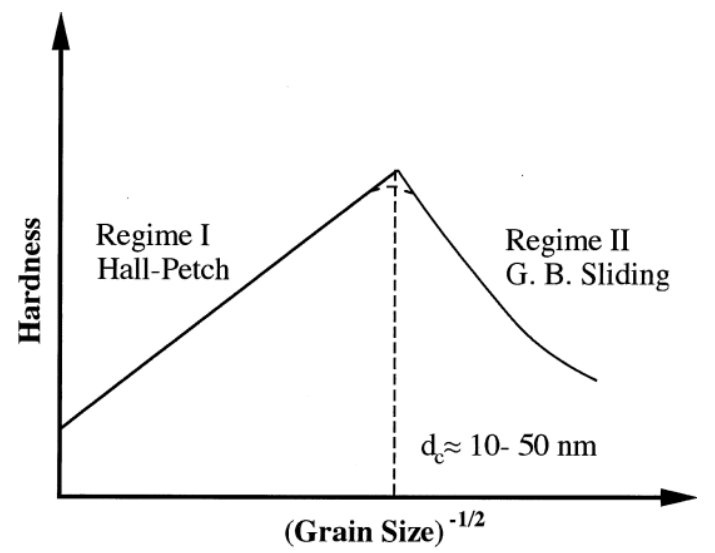

Figure 3. Schematic of the variation of hardness $H$ with grain size d. [Source: H. Conrad and J. Narayan, Script. Met. 42, 1025 (2000), Figure 1]

\subsubsection{Glassy Alloy Powders}

Modern diffusion and kinetic theory has led to the development of metallic alloys that stay glassy at room temperature. The DARPA Structurally Amorphous Materials (SAM) Program sponsored research to develop glassy steel alloys that were high in hardness, and extremely wear resistant. This is accomplished by developing compositions that contain several elements, have negative heats of mixing, and have a wide range of atomic sizes making atomic rearrangement difficult when rapidly cooled [16]. Furthermore, these steels have a significant amount of interstitial elements, such as boron and carbon, that are known for making ferrous alloys strong and hard. Other elements typically found in these steel compositions include Cr, Mo, Y, W, Mn, V, and Si. Developing manufacturing methods for meeting critical cooling rates is key for manufacturing glassy alloys. Amorphous alloy powders have been produced via gas atomization in bulk quantities as shown in Figure 4. Gas atomization is the process of melting an alloy in a tundish, flowing the melt through an orifice, and breaking the melt stream into droplets via an inert gas. The droplets rapidly cool, and form powders upon solidification. 


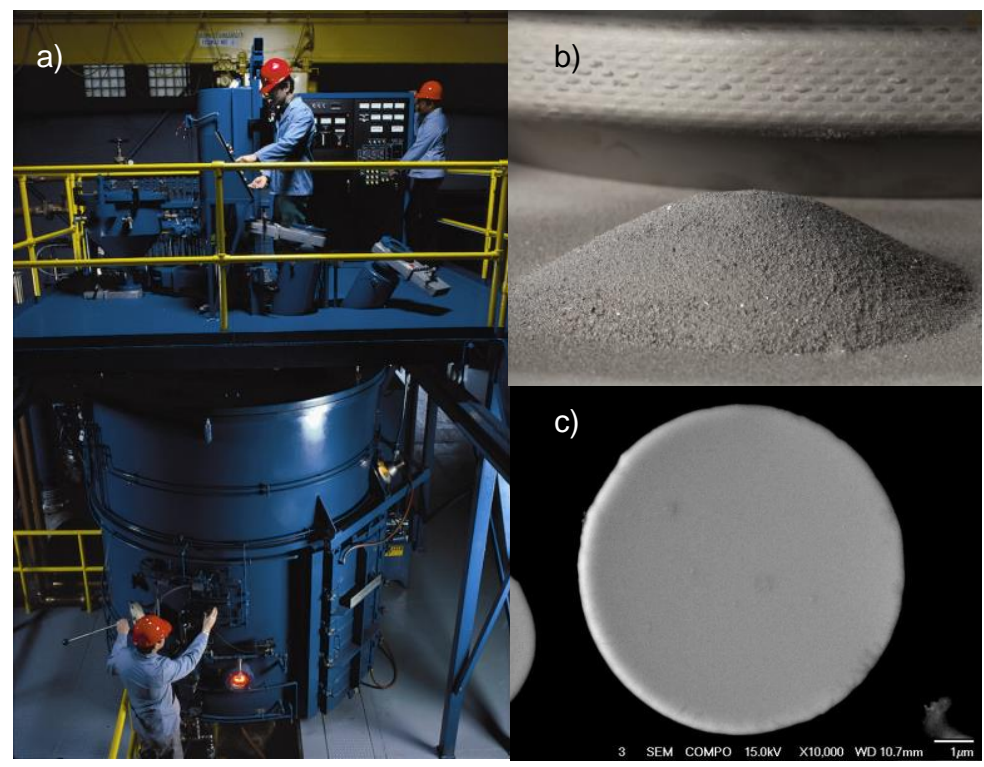

Figure 4. Gas atomization of glassy powder. a) gas atomization furnace, b) glassy powder in front of coated disc cutter, c) cross section of etched single powder particle showing glassy nature (lack of crystal structure). 2.1.2 Laser Fusing

Glassy powders coatings can be fused to steel substrates using lasers, electron beams, or other energy sources. The nanocomposite coatings evaluated in this project were fused using $4 \mathrm{~kW} \mathrm{Nd:YAG} \mathrm{and} 1 \mathrm{~kW}$ diode lasers. In early fabrication procedures, nanocomposites were deposited via aspiration or other means onto the steel substrate generally with an included polymer based binder. The ratio of amorphous powder to binder was between 5 to 1 and 10 to 1 . The binder retained the powder in place on the steel substrate until laser fusing was carried out at which time the excess binder and amorphous powder was extricated by a variety of means including wire brush removal. The powder-binder coating precursor thickness was usually between 200 and 600 micrometers in thickness. With this laser setup, the laser is guided by a gantry system allowing for the coating to be applied in patterns such as stripes and/or freckles. In more aggressive loading applications, a discontinuous coating (i.e., stripes or freckles) can be very useful allowing distortion of the component (substrate) without requiring the same distortion of the coating; this phenomenon is similar to the idea of expansion joints in concrete and can prevent spalling during heavy distortion. The laser fuses the nanocomposite coating to the substrate to form a strong metallurgical bond with the component. This approach is still the preferred method for large components (e.g., coating disc cutters) due to the large area that can be covered with the open gantry system. 


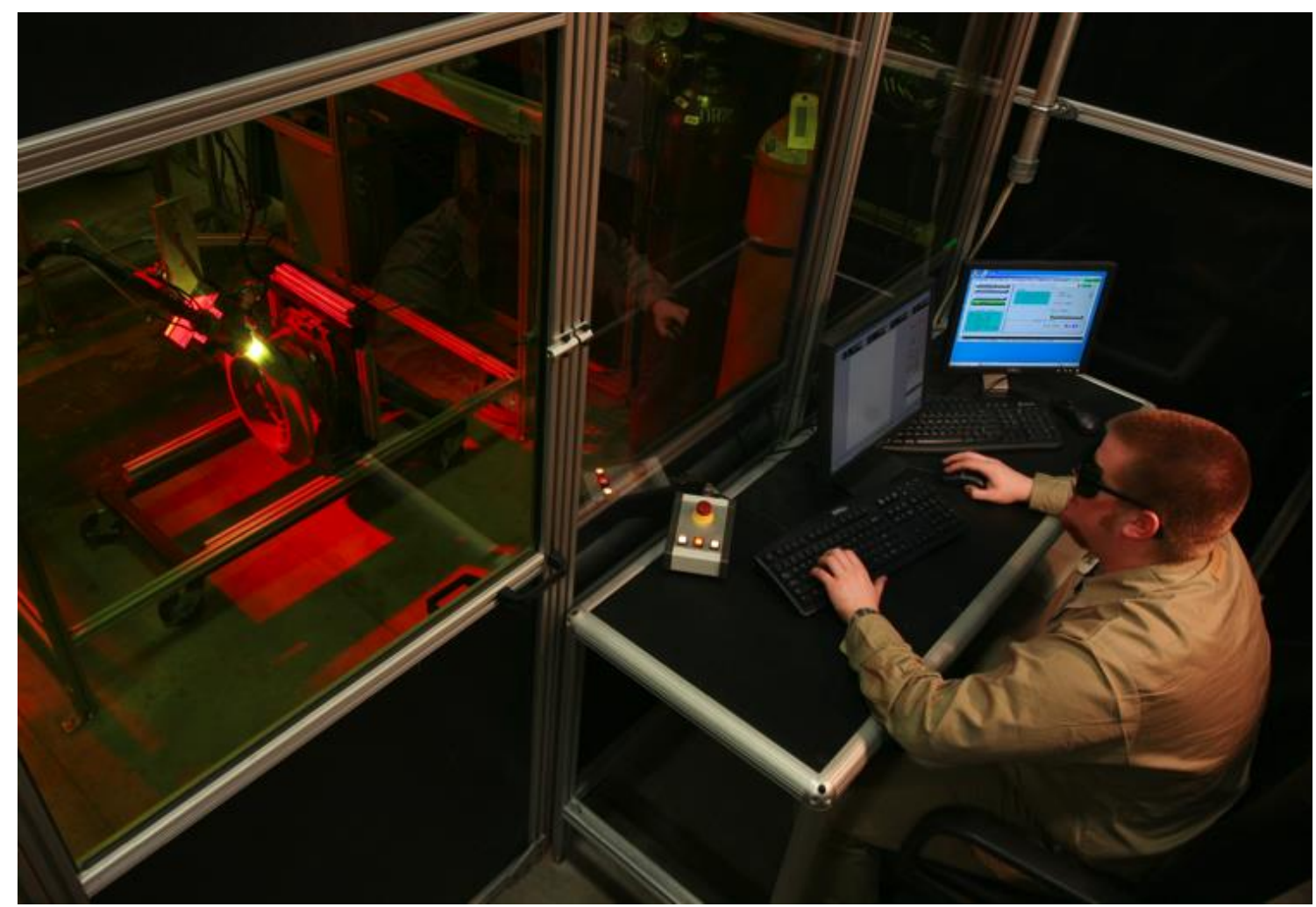

Figure 5. Original laser processing setup for applying laser coatings to disc cutters.

In more recent processing, a POM DMD ${ }^{\mathrm{TM}}$ free form laser is used (Figure 6). With this new approach, binders are not applied, but rather the powder is delivered from the powder hopper to the area of application by argon gas. The powder forms a conical point where the laser interacts with the substrate material. In addition, the software package controlling the laser and the robotics are much more sophisticated, and therefore, able to coat more complex geometries. Paddles such as those used in aggregate mixers later discussed in this project have been coated with amorphous powders using this approach.
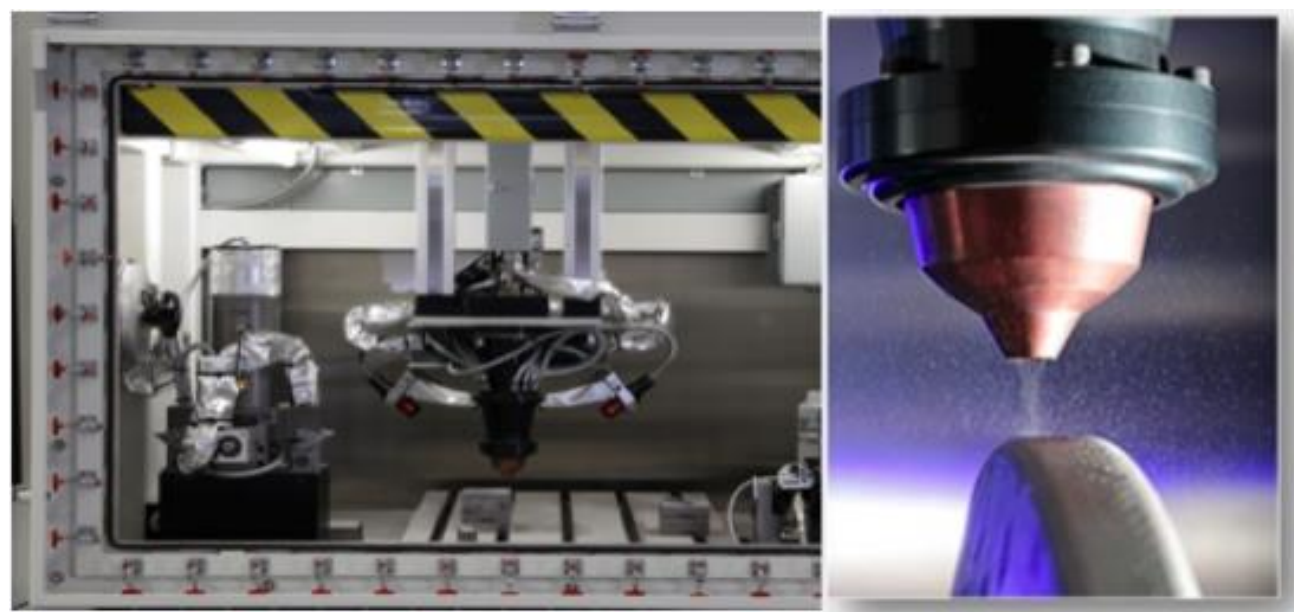

Figure 6. POM DMD ${ }^{\mathrm{TM}}$ laser deposition system for coating complex components and a close up of the powder delivery to substrate. 


\subsubsection{Resulting Coatings}

The laser fusing of NanoSHIELD coatings leads to bulk nanocrystalline, glassy, and nanocrystallineglassy composites with incredible mechanical properties. Hardness and strength values have been observed to be 2 to 10 times greater than conventional steels. Laser controlled devitrification of these amorphous Fe-based coatings has led to ultra-hard alloys with "dial-in" or precisely engineered nanostructures, as shown in Figure 7. The composite structure is one of nano-crystalline carbide, boride, and or carboboride particles in an iron based metal matrix with nano to micron-sized grain structure, based on processing parameters.

Typically coating thicknesses are in the area of 100 to 700 micrometers. However, multiple passes or layers can allow for final thicknesses to be a few millimeters. In general, this approach has developed coatings with the amorphous Fe-based powders that can be from 1.3 to more than 7 times the hardness of the tool steel substrate, as measured as a Vicker's hardness, depending on the tool steel selected as the substrate, the amorphous powder used, and the conditions of the process.

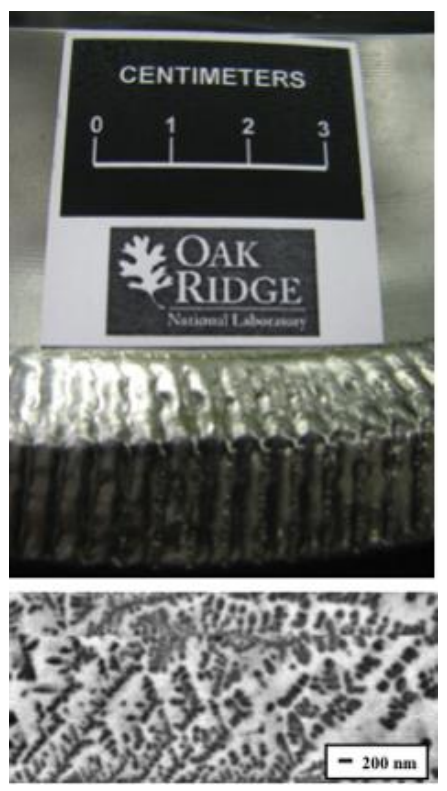

Figure 7. Close up of finished coating and microstructure.

\subsubsection{Powder metallurgy consolidation}

Another method for the consolidation of powders is through powder metallurgy. In this process, pressure and heat are applied to the powders to consolidate. The process is performed in the solid state. Powder metallurgy has been used for many years to fabricate such components as tungsten filaments for lighting, tungsten carbide cobalt for drilling and tool bits, and nickel superalloys for aircraft engines. Historically, powder metallurgy was performed with amorphous alloys to determine if fully dense large amorphous components could be fabricated from this approach. Consolidation was performed in the super-cooled liquid region where plastic deformation of the glassy alloy is possible. However, long time periods at elevated temperatures close to the crystallization temperature will result in devitrification. Prior to this project, ORNL had attempted to fully consolidate the Fe-based amorphous powders which resulted in crystallization. However, the approach allows for close control of the time at temperature, as well as the resulting relative size of grain structure and diffusion. 


\subsection{RESPONSIVENESS TO ORIGINAL RESEARCH CALL AND FOCUS AREAS}

"Application of Wear-Resistant, NanoComposite Coatings Produced from Iron-Based Glassy Powders" was a direct response to the Office of Energy Efficiency and Renewable Energy's "Nanomanufacturing for Energy Efficiency 2008 Research Call”, and addressed the Platform Focus Area of Interest 2: Nanomanufacturing Process Development in the Focus Area of Coatings and Thin-Films.

\subsection{POTENTIAL ENERGY AND COST BENEFITS OF WEAR RESISTANT COATINGS AND STEEL COMPONENTS}

Steel is widely used through a broad range of engineering applications due to its mechanical properties, availability, and relatively low cost. However, most steels are not optimum for wear resistance. Wear of steel components leads to both direct and indirect costs and energy losses including losses due to plant inefficiencies and down time for repairs. The cost of wear to the U.S. economy was estimated at $\$ 20$ billion annually in 1978 , which would have the same buying power as $\sim \$ 65$ billion dollars annually today [17]. Estimates provided in an ASM handbook from 2001 listed annual energy loses in lost weight of steel due to wear of components in industrial operations. Included in their estimate is 505 TBtus of energy in steel loss due to wear in Utilities, 52 TBtus in Mining, 19 TBtus in agriculture, and 14 TBtus in Primary Metal Fabrication [17]. Another statistic [17] stated that "Highway vehicles alone use annually $14,600 \mathrm{TBtu} / \mathrm{ton}$ of energy represented in lost weight of steel and $18.6 \%$ of this energy could be saved through effective wear-control measures."

Preliminary results found in the application of tunnel boring with the wear resistant coatings in a previous project funded by the Office of Civilian Radioactive Waste Management were promising. When excavating tunnels, such as might be used at Yucca Mountain for nuclear waste storage or a typical road tunnel, Tunnel Boring Machines (TBM) are used. A typical TBM consists of a large (20 foot to 60 foot diameter) rotating face with 20 or more disc cutters (17" diameter tool steel discs). As the machine advances into the tunnel, the "crown" area of the disc cutters compresses and pulverizes the rock face resulting in cracking and shear stresses in the rock. Pieces of rock are extracted from the rock face as the cracks from adjacent disc cutters intersect. The wear on the disc cutters causes their frequent replacement. During each rotation of the disc cutter, the cutter experiences a cycle of tensile and compressive stresses. This cycling has thwarted attempts to improve disc cutter life by the application of hardened coatings.

Tests of the ORNL coated disc cutters at the Colorado School of Mines (CSM) have shown these coatings to be extremely resistant to spallation. The coatings did not spall under loads as high as 105,000 psi. In twenty-five years of testing disc cutter coatings at CSM, these coatings were the first to not spall after one pass of rock cutting. Because of these positive laboratory test results, full-scale field tests were performed at the Combined Sewer Overfill Project in Atlanta, GA. The rock in this tunnel was hard and abrasive. Four of the fifty-two disc cutters on the 32' diameter TBM were replaced with the laser applied, nanocomposite coated discs. The coatings did not spall, and were found to improve life of the disc cutter by at least $20 \%$. The TBM advances in the tunnel in 5' increments called "pushes". The nanocomposite coated discs survived 13 pushes without cracking or spalling. These were the first coatings known in this application to have survived more than one "push". It has been calculated that the $0.2 \mathrm{~mm}$ thick coatings survived over 304,000 feet of linear travel against hard rock face. Observations and profile measurements during field testing also showed that the original cutter tip profile was maintained for a longer period of time for the coated cutters. This means the cutters can maintain their "sharpness" longer, resulting in higher penetration rates and less machine energy consumption as cutter wear develops. It was estimated by CSM that this benefit would result in about a 10 percent savings in machine power consumption based on the preliminary results. This is significant when considering the power required for the cutterhead ranges between $2,000 \mathrm{~kW}$ and $14,000 \mathrm{~kW}$. The TBM used to bore the new urban motorway tunnel in Madrid Spain required $14,000 \mathrm{~kW}$; this would be $0.4 \mathrm{TBtu} / \mathrm{year}$ if the machine performed continuously at 
full power.

\subsection{POTENTIAL MARKETS FOR NANOCOMPOSITE COATINGS}

The need for a hard coating for steel substrates is not limited to the tunnel boring industry. The resulting fabrication methods and development of coatings with CMBCs will be applicable to a wide array of applications, such as punches, dies, mining equipment, machining tools, and abrasive products. The following list contains other possible applications for nanocrystalline materials: grader blades, maintenance blades, v-slicers, furrow firming points, seed boots, road milling bits, buttons and compacts for rock drilling, construction drill bits, grinder hammer tips, dragline adaptors and teeth, grinder hammer tips, rock crushing equipment, pump seals, hardware, auger equipment, sports equipment, and tool cutting/shaping materials. 


\section{RESULTS AND DISCUSSION}

The project involved five tasks: 1 . development and atomization of the powders, 2. laser processing of the powders into coatings, 3. powder metallurgy consolidation of the powders into bulk components, 4. laboratory abrasive wear evaluations and other mechanical tests, and field evaluations. In the development of the powder, the task will be split into subtasks that describe the alloy development, powder production design, and finally commercial quantity synthesis. In the area of laser fusing, two approaches/setups have been utilized. The majority of the discussion will revolve around the more recent technology using a diode laser. In bulk consolidation, three consolidation technologies were evaluated including vacuum hot pressing, hot isostatic pressing, and Carpenter's Dynaforging. These three approaches have different times at temperature, and pressures. We will then discuss the laboratory evaluations of the coatings and bulk components. Lastly, field evaluations of coatings in the area of rock crushing will be discussed.

\subsection{DESIGN AND EVALUATION OF AMORPHOUS METAL POWDERS}

\subsubsection{Powder Production Design and R\&D Atomization}

A review was made of all work previously performed involving iron-based amorphous metal powders at ORNL or by others from the literature. Ten alloy compositions were designed (Tables 1 and 2) for optimized hardness when laser clad as a coating or when consolidated in bulk. These compositions became the core of the work performed with the commercial partner for powder production, Carpenter Powder Products.

Several of the new powder chemistries are modified from compositions sponsored by a previous DOD project and a DOE OCRWM tunnel boring evaluation. The designation for the previous alloys was SAM2X5 and SAM1651. In previous work, it was found that these alloys, which were designed to be amorphous when thermally sprayed, could be very wear resistant and tough when devitrified. Original chemistries were based on developing low critical cooling rates in order to have a high glass forming ability. Since the development of laser deposition and powder metallurgy with these chemistries are focused on the development of nanocomposite coatings, a much broader chemistry range was available for use in this project. Further improvements could be realized by optimizing the alloy composition for hardness when devitrified as opposed to trying to maintain a fully amorphous condition after deposition.

The ten alloys chosen were designed to have the best combination of hardness and toughness when de-vitrified while trying to improve yields in useful powder size distribution and production. Ten separate powder runs were made to produce one run of each alloy. Each run produced approximately $200 \mathrm{lbs}$. of each powder composition. The runs were performed as two different sets, in order to facilitate any modifications to chemistry or processing required for improved success of the project. Table 1 describes the first set of compositions designed and atomized. A description of the alloy is provided below the table. 
Table 1: Alloy compositions determined for atomization based on the SAM 2x5 and SAM 1651 compositions shown in both atomic and weight percent. A brief description of each alloy relative to the initial compositions is included.

FIRST SET OF COMPOSITIONS FOR POWDER PRODUCTION

\begin{tabular}{|l|c|c|c|c|c|c|c|c|c|c|c|}
\hline & DOE & NC1 $^{1}$ & \multicolumn{1}{|c|}{ DOE } & NC2 $^{2}$ & \multicolumn{2}{|c|}{ DOE NC3 $^{\mathbf{3}}$} & DOE & NC4 $^{4}$ & \multicolumn{2}{c|}{ DOE $^{\text {NC5 }^{5}}$} \\
\hline & at $\%$ & $w t \%$ & at $\%$ & $w t \%$ & at $\%$ & $w t \%$ & at \% & $w t \%$ & at \% & $w t \%$ \\
\hline $\mathrm{Cr}$ & 18 & 19.15 & 18 & 18.81 & 15.73 & 18 & 15 & 15.11 & 15 & 15.8 \\
\hline $\mathrm{Mn}$ & 2 & 2.25 & 2 & 2.21 & 0 & 0 & 0 & 0 & 0 & 0 \\
\hline $\mathrm{Mo}$ & 7.4 & 14.52 & 7.4 & 14.27 & 7.11 & 15 & 14 & 26.03 & 7 & 13.61 \\
\hline $\mathrm{V}$ & 0 & 0 & 0 & 0 & 8.03 & 9 & 0 & 0 & 0 & 0 \\
\hline $\mathrm{W}$ & 1.6 & 6.02 & 1.6 & 5.91 & 0 & 0 & 0 & 0 & 0 & 0 \\
\hline $\mathrm{B}$ & 16 & 3.54 & 16 & 3.48 & 13.67 & 3.25 & 6 & 1.26 & 15 & 3.29 \\
\hline $\mathrm{C}$ & 8 & 1.97 & 6 & 1.45 & 12.87 & 3.4 & 15 & 3.49 & 6 & 1.46 \\
\hline $\mathrm{Si}$ & 2 & 1.15 & 2 & 1.13 & 1.62 & 1 & 0 & 0 & 0 & 0 \\
\hline $\mathrm{Y}$ & 0 & 0 & 0 & 0 & 0 & 0 & 0 & 0 & 2 & 3.6 \\
\hline $\mathrm{Fe}$ & 45 & 51.41 & 47 & 52.75 & 40.98 & 50.35 & 50 & 54.11 & 48 & 61.59 \\
\hline
\end{tabular}

\section{SECOND SET OF COMPOSITIONS FOR POWDER PRODUCTION}

\begin{tabular}{|c|c|c|c|c|c|c|c|c|c|c|}
\hline & DOE & $\mathrm{NC6}^{2}$ & DOE & $\mathrm{NC7}^{3}$ & DOE & $\mathrm{NC8}^{4}$ & DOE & $\mathrm{NC9}^{5}$ & DOE & $\underset{6}{\mathrm{NC10}}$ \\
\hline & at \% & $w t \%$ & at \% & $w t \%$ & at \% & $w t \%$ & at \% & $w t \%$ & at \% & $w t \%$ \\
\hline $\mathrm{Cr}$ & 18 & 19.13 & 18 & 18.82 & 18 & 18.81 & 18 & 18.81 & 15 & 15.77 \\
\hline $\mathrm{Mn}$ & 2 & 2.25 & 4 & 4.42 & 2 & 2.21 & 2 & 2.21 & 0 & 0 \\
\hline Mo & 7.4 & 14.51 & 7.4 & 14.27 & 7.4 & 14.27 & 7.4 & 14.27 & 7 & 13.58 \\
\hline $\mathrm{V}$ & 0 & 0 & 0 & 0 & 0 & 0 & 0 & 0 & 0 & 0 \\
\hline $\mathrm{W}$ & 1.6 & 6.01 & 1.6 & 5.91 & 1.6 & 5.91 & 1.6 & 5.91 & 0 & 0 \\
\hline B & 16 & 3.54 & 16 & 3.48 & 16 & 3.48 & 16 & 3.48 & 6 & 1.31 \\
\hline C & 6 & 1.47 & 6 & 1.45 & 6 & 1.45 & 6 & 1.45 & 15 & 3.64 \\
\hline $\mathrm{Si}$ & 5 & 2.87 & 2 & 1.13 & 2 & 1.13 & 2 & 1.13 & 0 & 0 \\
\hline $\mathrm{Y}$ & 0 & 0 & 0 & 0 & 0 & 0 & 0 & 0 & 2 & 3.60 \\
\hline $\mathrm{Fe}$ & 44 & 50.22 & 45 & 50.52 & 47 & 52.75 & 47 & 52.75 & 55 & 62.10 \\
\hline
\end{tabular}

DOE NC1- is a variation on SAM2X5 with a doubling of the carbon content.

DOE NC2 is a variation on SAM2X5 with 1.5 times the carbon content.

DOE NC3 was recommended by Carpenter Technology, as a means to improve the wear resistance of the base compositions and also provide for easier, higher yield atomization. It replaces the tungsten found in the other alloys with vanadium.

DOE NC4 was designed to eliminate the use of yttrium and hopefully improve yields, increase toughness, and retain superior wear resistance. This alloy was based on alloy SAM1651.

DOE NC5 was designed to evaluate the effect of molybdenum content. In addition, the carbon and boron contents have been reversed compared to the original alloy.

DOE NC6 is a variation on DOE NC2 with 5 at. \% silicon.

DOE NC7 is a variation on DOE NC2 with $2 x$ the at $\% . \%$ of manganese content.

DOE NC8 is DOE NC2 that has been atomized with nitrogen.

DOE NC9 is DOE NC2 that has been atomized with a mixture of 50\% argon and 50\% nitrogen. 
DOE NC10 is SAM 1651 with $1 / 2$ the moly.

Chemical analysis was performed on the powder compositions produced in both the first and second research sized atomization run as shown in Table 2. During the first set of atomization runs (first 5 alloys) produced, the chemical compositions measured are nearly on specification with the desired chemistries. However, it can be noted that for the first set of alloys atomized, the Cr content was approximately $0.5 \mathrm{wt} . \%$ higher than expected. No other trends were readily observed. Based on the results of alloy chemistry, modifications were made to the atomization procedure for calculating the amount of input material/elements required to produce a desired chemistry. In the second set of atomization runs, the measured chemical is significantly closer to the desired chemistry. It should also be noted that the atomization process did not raise the impurity content of oxygen, nitrogen, and sulfur. Alloy DOE NC8 and DOE NC9 show increased nitrogen contents by design.

Table 2: Target composition and actual composition of fabricated powder materials.

\begin{tabular}{|c|c|c|c|c|c|c|c|c|c|c|}
\hline Element (wt.\%) & \multicolumn{2}{|c|}{ DOE NC1 ${ }^{1}$} & \multicolumn{2}{|c|}{$\mathrm{DOE} \mathrm{NC2}^{2}$} & \multicolumn{2}{|c|}{ DOE $\mathrm{NC3}^{3}$} & \multicolumn{2}{|c|}{ DOE NC4 ${ }^{4}$} & \multicolumn{2}{|c|}{ DOE NC5 $^{5}$} \\
\hline $\mathrm{Cr}$ & 19.15 & 20 & 18.81 & 19.6 & 18 & 18.6 & 15.11 & 15.6 & 15.8 & 16.2 \\
\hline $\mathrm{Mn}$ & 2.25 & 2.38 & 2.21 & 2.4 & 0 & $<0.1$ & 0 & $<0.1$ & 0 & $<0.1$ \\
\hline Mo & 14.52 & 14.3 & 14.27 & 14.1 & 15 & 15.8 & 26.03 & 26.8 & 13.61 & 13.9 \\
\hline $\mathrm{V}$ & 0 & $<0.01$ & 0 & $<0.01$ & 9 & 8.93 & 0 & $<.01$ & 0 & $<.01$ \\
\hline $\mathrm{W}$ & 6.02 & 6.14 & 5.91 & 5.9 & 0 & $<0.01$ & 0 & $<0.01$ & 0 & $<0.01$ \\
\hline B & 3.54 & 3.79 & 3.48 & 3.69 & 3.25 & 3.37 & 1.26 & 1.36 & 3.29 & 3.21 \\
\hline $\mathrm{C}$ & 1.97 & 1.84 & 1.45 & 1.49 & 3.4 & 3.33 & 3.49 & 3.44 & 1.46 & 1.56 \\
\hline$\overline{\mathrm{Si}}$ & 1.15 & 1.09 & 1.13 & 1.2 & 1 & 1.13 & 0 & $\begin{array}{l}<.01 \\
\end{array}$ & 0 & $<.01$ \\
\hline $\bar{Y}$ & 0 & $<.01$ & 0 & $<.01$ & 0 & $<.01$ & 0 & $<.01$ & 3.6 & 3.99 \\
\hline $\mathrm{Fe}$ & 51.41 & 50 & 52.75 & 52 & 50.35 & 49 & 54.11 & 53 & 61.59 & 61 \\
\hline$\overline{\mathrm{O}}$ & & 0.025 & & 0.021 & & 0.015 & & 0.016 & & 0.03 \\
\hline$\overline{\mathrm{N}}$ & & $<.01$ & & $<.01$ & & $<.01$ & & $<.01$ & & $<.01$ \\
\hline $\bar{S}$ & & 0.004 & & 0.006 & & 0.006 & & 0.006 & & 0.003 \\
\hline
\end{tabular}

\begin{tabular}{|c|c|c|c|c|c|c|c|c|c|c|}
\hline Element (wt.\%) & \multicolumn{2}{|c|}{ DOE NC6 $^{2}$} & \multicolumn{2}{|c|}{ DOE NC7 ${ }^{3}$} & \multicolumn{2}{|c|}{ DOE NC8 $^{4}$} & \multicolumn{2}{|c|}{ DOE NC9 $^{5}$} & \multicolumn{2}{|c|}{ DOE NC10 $^{6}$} \\
\hline $\mathrm{Cr}$ & 19.13 & 19.13 & 18.82 & 18.92 & 18.81 & 18.88 & 18.81 & 18.95 & 15.77 & 15.78 \\
\hline $\mathrm{Mn}$ & 2.25 & 2.32 & 4.42 & 4.48 & 2.21 & 2.32 & 2.21 & 2.3 & 0 & 0 \\
\hline Mo & 14.51 & 14.43 & 14.27 & 14.3 & 14.27 & 14.15 & 14.27 & 14.22 & 13.58 & 13.59 \\
\hline $\mathrm{V}$ & 0 & 0 & 0 & 0 & 0 & 0 & 0 & 0 & 0 & 0 \\
\hline $\mathrm{W}$ & 6.01 & 5.92 & 5.91 & 6.15 & 5.91 & 5.98 & 5.91 & 5.96 & 0 & 0 \\
\hline $\mathrm{B}$ & 3.54 & 3.74 & 3.48 & 3.63 & 3.48 & 3.6 & 3.48 & 3.65 & 1.31 & 1.46 \\
\hline $\bar{C}$ & 1.47 & 1.56 & 1.45 & 1.47 & 1.45 & 1.53 & 1.45 & 1.55 & 3.64 & 3.7 \\
\hline $\mathrm{Si}$ & 2.87 & 2.96 & 1.13 & 1.16 & 1.13 & 1.2 & 1.13 & 1.19 & 0 & 0 \\
\hline $\mathrm{Y}$ & 0 & 0 & 0 & 0 & 0 & 0 & 0 & 0 & 3.6 & 3.4 \\
\hline $\mathrm{Fe}$ & 50.22 & 49.93 & 50.52 & 49.88 & 52.75 & 52.31 & 52.75 & 52.11 & 62.1 & 62.06 \\
\hline $\mathrm{O}$ & & 0.0075 & & 0.01 & & 0.01 & & 0.006 & & 0.01 \\
\hline $\mathrm{N}$ & & 0.0013 & & 0.0019 & & 0.0159 & & 0.0359 & & 0.001 \\
\hline $\mathrm{S}$ & & 0.003 & & 0.003 & & 0.003 & & 0.03 & & 0.001 \\
\hline
\end{tabular}

All ten compositions were atomized in a small commercial scale reactor. The charged weight of each run on alloy 1-5 was $290 \mathrm{lbs}$. The material was then separated into two different size distributions of powder, -325 and +325 mesh. Alloys $6-10$ were atomized at a later date, and also sieved to $+/-325$ mesh sizes. The distribution of powder size as a function of weight is shown in Table 3. Overall, the material yield was very good as a function of starting charge weight. Powders were sieved to +325 and -325 mesh because there were specific targeted processing routes for each powder size. Initial laser deposition was conducted by utilizing the -325 mesh powder cold aspirated onto a substrate 
while the larger powder would be consolidated in bulk shapes. However, as will be discussed later, the larger powder was utilized for laser deposition as well and bulk components were fabricated from -325 mesh powder.

Table 3: Particle size distribution as a function of weight for alloys 6-10

\begin{tabular}{|c|c|c|c|}
\hline \multirow{2}{*}{ Alloy } & Heat & Mesh & $\begin{array}{c}\text { Total } \\
\text { Weight }\end{array}$ \\
\hline \multirow{2}{*}{ NC6 } & 130818 & -325 & $\mathbf{8 2}$ \\
\cline { 2 - 4 } & 130818 & +325 & $\mathbf{1 6 7}$ \\
\hline \multirow{2}{*}{ NC7 } & 130819 & -325 & $\mathbf{7 7}$ \\
\cline { 2 - 4 } & 130819 & +325 & $\mathbf{1 7 4}$ \\
\hline \multirow{2}{*}{ NC8 } & 130820 & -325 & $\mathbf{1 2 0}$ \\
\cline { 2 - 4 } & 130820 & +325 & $\mathbf{1 4 6}$ \\
\hline \multirow{2}{*}{ NC9 } & 130821 & -325 & $\mathbf{1 1 4}$ \\
\cline { 2 - 4 } & 130821 & +325 & $\mathbf{1 5 0}$ \\
\hline \multirow{2}{*}{ NC10 } & 130822 & -325 & $\mathbf{8 0}$ \\
\cline { 2 - 4 } & 130822 & +325 & $\mathbf{1 5 9}$ \\
\hline
\end{tabular}

\subsubsection{Commercial Size Atomization of Powders}

After a review of the data (details of the data review are provided in the RESULTS section below) with the powder from the $200 \mathrm{lb}$. runs, it was decided to use alloy composition NC-8 for the $1000 \mathrm{lb}$. production scale run. NC-8 is based on SAM2X5 with 1.5x carbon and was atomized with nitrogen. The material atomized without incident, however, upon completion of the run evidence of un-melted raw material was present on the bottom of the crucible. Chemical analysis was performed by ICP and gas combustion to determine the chemistry of the powder and is shown in Table 4:

Table 4: Target composition and resulting chemical analysis of the large-scale commercialization run of alloy NC-8

\begin{tabular}{|c|c|c|c|c|c|c|c|c|c|c|}
\hline NC8 & C & Cr & Mn & Mo & W & B & Si & Fe & N & O \\
\hline Actual & 1.68 & 19.8 & 2.3 & 11.6 & 4.8 & 3.16 & 0.34 & Bal & 0.016 & 0.012 \\
\hline Aim & 1.45 & 18.8 & 2.2 & 14.25 & 5.9 & 3.48 & 1.13 & Bal & - & - \\
\hline
\end{tabular}

Since the targeted composition was the aim, we can deduce that the unmelted material on the bottom of the crucible contained Mo and $\mathrm{W}$ since these lab results are low. In reviewing the melt mix that went into the heat, fairly large sized pure Mo and W plate sections were used. Since both Mo and W have a high melting point and density, these elemental plate sections sunk to the bottom of the crucible during melting effectively forming a larger cluster of high melting temperature material. From a scale-up perspective, we can now say that with the large amount of Mo and W in the alloy, the resonance time at temperature was not enough to melt in all the raw material and the for future melting of alloy NC8 the cuttings will either need to be significantly reduced in size or switched to FeMo and FeW. Although the lower values for the Mo and $\mathrm{W}$ can be explained, there is no reason for a low Si level. Since Si at higher levels can be harder to digest, it's possible that the ICP solution did not fully dissolve the Si.

The targeted size ranges for this alloy are $-60+325$ mesh and -325 mesh. The powder was screened on a 48" diameter production unit. The yield results are shown in Table 5. 
Table 5: Yield weight and percentage of large scale commercialization run. Total charge weight of the run was 1278 lbs.

\begin{tabular}{|l|l|ll|}
\hline \multicolumn{4}{|l|}{ Yield of powder as atomized $=1278 \mathrm{lbs}}$. \\
\hline+60 & $89 \mathrm{lbs}$. & $7 \%$ & \\
\hline$-60+325$ & $740 \mathrm{lbs}$. & $59 \%$ & with $0.2 \%+60$ and $6.4 \%-325$ \\
\hline-325 & $398 \mathrm{lbs}$. & $31 \%$ & with $0.3 \%+325$ \\
\hline Process Loss & $51 \mathrm{lbs}$. & $4 \%$ & \\
\hline
\end{tabular}

Needles were present in the material which is consistent with glassy behavior during atomization and commonly show up during screening where agglomeration occurs into what appear to be 'fuzz' balls. The powder was packed in plastic lined 50lbs pails and shipped to Oak. Fifty pounds of each size was retained at CPP for any future work including bulk consolidation.

With the lessons learned from the $1^{\text {st }}$ production heat, we are confident that the chemistry aim can be consistently achieved with the right melt mix charge. Any left-over powder not required for your welding trials an analysis can be used as input stock for future runs of NC8 and can also be used to demonstrate the recycling of off size or scrap NC8 material which is an important consideration in keeping the process costs down.

\subsubsection{Powder Characterization}

The chemical analysis of the powders has been discussed in Table 2 and show that the resulting powder is very close to the specified chemical composition. The material was screened to $-60+325$ mesh (referred to as +325 mesh) and -325 mesh. Larger particles, flakes, and needles apparent in the bulk material but greater than +60 mesh were not analyzed. Larger agglomerated particles can result, especially when producing glassy like alloys such as those in this project. However, because they will not be utilized in bulk processing or laser deposition, they were not analyzed.

Samples of powders of both + and -325 mesh were examined using a scanning electron microscope in both the as received and mounted/polished condition. The mounted and polished samples were polished using SiC grit abrasive paper down to 1200 grit and final polished using colloidal silica. Samples were examined in both secondary electron and back scattered imaging mode (dependent on observations required). Mounted and cross-sectioned samples of alloy 1 and alloy 2 are shown in Figure 8 and Figure 9 respectively at low magnification. These two samples are representative in terms of morphology and size distribution for all 10 alloys. The morphology of the powders is nearly symmetrical, although the majority of the powder is not spherical. There is a significant volume fraction of very small particles, sub $10 \mu \mathrm{m}$ in the -325 mesh powder. 

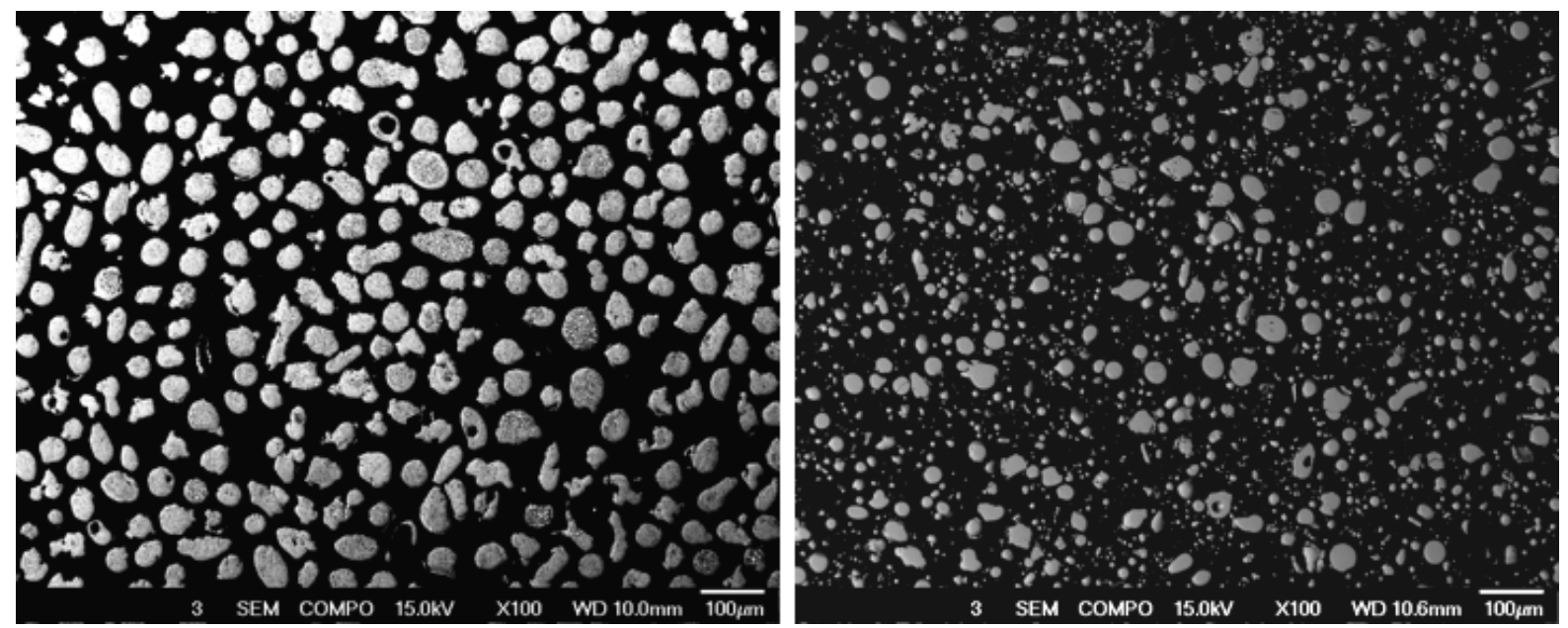

Figure 8: BSE Image of Alloy 1 in the +325 mesh size range (left) and -325 mesh size range (right)
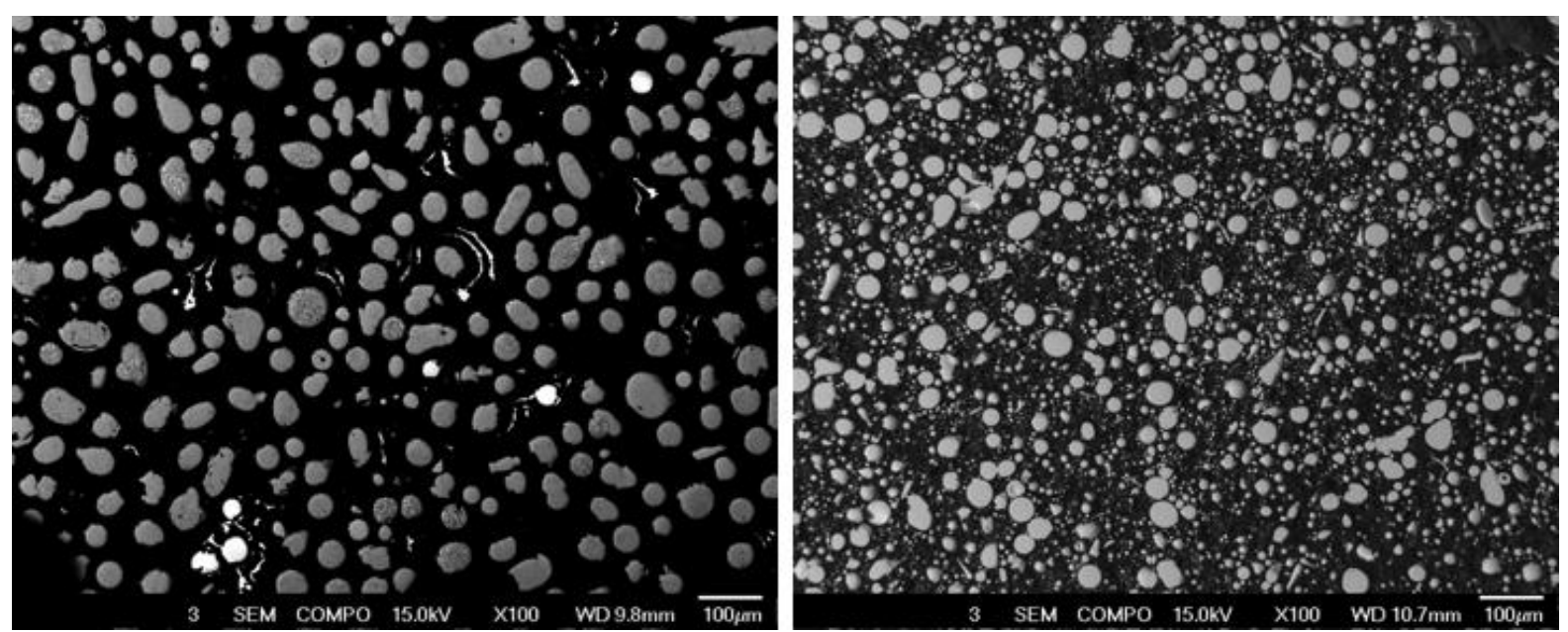

Figure 9: BSE Image of Alloy 2 powder in the +325 mesh size range (left) and -325 mesh size range (right)

Increased magnification of the powder particles in the +325 mesh range are shown for Alloy 1 , Alloy 2, and Alloy 4 in Figure 10, Figure 11 and Figure 12 respectively. In nearly all of the particles, devitrification of the amorphous material was evident. Crystallization was observed in the form of complex carbides and borides in an Fe-based matrix phase. Large blocky particles were apparent on the order of $1 \mu \mathrm{m}$ in size. In addition, dendrites with nanoscale arm spacings were observed. The distribution, quantity, size and morphology were dependent on alloy and particle size. For example, Figure 11 shows two similar sized particles of Alloy 1 with significantly different phase present in distinctly different morphologies and non-uniform distributions. 

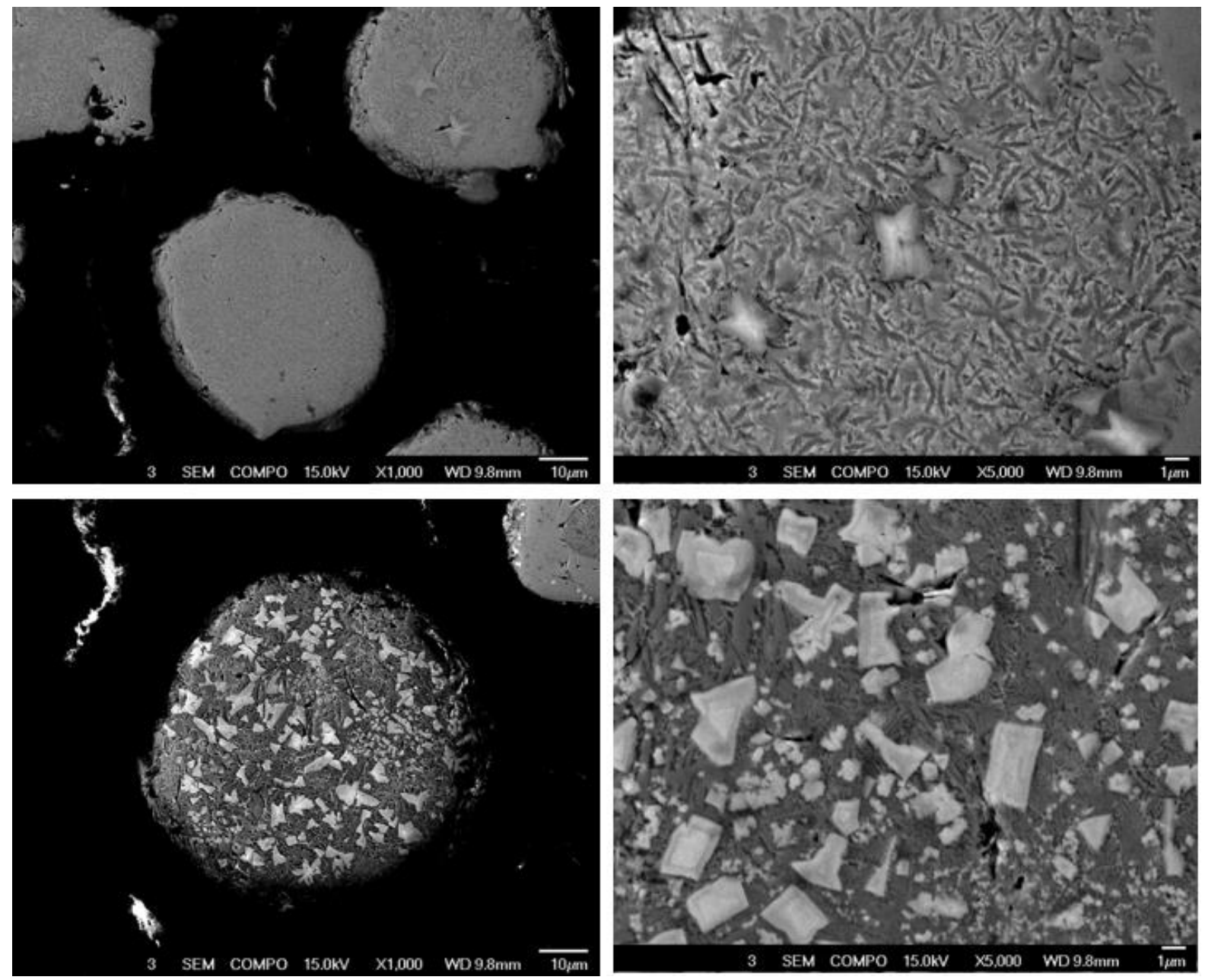

Figure 10: Increase magnification BSE images of Alloy 1 in the +325 mesh size range.
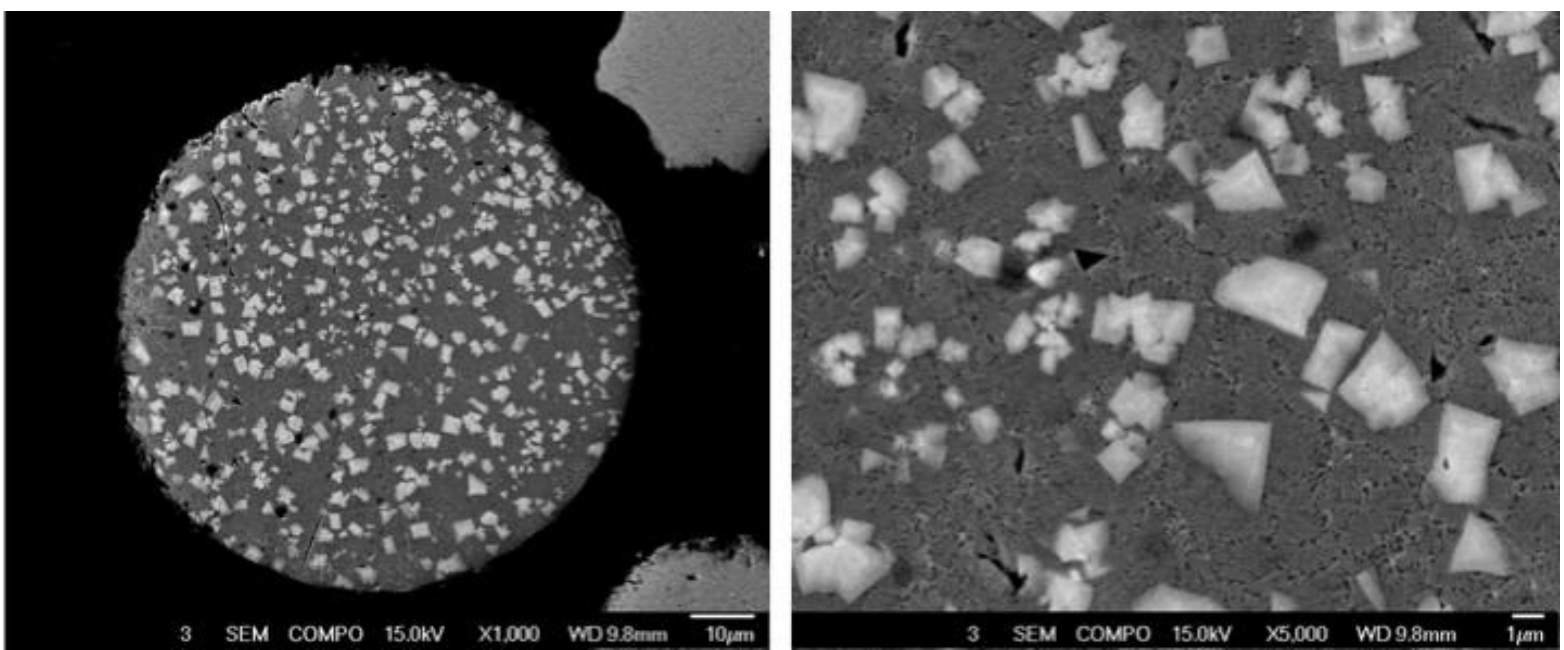

Figure 11: Increased magnification BSE images of Alloy 2 in the +325 mesh size range. 

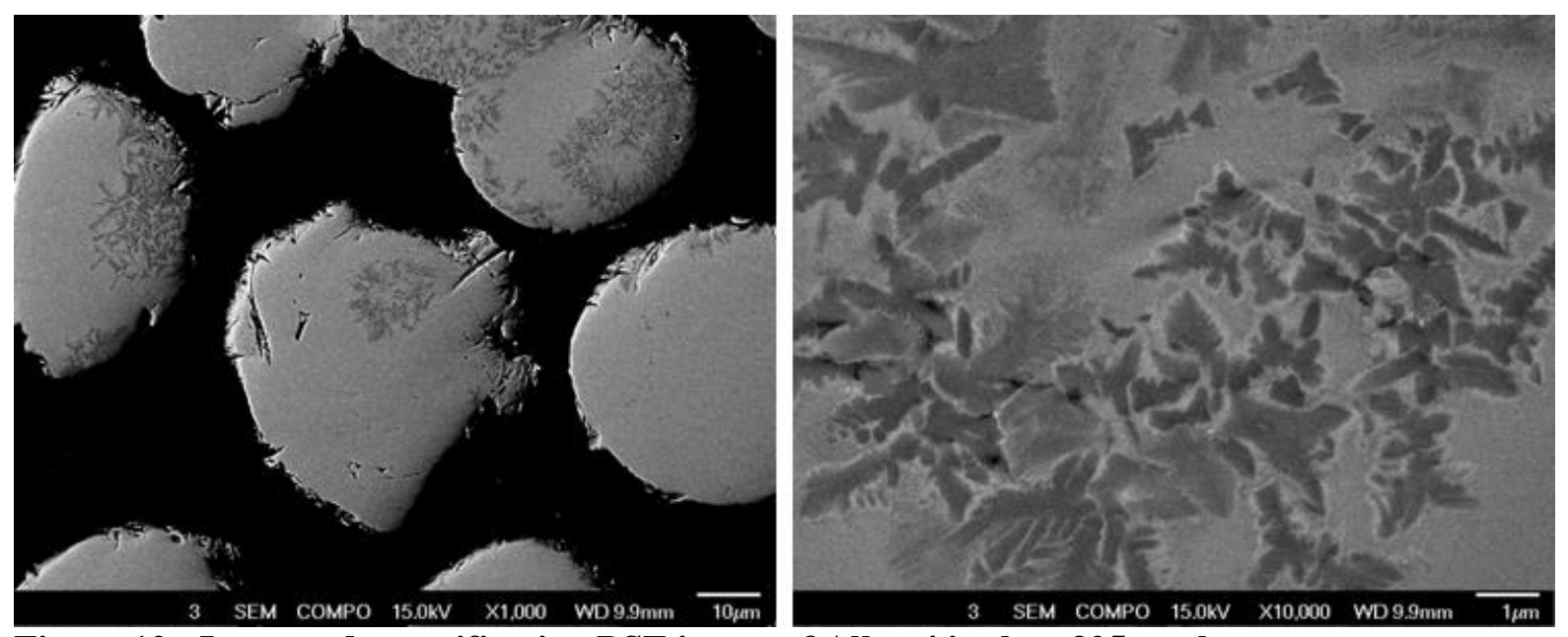

Figure 12: Increased magnification BSE image of Alloy 4 in the +325 mesh range.

Figure 13 and Figure 14 are BSE images of Alloy 1 and Alloy 2 respectively for powder materials in the -325 mesh size range. It was observed that a similar phase fraction, morphology and distribution of particles were present as in the +325 mesh powder. However, the size of the particles as examined in Figure 13 (top) are comparable to smaller particles in the +325 mesh powder. Examination of fine particles in Figure 13 (bottom) show a very limited number of finely distributed nano precipitates in an amorphous matrix. Similarly, in Alloy 2, nearly all of the powder in the -325 mesh size range appears to be amorphous.

Based on the comparison between Alloy 1 (SAM2X5 with a doubling of the carbon content) and Alloy 2 (SAM2X 5 with 1.5 times the carbon content), it appears that increasing the carbon content in these materials increases the tendency of the material to devitrify. This is a consistent observation in these materials. In addition, it should be noted that there does appear to be a minimum size at which particles under this size remain amorphous and powder particles over this size show distinct crystals and devitrification. This could be due to chemical variation within the molten tundish during the atomization process. However, EDS examination indicated that the chemistry was consistent between small amorphous particles and larger devitrified particles which indicates chemistry of the two material is homogeneous. Although it is noted that EDS analysis may vary by several percent for each element, the expected relative amounts in the material should be similar. This then implies that the devitrification process results from variations in thermal cooling rate of powders during processing.

Cooling rates in the atomization process can vary with powder particle size as well as location within the atomization chamber. For example, powder that is disbursed toward the chamber wall (colder) will have a faster cooling rate than powder disbursed toward the center of the atomization chamber. This would explain why powders of similar size can show variations in amount and phase distribution of crystalline material. In addition, this shows that although the materials are amorphous based, they do have a tendency to devitrify into nano precipitates at slower cooling rates. Based on these results, it is expected that nanoparticles will form during the laser deposition process. 

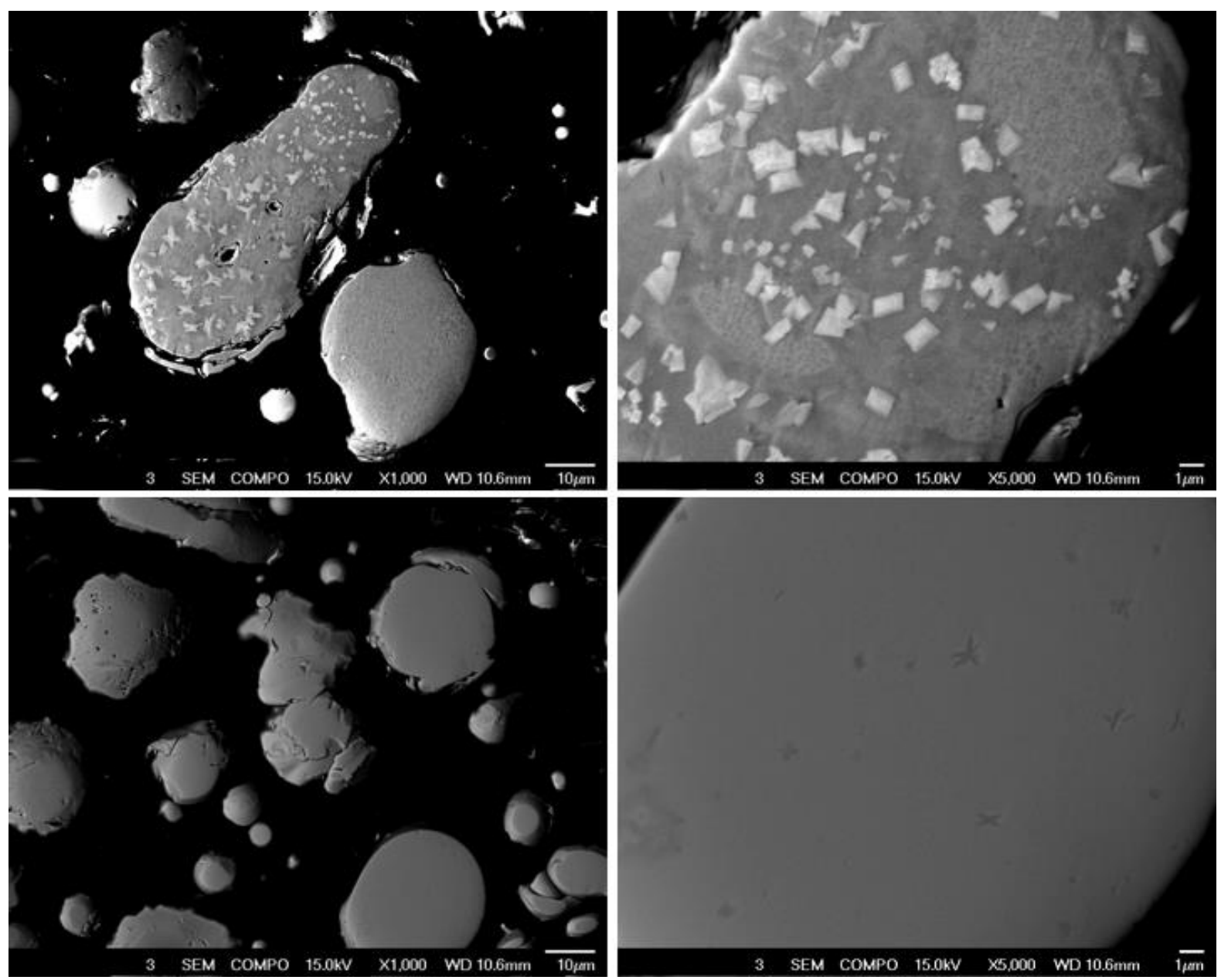

Figure 13: Higher magnification BSE image of Alloy 1 in the -325 mesh range
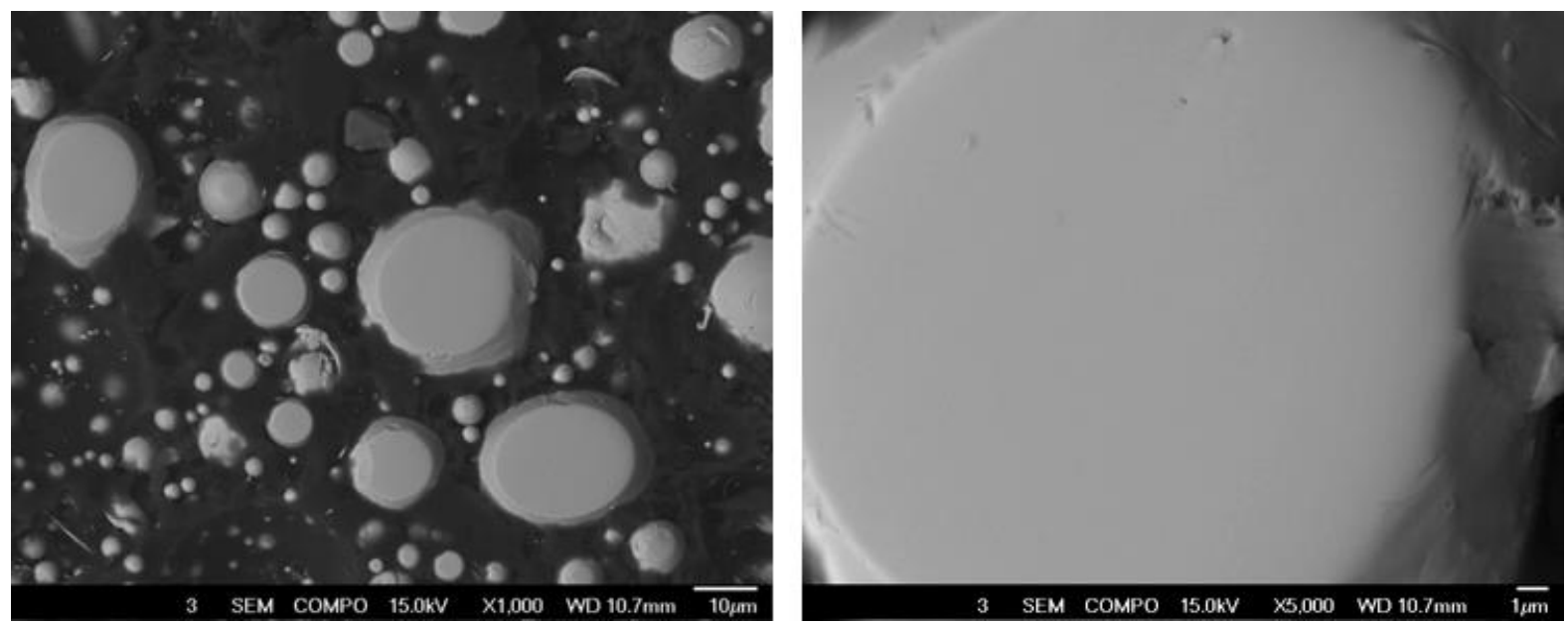

Figure 14: High magnification BSE image of Alloy 2 with size distribution at -325 mesh

X-ray diffraction techniques were utilized to confirm the amount of amorphous content in the powder materials in the as-received conditions. Table 6 lists the details of the experimental conditions for the X-ray measurements. Briefly, a 4-circle $(\phi, \chi, \Omega, \theta)$ goniometer (Krause and Haase, 1986) was employed for the measurements using CoK $\alpha$ radiation. Specimen alignment was accomplished using a dial gauge probe that is accurate to $\pm 5 \mu \mathrm{m}$. Here, the relative distance to the center of rotation is known, and the diffracting surface is positioned accordingly. Incident slits and diffracted-side radial 
divergence limiting slits were used. The samples were scanned in the $\theta-2 \theta$ continuous mode from 36 to $134^{\circ} 2 \theta$. Data analyses and plotting done with Jade 9.1 (2009).

Table 6: Experimental conditions of the X-ray measurements with the 4-circle diffractometer

\begin{tabular}{ll}
\hline Parameter & Condition \\
\hline Equipment & Scintag PTS goniometer \\
& Spellman DF3 series $4.0 \mathrm{~kW}$ generator \\
& Scintag liquid $\mathrm{N}_{2}$-cooled Ge detector \\
Power & $1.44 \mathrm{~kW} ; 40 \mathrm{kV}, 36 \mathrm{~mA}$ \\
Radiation & $\mathrm{Co}, \lambda \mathrm{K \alpha}=1.78897 \AA$ A \\
Incidence divergence & $0.3^{\circ}$ \\
Receiving slit acceptance & $0.25^{\circ} ;$ radial divergence limiting parallel plate \\
& collimator \\
Goniometer radius & $290 \mathrm{~mm}$ \\
Axial Soller slit divergence & $\pm 1.7^{\circ}$ \\
$\theta-2 \theta$ Scans & $0.02^{\circ} 2 \mu / \mathrm{step} ; 1^{\circ} / \mathrm{min}$ \\
\hline
\end{tabular}

Figure 15 is the XRD results for powders in the -325 and +325 size range. From the first batch of powders examined, the results show very few distinct diffraction peaks for Alloys 1, 2, and 4. The broad peak over the entire scan range demonstrates that very few if any crystalline peaks are observed, indicating powder in the -325 mesh size range tends to be amorphous. However, Alloy 3 in Figure 15 shows distinct diffraction peaks in the -325 mesh size range. This is consistent with SEM micrographs for the -325 mesh powder for Alloy 3 shown in Figure 16. Smaller particles under $\sim 10 \mu \mathrm{m}$ do appear to be amorphous in Figure 16, which is consistent with the shape of the XRD results shown in Figure 15.

The XRD results of the +325 mesh powder shown in Figure 15 indicate all of the powders tested were devitrified in this size range. Therefore, the XRD results confirm the SEM results of larger powders having a tendency to be crystalline while smaller powders remain amorphous. Phase analysis was conducted on the XRD results and shown in Figure 17 and Figure 18. The results of phase identification are shown in Table 7 showing the formation of complex carbides and borides in a Rebased matrix.

Table 7: XRD Phase analysis for Alloy 1 in the +325 mesh size range.

\begin{tabular}{|l|l|l|l|l|l|}
\hline File & Name & Form & Phases & PDF \# & $\begin{array}{l}\text { Lattice } \\
\text { Parameter (A) }\end{array}$ \\
\hline D14837 & $130789+325$ & Powder & $\mathrm{BCC}-$ Ferrite & $6-696$ & $2.867(3)$ \\
\hline & & & $\mathrm{Cr}_{23} \mathrm{C}_{6}$ & $0-35-783$ & \\
\hline & & & $\mathrm{Ti}_{0.5} \mathrm{Cr}_{0.5} \mathrm{~W}_{0.5} \mathrm{MoFe}_{0.5} \mathrm{~B}_{2}$ & $4-7-5100$ & \\
\hline
\end{tabular}




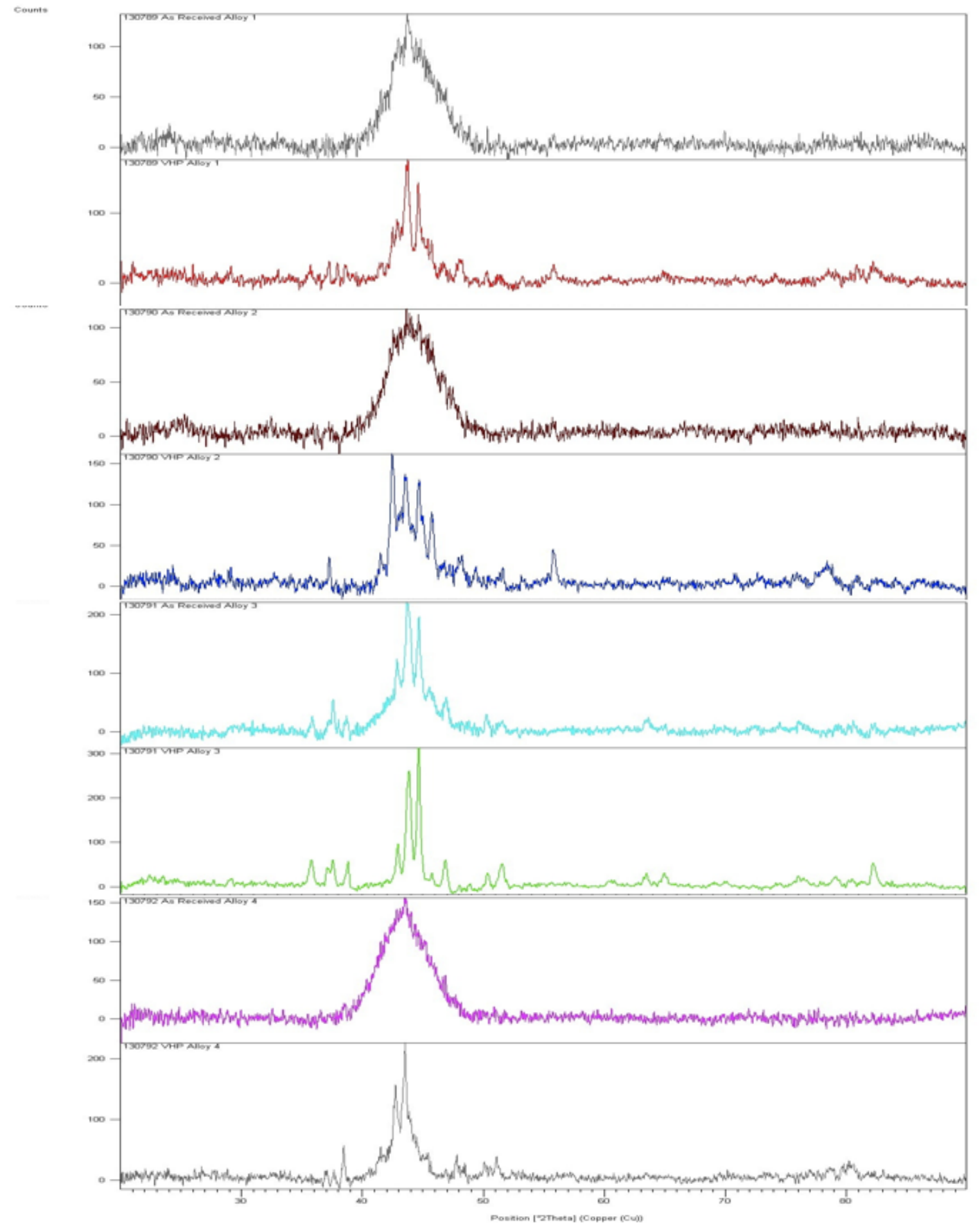

Figure 15: XRD Scans for Alloy 1-4 for -325 and +325 mesh size range. 

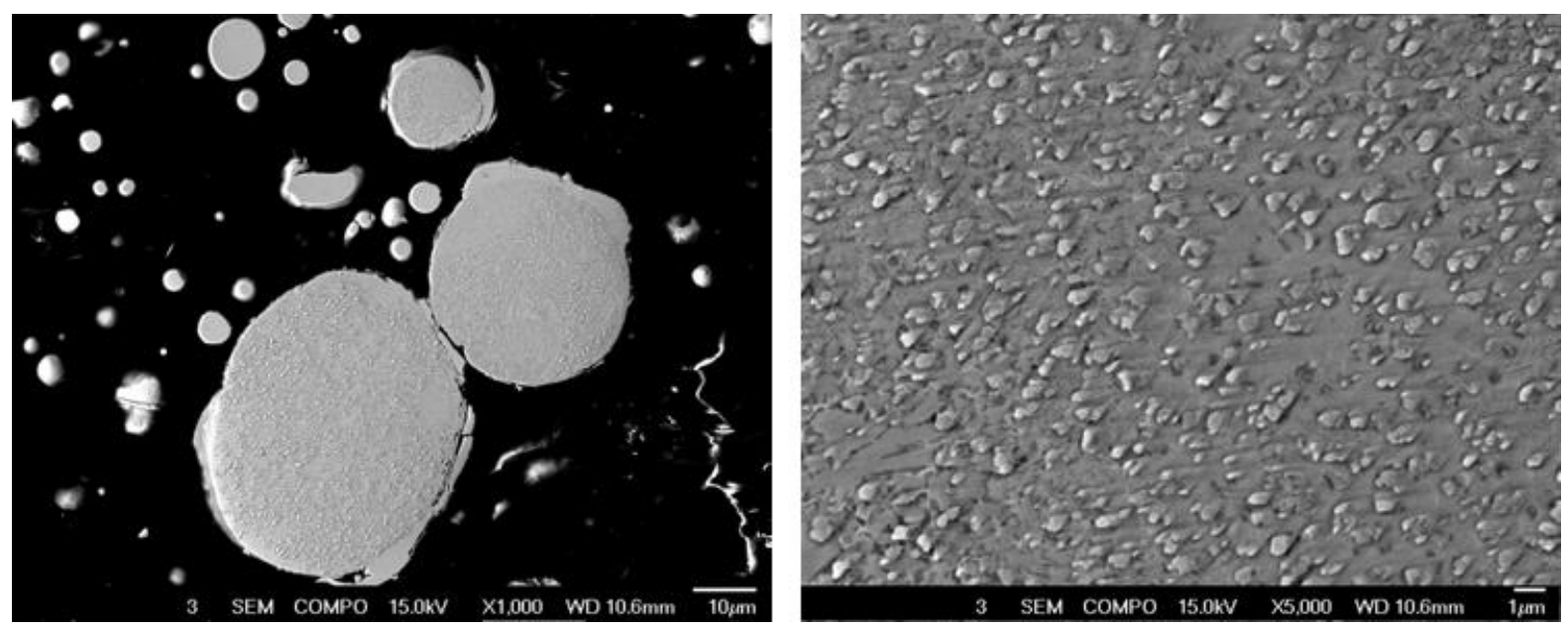

Figure 16: SEM images of $\mathbf{- 3 2 5}$ mesh size range powder of Alloy 3 showing small crystalline particles.

Particles under $10 \mu \mathrm{m}$ appear to be amorphous.

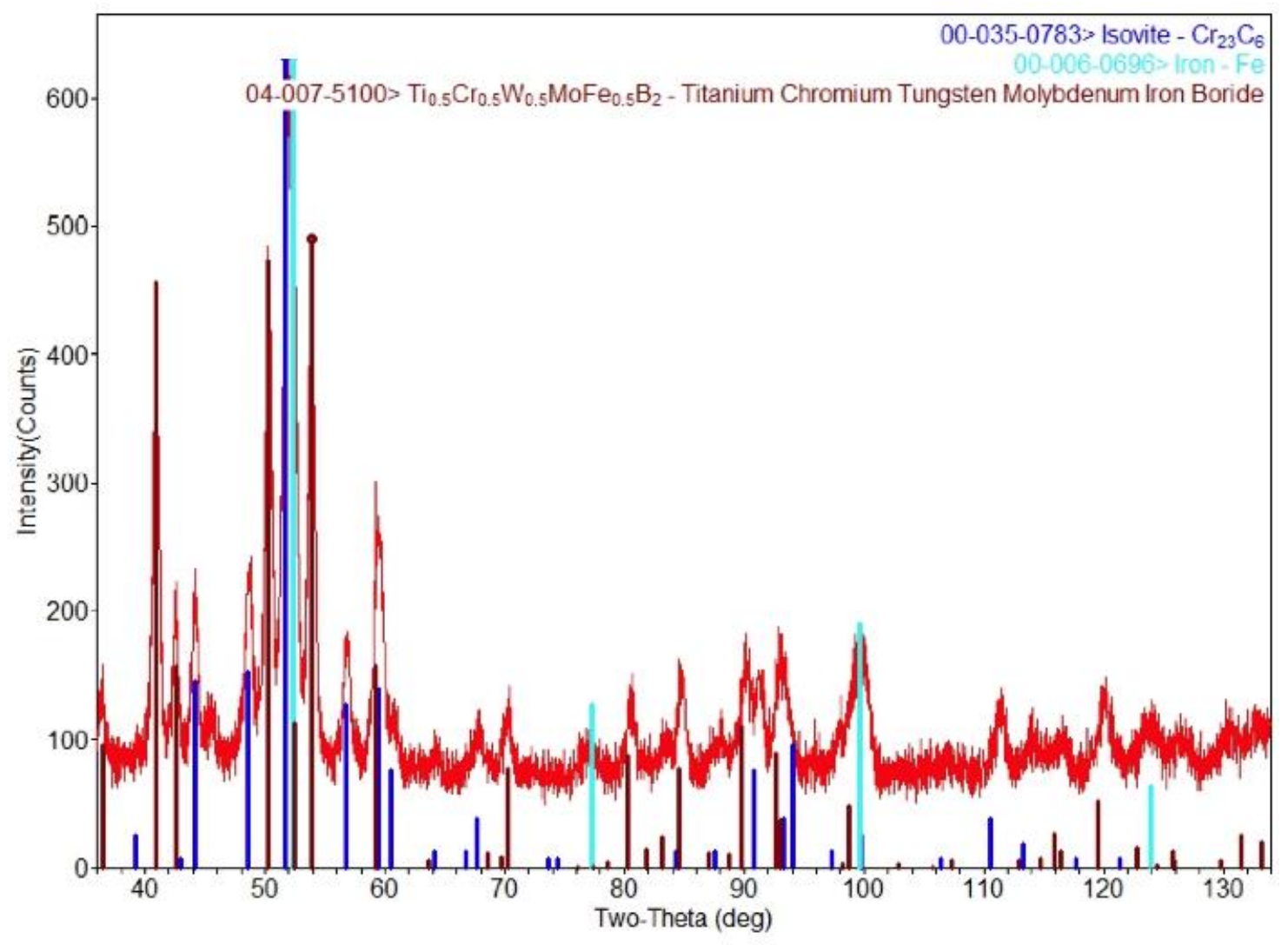

Figure 17: XRD Phase analysis for Alloy 1 in the +325 mesh size range. 


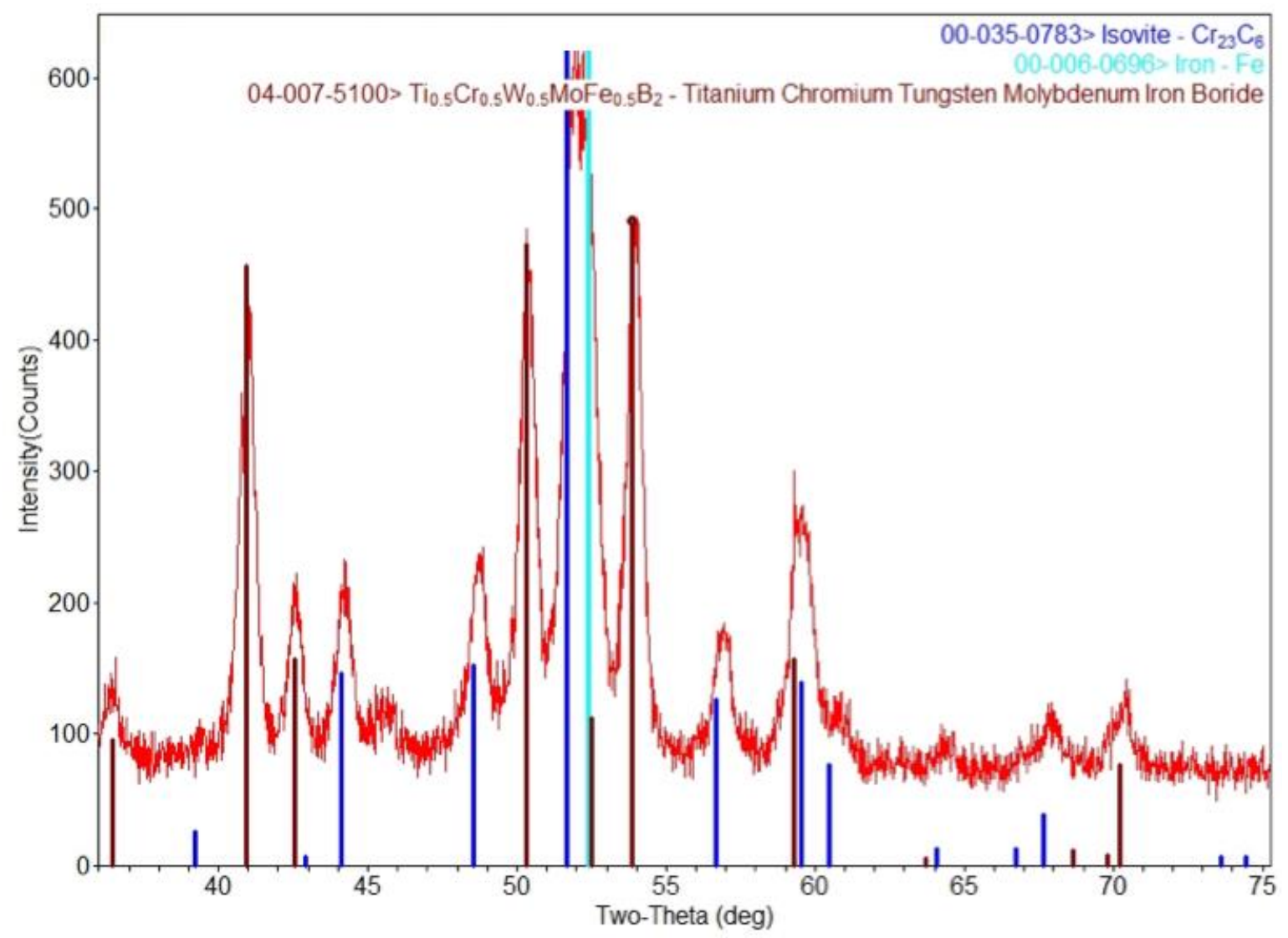

Figure 18: A close up of the lower 2 Theta region of the diffraction patterns of Alloy 1 in the +325 mesh size range

\subsection{LASER FUSING AND BULK PROCESSING OF NANOCOMPOSITE}

The intent of the project was to fabricate both laser-fused coatings and bulk components in order to utilize maximum yield of the powder materials. Economical powder utilization is critical for improving the cost structure of the powder materials and therefore increasing the potential for industrial adoption. For example, on the large-scale commercial run, nearly $11 \%$ of the run would be considered scrap material (Table 5). In addition, 4\% is lost during processing, while 7\% (greater than +60 mesh) could be re-melted and recycled in subsequent atomization runs. Although material could be recycled, the cost of the powders would increase due to atomization costs. Therefore, maximum utilization of the material is desired.

Two different laser methodologies and three bulk consolidation processes were examined during the project duration. The initial project concept utilized small powder to utilize for powder deposition utilizing cold aspiration of the powders in a polymer-based binder followed by laser fusing. For this process, the cold aspiration process requires a fine powder size (-325 mesh) in order to be properly suspended in the binder and capable of not clogging the spray nozzle. If this case were successful, the larger powder (+325 mesh) powders would be utilized for bulk consolidation. Midway into the duration of the project, ORNL acquired a new POM laser deposition system and added additional capability in laser fusing. The POM laser system utilizes larger powders (+325 mesh). After examination of thee microstructure results on the powders and quality of initial laser coated samples using the $4 \mathrm{~kW} \mathrm{Nd:YAG} \mathrm{laser} \mathrm{system,} \mathrm{it} \mathrm{was} \mathrm{determined} \mathrm{that} \mathrm{the} \mathrm{ideal} \mathrm{utilization} \mathrm{of} \mathrm{powder} \mathrm{would} \mathrm{be}$ for +325 mesh powder to be used for laser fusing and -325 mesh powder would be utilized for 
fabrication of bulk material. The justification for this assumption stems from the research presented in the section on laser fusing and bulk consolidation.

\section{Laser Deposition of Fe-based Powders:}

\subsubsection{Deposition Of -325 Mesh Powder Using A 4 Kw Nd:YAG Laser}

Deposition of the -325 mesh powder was conducted using a multistep approach in which powder was cold aspirated via a polymer binder onto the surface of the substrate material. The powder/polymer binder was exposed to air and allowed to dry for several hours to evaporate any volatile organic material due to the binder process. After drying, the coupon was placed onto a table system where a laser was utilized to melt the coating onto the substrate material.

For the powder-coating step in the process, only -325 powder was utilized because larger powders will result in clogging of the powder spray nozzle. The metal powder is mixed with LISI Vehicle 100 binder with a powder to binder ratio of 5:1. Once mixed, the slurry was shaken vigorously until it was in solution. Then, using a paint sprayer the mixture is then immediately sprayed onto the surface of a metal coupon. Coupons were wire brushed and blasted with a conventional grit blasting system containing granite blasting media to remove any oil or other contaminates and ensure that the substrate material is non-reflective. Samples were cleaned with alcohol prior to spraying on the metal/polymer coating. When depositing, the spray gun is moved in a sweeping motion, and the coupon is rotated $90^{\circ} 4$ times to ensure that the coating is deposited evenly over the surface of the coupon. The thickness of the coating is determined by the amount of powder mixed e.g. $100 \mathrm{~g}$ powder results in an $\sim 200$ microns thick layer, 200g powder results in an $\sim 400$ micron thick layer, etc. An example of a coated coupon (typically H13 or 4340) is shown in Figure 19.

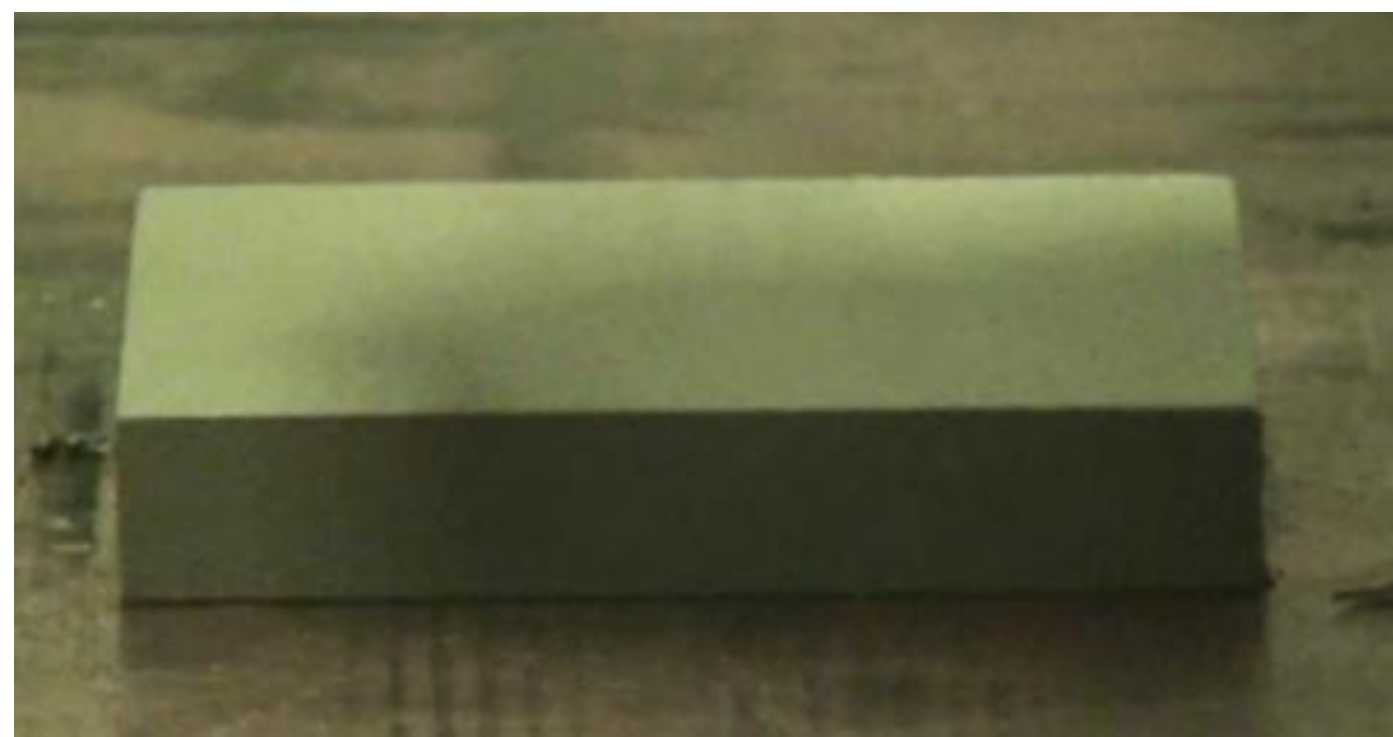

Figure 19: Coated coupon utilized in laser fusing with the $4 \mathrm{~kW}$ Nd:YAG laser system.

Once coated, the coupon is allowed to dry prior to being laser fused. The laser set up is shown in Figure 20. The laser system is positioned on a gantry system which controls the position and movement of the laser head. Two gas nozzles are located near the laser head (orange nozzles in Figure 20) that can be used to run shielding gas tot eh focal/melt point of the laser system. Gasses such as Ar, N, He, etc. can be used to shield the molten pool during the deposition process. However, it is expected that because the samples are exposed to atmosphere, some contamination may occur during the fusing process due to reaction with atmospheric gasses such as oxygen. The flow rate of the cover gas can be controlled to improve contamination during deposition. 

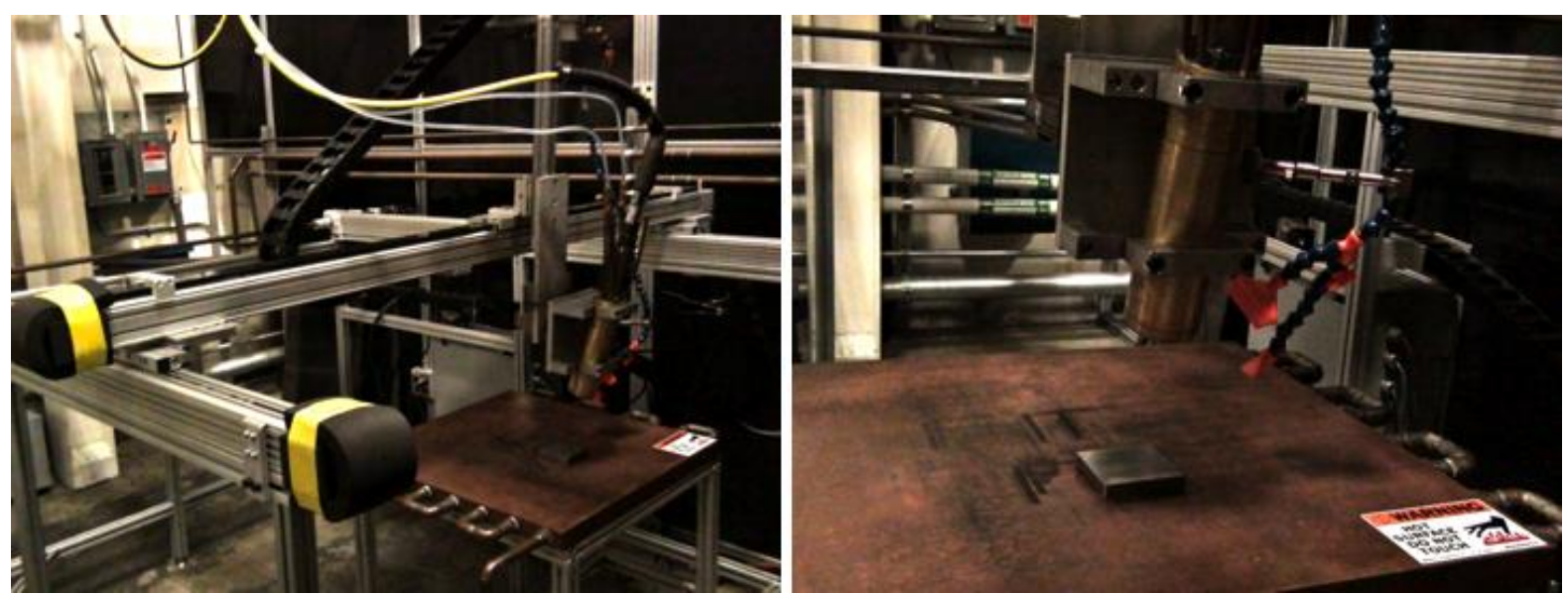

Figure 20: $4 \mathrm{~kW}$ Nd:YAG laser system utilized to fuse coatings onto coupons. The gantry system for the laser is computer controlled.

The laser and gantry system allow for various process controls to be changed during the deposition process leading to a variety of different processing parameter matrices to be evaluated. The major parameters that were evaluated to determine an effective coating were alloy composition, thickness of the coated layer, the number of total layers deposited, the offset of the focal point of the laser (zdistance), preheat temperature of the substrate, preheat duration, substrate material, cover gas, travel speed of the laser, laser power (Watts), and width of the line overlap. Many of the parameters were kept constant during the various builds to minimize the total number of variables in the process matrix. Each of the 10 different alloy compositions was fused in single layers. Several alloys and parameter combinations were utilized to deposit a second layer to create a thicker coating capable of being tested for wear performance. The laser power utilized for fusing was between 2 and $4 \mathrm{~kW}$ and changed at $0.5 \mathrm{~kW}$ power increments. The typical focus offset or z-distance was kept at 0 to maintain the laser focus. Additional studies not presented here were conducted to evaluate the effect of distance on laser focus. Two substrates were used for experimentation, H13 and 4340 materials. Both Argon gas (Ar) and Nitrogen gas $\left(\mathrm{N}_{2}\right)$ were used as cover gases during experimentation. The laser processing conditions are shown in Table 8.

Table 8: Laser processing parameters utilized to fuse Alloy 1-10 using the $4 \mathrm{~kW}$ laser system.

\begin{tabular}{|c|c|c|c|c|c|c|c|c|c|c|c|}
\hline 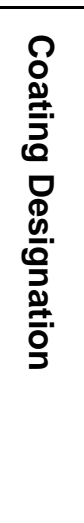 & 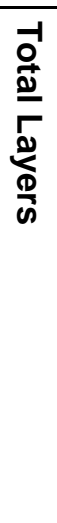 & $\underset{\Phi}{\stackrel{\Phi}{\infty}}$ & 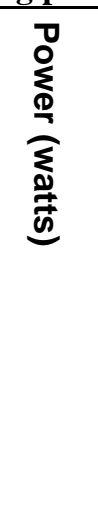 & 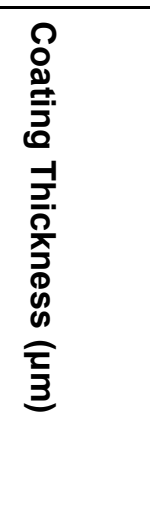 & 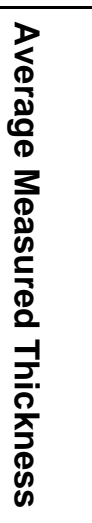 & 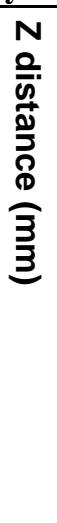 & 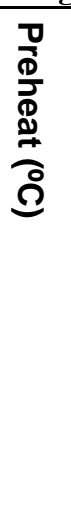 & 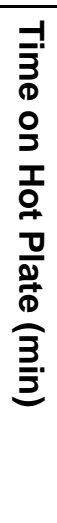 & 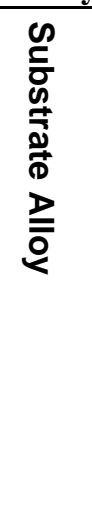 & 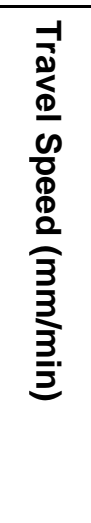 & 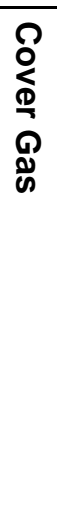 \\
\hline NC1 & 1 & 1 & 2200 & $150-200$ & $\bar{N} / \mathrm{A}$ & 0 & RT & 0 & $\mathrm{H} 13$ & 1500 & $\mathrm{Ar}$ \\
\hline NC1 & 1 & 1 & 3000 & $150-200$ & $\mathrm{~N} / \mathrm{A}$ & 0 & RT & 0 & 4340 & 1500 & $\mathrm{Ar}$ \\
\hline NC1 & 1 & 1 & 3500 & $150-200$ & $\mathrm{~N} / \mathrm{A}$ & 0 & RT & 0 & 4340 & 1500 & $\mathrm{Ar}$ \\
\hline NC1 & 1 & 1 & 3500 & $150-200$ & $\mathrm{~N} / \mathrm{A}$ & 0 & RT & 0 & $\mathrm{H} 13$ & 1500 & $\mathrm{Ar}$ \\
\hline NC1 & 1 & 1 & 2500 & $150-200$ & $\mathrm{~N} / \mathrm{A}$ & 0 & RT & 0 & 4340 & 1500 & $\mathrm{Ar}$ \\
\hline NC2 & 1 & 1 & 2200 & $150-200$ & $\mathrm{~N} / \mathrm{A}$ & 0 & RT & 0 & $\mathrm{H} 13$ & 750 & $\mathrm{Ar}$ \\
\hline
\end{tabular}




\begin{tabular}{|c|c|c|c|c|c|c|c|c|c|c|c|}
\hline NC2 & 1 & 1 & 2200 & $150-200$ & $\mathrm{~N} / \mathrm{A}$ & 0 & $\mathrm{RT}$ & 0 & $\mathrm{H} 13$ & 1250 & $\mathrm{Ar}$ \\
\hline NC2 & 1 & 1 & 2200 & $150-200$ & $\mathrm{~N} / \mathrm{A}$ & 0 & $\mathrm{RT}$ & 0 & $\mathrm{H} 13$ & 1000 & $\mathrm{Ar}$ \\
\hline $\mathrm{NC2}$ & 1 & 1 & 2600 & $150-200$ & $\mathrm{~N} / \mathrm{A}$ & 0 & RT & 0 & $\mathrm{H} 13$ & 1250 & $\mathrm{Ar}$ \\
\hline $\mathrm{NC2}$ & 1 & 1 & 2200 & $150-200$ & $\mathrm{~N} / \mathrm{A}$ & 0 & RT & 0 & 4340 & 1000 & $\mathrm{Ar}$ \\
\hline NC2 & 1 & 1 & 2200 & $150-200$ & $\mathrm{~N} / \mathrm{A}$ & 0 & RT & 0 & 4340 & 750 & $\mathrm{Ar}$ \\
\hline NC2 & 1 & 1 & 3500 & $150-200$ & $\mathrm{~N} / \mathrm{A}$ & 0 & RT & 0 & 4340 & 1500 & $\mathrm{Ar}$ \\
\hline NC2 & 1 & 1 & 3000 & $150-200$ & $\mathrm{~N} / \mathrm{A}$ & 0 & RT & 0 & 4340 & 1500 & $\mathrm{Ar}$ \\
\hline NC2 & 1 & 1 & 2500 & $150-200$ & $\mathrm{~N} / \mathrm{A}$ & 1 & RT & 0 & 4340 & 1000 & $\mathrm{Ar}$ \\
\hline NC3 & 1 & 1 & 3500 & $150-200$ & $\mathrm{~N} / \mathrm{A}$ & 0 & RT & 0 & 4340 & 750 & $\mathrm{Ar}$ \\
\hline NC3 & 1 & 1 & 3500 & $150-200$ & $\mathrm{~N} / \mathrm{A}$ & 0 & RT & 0 & 4340 & 1000 & $\mathrm{Ar}$ \\
\hline NC3 & 1 & 1 & 3000 & $150-200$ & $\mathrm{~N} / \mathrm{A}$ & 0 & RT & 0 & 4340 & 1500 & $\mathrm{Ar}$ \\
\hline NC3 & 1 & 1 & 3500 & $150-200$ & $\mathrm{~N} / \mathrm{A}$ & 0 & RT & 0 & $\mathrm{H} 13$ & 1250 & $\mathrm{Ar}$ \\
\hline NC3 & 1 & 1 & 3500 & $150-200$ & $\mathrm{~N} / \mathrm{A}$ & 0 & RT & 0 & $\mathrm{H} 13$ & 1000 & $\mathrm{Ar}$ \\
\hline NC3 & 1 & 1 & 3800 & $150-200$ & $\mathrm{~N} / \mathrm{A}$ & 0 & RT & 0 & $\mathrm{H} 13$ & 1000 & $\mathrm{Ar}$ \\
\hline NC4 & 1 & 1 & 2200 & $150-200$ & $\mathrm{~N} / \mathrm{A}$ & 0 & RT & 0 & 4340 & 1500 & $\mathrm{Ar}$ \\
\hline NC4 & $\overline{1}$ & $\overline{1}$ & 2200 & $150-200$ & $\mathrm{~N} / \mathrm{A}$ & 0 & RT & 0 & 4340 & 1000 & $\mathrm{Ar}$ \\
\hline NC4 & 1 & 1 & 2200 & $150-200$ & $\mathrm{~N} / \mathrm{A}$ & 0 & RT & 0 & 4340 & 1250 & $\mathrm{Ar}$ \\
\hline NC4 & 1 & 1 & 2500 & $150-200$ & $\mathrm{~N} / \mathrm{A}$ & 0 & RT & 0 & 4340 & 1000 & $\mathrm{Ar}$ \\
\hline NC4 & 1 & 1 & 2500 & $150-200$ & $\mathrm{~N} / \mathrm{A}$ & 0 & RT & 0 & $\mathrm{H} 13$ & 1000 & $\mathrm{Ar}$ \\
\hline NC4 & 1 & 1 & 2500 & $150-200$ & $\mathrm{~N} / \mathrm{A}$ & 0 & RT & 0 & $\mathrm{H} 13$ & 1250 & $\mathrm{Ar}$ \\
\hline NC4 & 1 & 1 & 2000 & $150-200$ & $\mathrm{~N} / \mathrm{A}$ & 0 & RT & 0 & $\mathrm{H} 13$ & 1250 & $\mathrm{Ar}$ \\
\hline NC4 & 1 & 1 & 2000 & $150-200$ & $\mathrm{~N} / \mathrm{A}$ & 0 & RT & 0 & $\mathrm{H} 13$ & 1500 & $\mathrm{Ar}$ \\
\hline NC1 & 1 & 1 & 3000 & $150-200$ & $\mathrm{~N} / \mathrm{A}$ & 0 & RT & 0 & 4340 & 1500 & $\mathrm{Ar}$ \\
\hline NC1 & 2 & 1 & 3000 & $150-200$ & $\mathrm{~N} / \mathrm{A}$ & 0 & RT & 0 & 4340 & 1500 & $\mathrm{Ar}$ \\
\hline NC1 & 3 & 1 & 3000 & $150-200$ & $\mathrm{~N} / \mathrm{A}$ & 0 & RT & 0 & 4340 & 1500 & $\mathrm{Ar}$ \\
\hline NC1 & 2 & 1 & 3000 & $150-200$ & $\mathrm{~N} / \mathrm{A}$ & 0 & RT & 0 & 4340 & 1500 & $\mathrm{Ar}$ \\
\hline NC5 & $\overline{1}$ & 1 & 2500 & $150-201$ & $\mathrm{~N} / \mathrm{A}$ & 1 & RT & 0 & $\mathrm{H} 13$ & 1000 & $\mathrm{Ar}$ \\
\hline NC5 & 1 & 1 & 2500 & $150-201$ & $\mathrm{~N} / \mathrm{A}$ & 1 & RT & 0 & $\mathrm{H} 13$ & 1250 & $\mathrm{Ar}$ \\
\hline NC 6 & 2 & 1 & 3500 & $150-200$ & $134-250$ & 0 & RT & 0 & 4340 & 1500 & $\mathrm{~N}_{2}$ \\
\hline NC 6 & 2 & 1 & 3000 & $150-200$ & $105-264$ & 0 & RT & 0 & 4340 & 1500 & $\mathrm{~N}_{2}$ \\
\hline NC 6 & 2 & 1 & 2500 & $150-200$ & $110-172$ & 0 & RT & 0 & 4340 & 1500 & $\mathrm{~N}_{2}$ \\
\hline NC 6 & 2 & 1 & 2500 & $150-200$ & $137-172$ & 0 & RT & 0 & 4340 & 1500 & $\mathrm{Ar}$ \\
\hline NC 6 & 2 & 1 & 3000 & $150-200$ & $105-131$ & 0 & RT & 0 & 4340 & 1500 & $\mathrm{Ar}$ \\
\hline NC 6 & 2 & 1 & 3500 & $150-200$ & $112-150$ & 0 & RT & 0 & 4340 & 1500 & $\mathrm{Ar}$ \\
\hline NC 6 & 2 & 1 & 3500 & $150-200$ & $107-144$ & 0 & 400 & 15 & 4340 & 1500 & $\mathrm{Ar}$ \\
\hline NC 6 & 2 & 1 & 3000 & $150-200$ & $103-176$ & 0 & 400 & 15 & 4340 & 1500 & $\mathrm{Ar}$ \\
\hline NC 6 & 2 & 1 & 2500 & $150-200$ & $99-232$ & 0 & 400 & 15 & 4340 & 1500 & $\mathrm{Ar}$ \\
\hline$\overline{N C} 6$ & 2 & 1 & 2500 & $150-200$ & 104-155 & 0 & 400 & 15 & 4340 & 1500 & $\mathrm{~N}_{2}$ \\
\hline NC 6 & 2 & 1 & 3000 & $150-200$ & $107-158$ & 0 & 400 & 15 & 4340 & 1500 & $\mathrm{~N}_{2}$ \\
\hline NC 6 & 2 & 1 & 3500 & $150-200$ & $75-117$ & 0 & 400 & 15 & 4340 & 1500 & $\mathrm{~N}_{2}$ \\
\hline NC7 & 2 & 2 & 3500 & $150-200$ & $\mathrm{~N} / \mathrm{A}$ & 0 & RT & 0 & $\mathrm{H} 13$ & 1500 & $\mathrm{Ar}$ \\
\hline NC7 & 2 & 2 & 3000 & $150-200$ & $\mathrm{~N} / \mathrm{A}$ & 0 & RT & 0 & $\mathrm{H} 13$ & 1500 & $\mathrm{Ar}$ \\
\hline NC7 & 2 & 2 & 2500 & $150-200$ & $\mathrm{~N} / \mathrm{A}$ & 0 & RT & 0 & $\mathrm{H} 13$ & 1500 & $\mathrm{Ar}$ \\
\hline NC7 & 1 & 2 & 3500 & $150-200$ & $113-196$ & 0 & 400 & 15 & $\mathrm{H} 13$ & 1500 & $\mathrm{Ar}$ \\
\hline NC7 & 1 & 2 & 3000 & $150-200$ & $86-232$ & 0 & 400 & 15 & $\mathrm{H} 13$ & 1500 & $\mathrm{Ar}$ \\
\hline NC7 & 1 & 2 & 2500 & $150-200$ & $106-181$ & 0 & 400 & 15 & $\mathrm{H} 13$ & 1500 & $\mathrm{Ar}$ \\
\hline NC7 & 2 & 2 & 3500 & $150-200$ & $\mathrm{~N} / \mathrm{A}$ & 0 & 400 & 15 & $\mathrm{H} 13$ & 1500 & $\mathrm{Ar}$ \\
\hline NC7 & 2 & 2 & 3000 & $150-200$ & $\mathrm{~N} / \mathrm{A}$ & 0 & 400 & 15 & $\mathrm{H} 13$ & 1500 & $\mathrm{Ar}$ \\
\hline NC7 & 2 & 2 & 2500 & $150-200$ & $\mathrm{~N} / \mathrm{A}$ & 0 & 400 & 15 & $\mathrm{H} 13$ & 1500 & $\mathrm{Ar}$ \\
\hline NC7 & 2 & 1 & 2500 & $150-200$ & $150-290$ & 0 & 400 & 15 & $\mathrm{H} 13$ & 1500 & $\mathrm{Ar}$ \\
\hline NC7 & 2 & 1 & 3500 & $150-200$ & 133-235 & 0 & 400 & 15 & $\mathrm{H} 13$ & 1500 & $\mathrm{Ar}$ \\
\hline NC7 & 2 & 1 & 2500 & $150-200$ & $136-287$ & 0 & RT & 0 & $\mathrm{H} 13$ & 1500 & $\mathrm{Ar}$ \\
\hline
\end{tabular}




\begin{tabular}{|c|c|c|c|c|c|c|c|c|c|c|c|}
\hline NC7 & 2 & 1 & 3500 & $150-200$ & $98-227$ & 0 & $\mathrm{RT}$ & 0 & $\mathrm{H} 13$ & 1500 & $\mathrm{Ar}$ \\
\hline NC8 & 2 & 2 & 2500 & $150-200$ & $\mathrm{~N} / \mathrm{A}$ & 0 & $\mathrm{RT}$ & 0 & $\mathrm{H} 13$ & 1500 & $\mathrm{Ar}$ \\
\hline NC8 & 2 & 2 & 3000 & $150-200$ & $\mathrm{~N} / \mathrm{A}$ & 0 & $\mathrm{RT}$ & 0 & $\mathrm{H} 13$ & 1500 & $\mathrm{Ar}$ \\
\hline NC8 & 2 & 2 & 3500 & $150-200$ & $\mathrm{~N} / \mathrm{A}$ & 0 & $\mathrm{RT}$ & 0 & $\mathrm{H} 13$ & 1500 & $\mathrm{Ar}$ \\
\hline NC8 & 1 & 2 & 2500 & $150-200$ & $133-314$ & 0 & 400 & 15 & $\mathrm{H} 13$ & 1500 & $\mathrm{Ar}$ \\
\hline NC8 & 1 & 2 & 3000 & $150-200$ & $116-306$ & 0 & 400 & 15 & $\mathrm{H} 13$ & 1500 & $\mathrm{Ar}$ \\
\hline NC8 & 1 & 2 & 3500 & $150-200$ & $155-266$ & 0 & 400 & 15 & $\mathrm{H} 13$ & 1500 & $\mathrm{Ar}$ \\
\hline NC8 & 2 & 2 & 2500 & $150-200$ & N/A & 0 & 400 & 15 & $\mathrm{H} 13$ & 1500 & $\mathrm{Ar}$ \\
\hline NC8 & 2 & 2 & 3000 & $150-200$ & $\mathrm{~N} / \mathrm{A}$ & 0 & 400 & 15 & $\mathrm{H} 13$ & 1500 & $\mathrm{Ar}$ \\
\hline NC8 & 2 & 2 & 3500 & $150-200$ & $\mathrm{~N} / \mathrm{A}$ & 0 & 400 & 15 & $\mathrm{H} 13$ & 1500 & $\mathrm{Ar}$ \\
\hline NC9 & 2 & 2 & 3500 & $150-200$ & $\mathrm{~N} / \mathrm{A}$ & 0 & $\mathrm{RT}$ & 0 & $\mathrm{H} 13$ & 1500 & $\mathrm{Ar}$ \\
\hline NC9 & 2 & 2 & 3000 & $150-200$ & $\mathrm{~N} / \mathrm{A}$ & 0 & $\mathrm{RT}$ & 0 & $\mathrm{H} 13$ & 1500 & $\mathrm{Ar}$ \\
\hline NC9 & 2 & 2 & 2500 & $150-200$ & $\mathrm{~N} / \mathrm{A}$ & 0 & $\mathrm{RT}$ & 0 & $\mathrm{H} 13$ & 1500 & $\mathrm{Ar}$ \\
\hline NC9 & 1 & 2 & 3500 & $150-200$ & $126-210$ & 0 & 400 & 15 & $\mathrm{H} 13$ & 1500 & $\mathrm{Ar}$ \\
\hline NC9 & 1 & 2 & 3000 & $150-200$ & $121-239$ & 0 & 400 & 15 & $\mathrm{H} 13$ & 1500 & $\mathrm{Ar}$ \\
\hline NC9 & 1 & 2 & 2500 & $150-200$ & $142-170$ & 0 & 400 & 15 & $\mathrm{H} 13$ & 1500 & $\mathrm{Ar}$ \\
\hline NC9 & 2 & 2 & 3500 & $150-200$ & N/A & 0 & 400 & 15 & $\mathrm{H} 13$ & 1500 & $\mathrm{Ar}$ \\
\hline NC9 & 2 & 2 & 3000 & $150-200$ & N/A & 0 & 400 & 15 & $\mathrm{H} 13$ & 1500 & $\mathrm{Ar}$ \\
\hline NC9 & 2 & 2 & 2500 & $150-200$ & N/A & 0 & 400 & 15 & $\mathrm{H} 13$ & 1500 & $\mathrm{Ar}$ \\
\hline NC10 & 2 & 2 & 2500 & $150-200$ & N/A & 0 & $\mathrm{RT}$ & 0 & $\mathrm{H} 13$ & 1500 & $\mathrm{Ar}$ \\
\hline NC10 & 2 & 2 & 3000 & $150-200$ & N/A & 0 & $\mathrm{RT}$ & 0 & $\mathrm{H} 13$ & 1500 & $\mathrm{Ar}$ \\
\hline NC10 & 2 & 2 & 3500 & $150-200$ & N/A & 0 & $\mathrm{RT}$ & 0 & $\mathrm{H} 13$ & 1500 & $\mathrm{Ar}$ \\
\hline NC10 & 1 & 2 & 3000 & $150-200$ & $123-195$ & 0 & 400 & 15 & $\mathrm{H} 13$ & 1500 & $\mathrm{Ar}$ \\
\hline NC10 & 1 & 2 & 3500 & $150-200$ & $97-185$ & 0 & 400 & 15 & $\mathrm{H} 13$ & 1500 & $\mathrm{Ar}$ \\
\hline NC10 & 1 & 2 & 4000 & $150-200$ & $127-267$ & 0 & 400 & 15 & $\mathrm{H} 13$ & 1500 & $\mathrm{Ar}$ \\
\hline NC10 & 2 & 2 & 3000 & $150-200$ & N/A & 0 & 400 & 15 & $\mathrm{H} 13$ & 1500 & $\mathrm{Ar}$ \\
\hline NC10 & 2 & 2 & 3500 & $150-200$ & N/A & 0 & 400 & 15 & $\mathrm{H} 13$ & 1500 & $\mathrm{Ar}$ \\
\hline NC10 & 2 & 2 & 4000 & $150-200$ & N/A & 0 & 400 & 15 & $\mathrm{H} 13$ & 1500 & $\mathrm{Ar}$ \\
\hline
\end{tabular}

Images of the laser fusing process and examples of coated coupons are shown in Figure 21 and Figure 22 respectively. As can be seen in Figure 22, the quality of the coating varies dramatically with processing parameters, alloy and substrate material. Several of the coatings showed cracking as demonstrated in Figure $22 \mathrm{C}$ while other coatings were free of cracks as in Figure $22 \mathrm{~A}$. In several cases, the morphology of the coating was rough and appeared to be very non-uniform in thickness over the coupon surface. This could be derived from chemical composition differences between the coating and substrate material that results in limited wetting of the coating on the coupon. The degree of wetting due to differences in surface tension cause the coating to melt when hit with the laser. Surface tension of the molten coating causes the melted material to form a molten sphere on the surface. Increasing the laser power minimized this for many alloys by melting of both the coating and substrate material although this approach also appeared to increase the dissolution of the coating into the substrate material.

Preheating of the substrate material improved the quality of the coatings on the coupons. Preheating the substrate material reduces the thermal gradient between the melt pool and the substrate. Larger temperature gradients result in larger thermal induced stresses during cooling. Minimizing the thermal gradient through preheating of the substrate minimizes thermally induced stresses and increases the probability the coating will be free of cracks. 

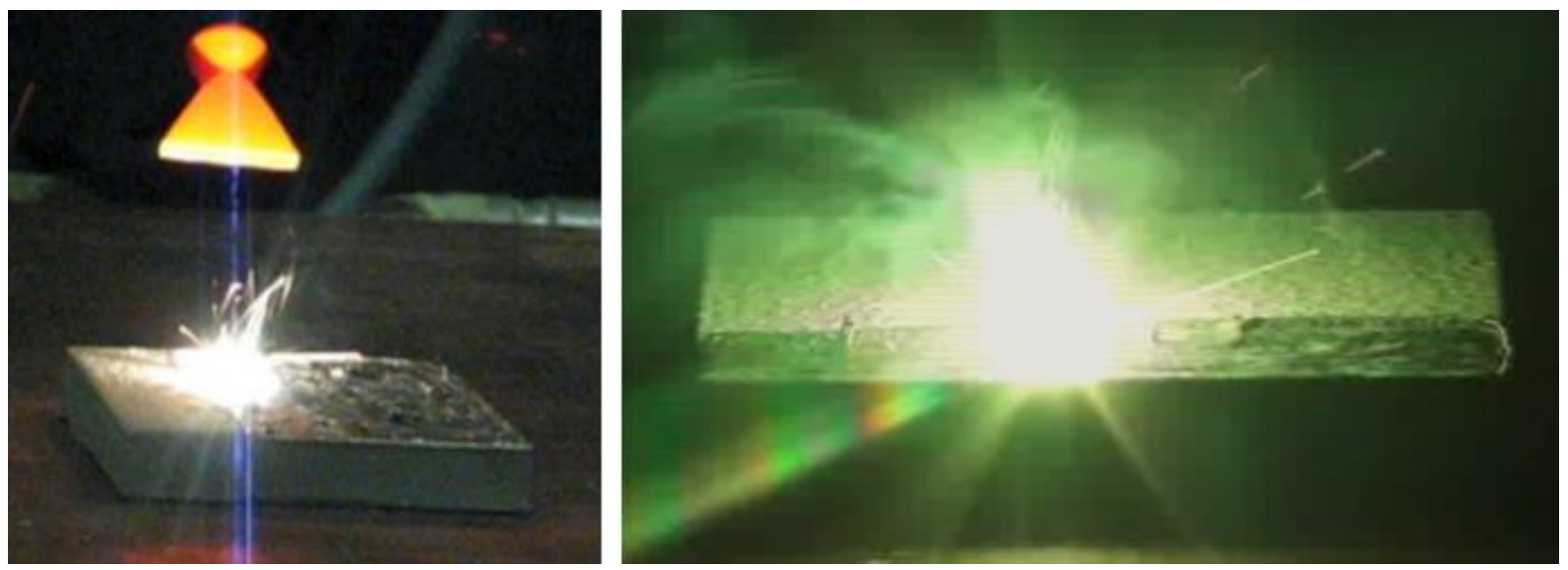

Figure 21: Image of the laser fusing process utilizing the $4 \mathrm{~kW}$ Nd: YAG laser system.
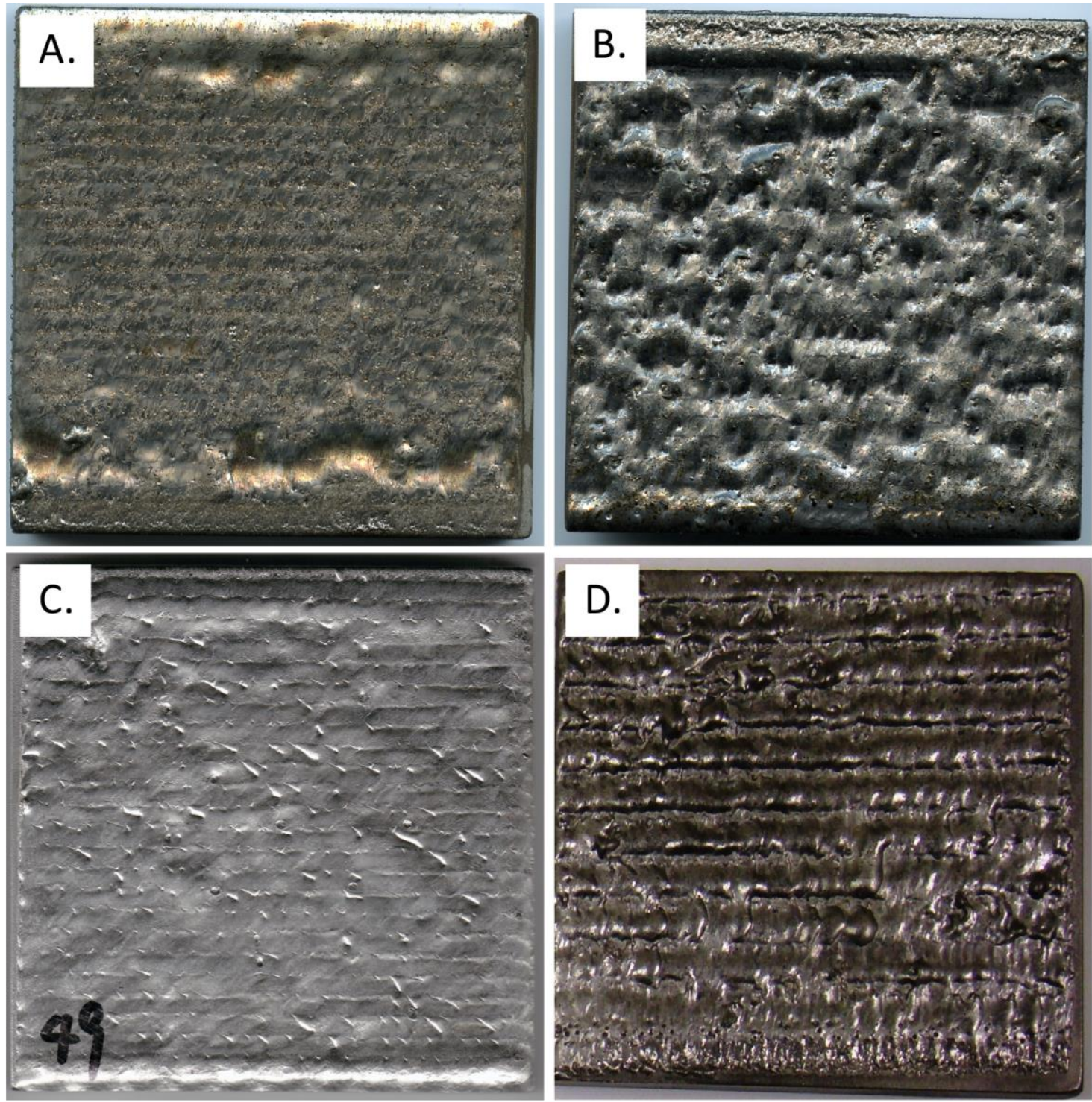

Figure 22: Example images showing the coating on the substrate material after laser fusing with the 4 kW Nd:YAG system. A) Alloy 5 on H13, 2500W, $1500 \mathrm{~mm} / \mathrm{min}$ B) Alloy 5 on 4340, 2200W, 1000 $\mathrm{mm} / \mathrm{min}$ C) Alloy 1 on 4340, 3500W, $1500 \mathrm{~mm} / \mathrm{min}$ D) Alloy 7 on H13, $2500 \mathrm{~W}, 1500 \mathrm{~mm} / \mathrm{min}$. 
The approach of using a binder mechanism to secure the powder coating to the substrate material presented several challenges. Firstly, it was difficult to get an accurate measure of the coating thickness on the coupon. Initially, the same procedure including ratio of binder to powder, mixing methodology, and coating methodology and the coating thickness was not measured. However, it appeared that several coupons processed under identical conditions did not produce coatings with similar appearance. This was attributed to differences in the powder coating thickness and differences in the fraction and distribution of polymer and metal powder. Coating thicknesses shown in Table 8 show a large variation in coating thickness for individually coated coupons with the variation in coating thickness as high as $\sim 200 \mu \mathrm{m}$ in some instances.

In addition to coating thickness variations during process, it was also observed that the coatings had a tendency to "peel" off of the substrate adjacent to the line of the melt pool. An example of this is shown in Figure 23. In some instances, the "peeled" layer of the coating completely detached from the substrate material and was not incorporated into the coating. In other cases, the "peeled" material was melted during the subsequent laser pass that resulted in the material being incorporated into the coating but not evenly distributed on the surface of the coupon. Instead, the "peeled" material melted to form a ball of molten material that grew in size as the laser traversed from right to left in the image. Once the molten ball reached a critical size, it attached to the coating resulting in large undulation in the surface profile. Increasing the uniformity of the polymer binder and powder mixture could help to minimize or eliminate this phenomenon.

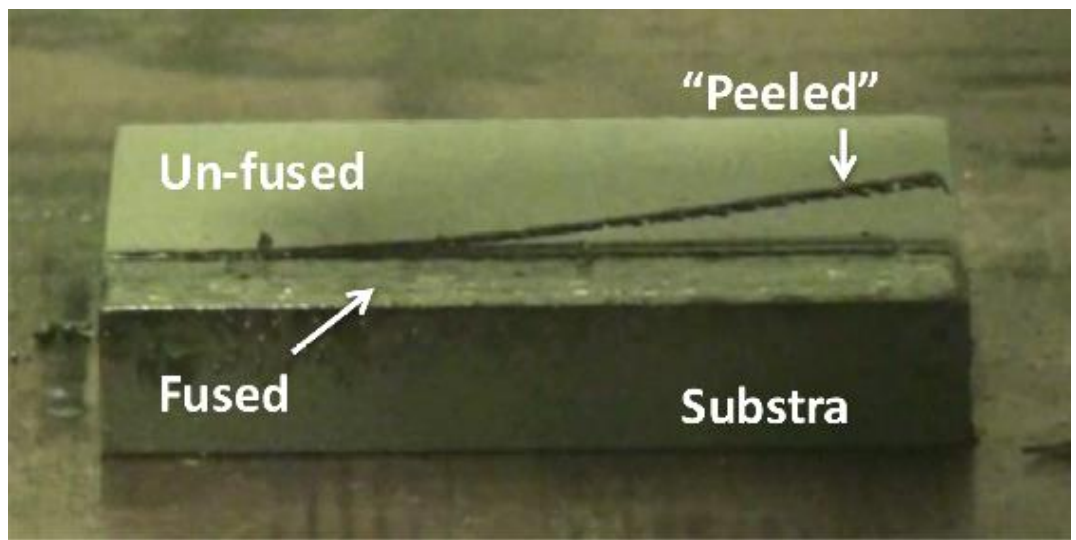

Figure 23: Image taken during the fusing process in between melt lines showing peeling of the coating.

The resulting coatings were approximately $100-400 \mu \mathrm{m}$ in thickness after laser processing. However, many of the coating surfaces were not even at this thickness and thicker coatings were required to accurately run abrasive loop testing. Therefore, a second layer was added to several of the coupons so that coating properties could be adequately tested. The additional layer resulted in less mixing between the coating and the substrate material and resulted in the second layer having a composition closer to the original powder composition. This resulted in harder coating as will be discussed in the following sections.

Microstructural evaluation was conducted on the coated material and images of the cross sectioned coating are shown in Figure 24 for Alloy 1. The interface between the coating and substrate is clearly visible in the images. In the case of Alloy 1, the coating did show cracking after processing. However, it should be noted that the coating appears well bonded to the substrate material. It is expected that the adhesion between the coating and the substrate material is improved because the coating and substrate both are Fe based materials. This minimizes strain associated with chemical mismatch. 

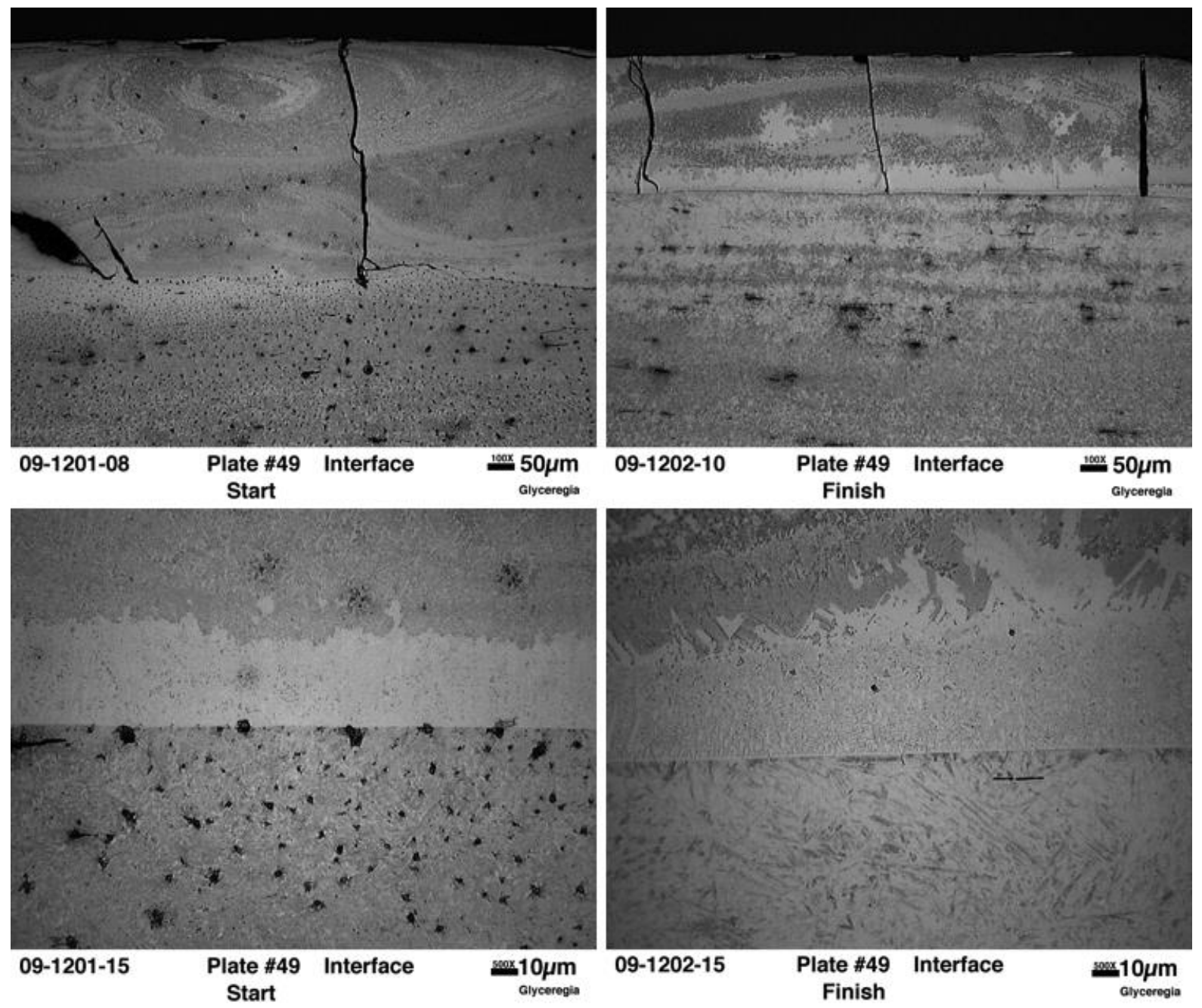

Figure 24: Optical micrographs of Alloy 1 laser fused with the $4 \mathrm{~kW}$ Nd:YAG laser system.

\subsubsection{Deposition of +325 Mesh Powder Using POM Deposition System}

Based on the challenges presented with laser fusing of material using a polymer binder/metal powder mixture to adhere the coating to the substrate prior to laser fusing, an alternative processing methodology was utilized which delivers the metal powder directly in the cover gas to the focal point of the laser. This technology is defined by the ASTM F-42 committee on additive manufacturing as a directed energy deposition process although it is analogous to techniques used for laser cladding. The main difference between laser cladding and the POM deposition technology is the POM system has the ability to accurately control the deposition of the material and can be used to fabricate 3dimensional structures. For this project, the POM was not used to build complex 3-dimensional structures although several coatings were produced that utilized multiple layers.

An image of the POM laser deposition system is shown in Figure 25. The laser deposition head, powder system, and stage are contained in a glove box that can be over pressurized with inert or other gas. There is an Ar recirculation system in place to continually removed oxygen from the glove box, enabling the inside of the chamber to be below 10 ppm oxygen. The chamber was not filled with inert gas for this project and all depositions were conducted in the presence of atmosphere. The powder material is placed into a hopper mechanism (bottom left of Figure 25). A motor is used to control the amount of powder flow during the deposition with a specific RPM correlating to powder mass flow rate. The mass flow rate utilized during the POM deposition process was 5 grams $/ \mathrm{min}$. This 
calculation was performed using a scale placed below the nozzle delivery system. Because the flow rate can vary as a function of RPM, the powder flow rate was calibrated prior to deposition for each powder.

The powder from the hopper is delivered to an inert gas stream and is carried in the gas to the nozzle (right images in Figure 25). The powder and gas flow through a concentric series of holes located at the bottom of the nozzle, which act to focus the flowing powder particles into a conical shape. A 1 $\mathrm{kW}$ diode laser is position through the center of the powder cone with a convergence point of the powder cone aligned with the focal point of the laser. The laser melts the powder into a small molten pool (melt pool). The position of the melt pool changes as the nozzle deposition head is rastered over the substrate. Layers were formed by rastering the melt pool in a snake pattern over the surface of the coupon.

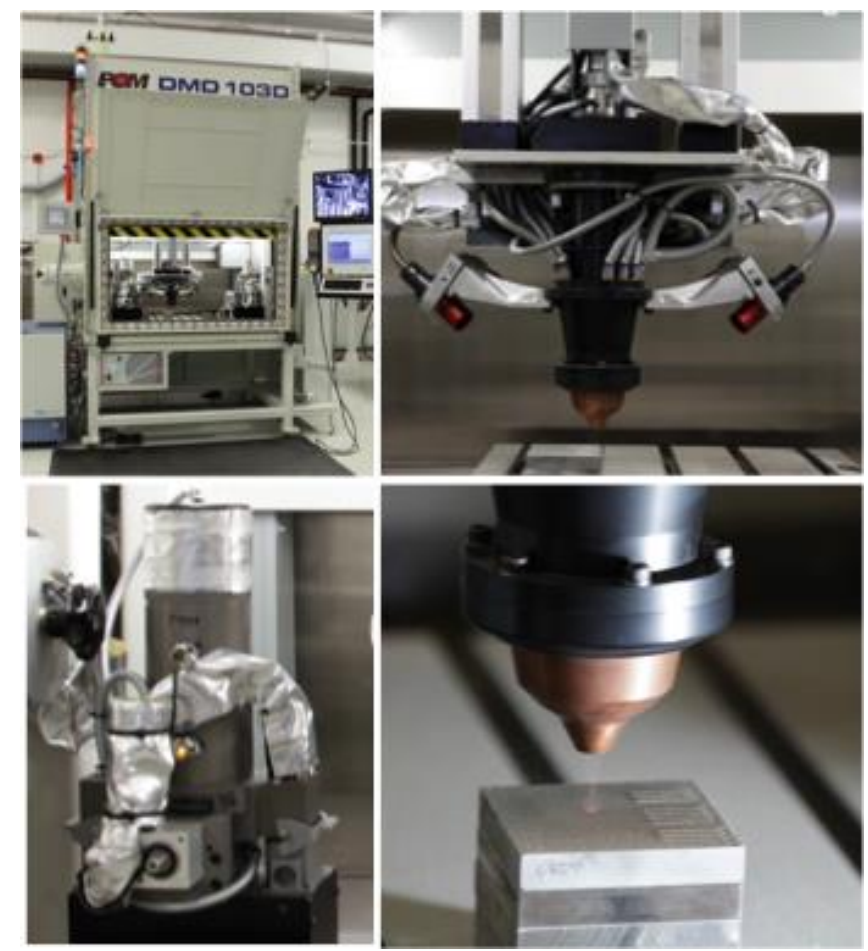

Figure 25: POM laser deposition system.

For each of the 10 alloys, a single line study was conducted to evaluate the effect of laser power and velocity on the quality of the deposited coating material (bottom right image of Figure 25). For these deposits, the powder flow rate was 5 grams $/ \mathrm{min}$. The process parameter matrix for each alloy is shown in Table 9. The results of these studies were used to determine the processing parameters to be used for full coating such as those conducted on the mixing paddle. 
Table 9: POM laser deposition processing parameter matrix conducted on all 10 alloys.

\begin{tabular}{|c|c|c|c|c|c|}
\hline $\begin{array}{c}\text { Test ID } \\
\text { Number }\end{array}$ & $\begin{array}{c}\text { Number } \\
\text { of Layers }\end{array}$ & $\begin{array}{c}\text { Substrate } \\
\text { Material }\end{array}$ & $\begin{array}{c}\text { Preheat } \\
\text { Temperature }\end{array}$ & $\begin{array}{c}\text { Laser Power } \\
\text { (watts) }\end{array}$ & $\begin{array}{c}\text { Velocity } \\
\text { (mm/min) }\end{array}$ \\
\hline 1 & 1 & 4340 & N/A & 400 & 800 \\
\hline 2 & 1 & 4340 & N/A & 600 & 800 \\
\hline 3 & 1 & 4340 & N/A & 800 & 800 \\
\hline 4 & 1 & 4340 & N/A & 1000 & 800 \\
\hline 5 & 1 & 4340 & N/A & 400 & 640 \\
\hline 6 & 1 & 4340 & N/A & 400 & 720 \\
\hline 7 & 1 & 4340 & N/A & 400 & 880 \\
\hline 8 & 1 & 4340 & N/A & 400 & 960 \\
\hline 9 & 1 & 4340 & N/A & 600 & 640 \\
\hline 10 & 1 & 4340 & N/A & 600 & 720 \\
\hline 11 & 1 & 4340 & N/A & 600 & 880 \\
\hline 12 & 1 & 4340 & N/A & 600 & 960 \\
\hline 13 & 1 & 4340 & N/A & 800 & 640 \\
\hline 14 & 1 & 4340 & N/A & 800 & 720 \\
\hline 15 & 1 & 4340 & N/A & 800 & 880 \\
\hline 16 & 1 & 4340 & N/A & 800 & 960 \\
\hline 17 & 1 & 4340 & N/A & 1000 & 640 \\
\hline 18 & 1 & 4340 & N/A & 1000 & 720 \\
\hline 19 & 1 & 4340 & N/A & 1000 & 880 \\
\hline 20 & 1 & 4340 & N/A & 1000 & 960 \\
\hline & & & & & \\
\hline
\end{tabular}

An example a laser deposited coating fused using the POM laser deposition system is shown in Figure 26 for Alloy 1 . The quality and consistency in the coatings were significantly improved over the $4 \mathrm{~kW}$ laser fused coatings using the polymer binder powder coatings. The snake pattern used in the deposition of the coating is clearly evident in Figure 26. Some micro cracking of several alloys did occur, although the scale of the cracking was minimized when compared to the other laserprocessing route.

The area of the coated area could be easily changed and did not show a significant effect on the quality of the coating. Several different sized samples were fabricated including 20x20 $\mathrm{mm}$ areas, $50 \times 50 \mathrm{~mm}$ areas, 20x60, etc. The aspect ratio and size did not appear to play a role in coating quality. In addition, the direction of raster was also changed in both the $\mathrm{x}$ and $\mathrm{y}$ direction and did not appear to have an effect on the quality of the coating. Therefore, it was determined that the quality of the coating would be independent of component geometry. 


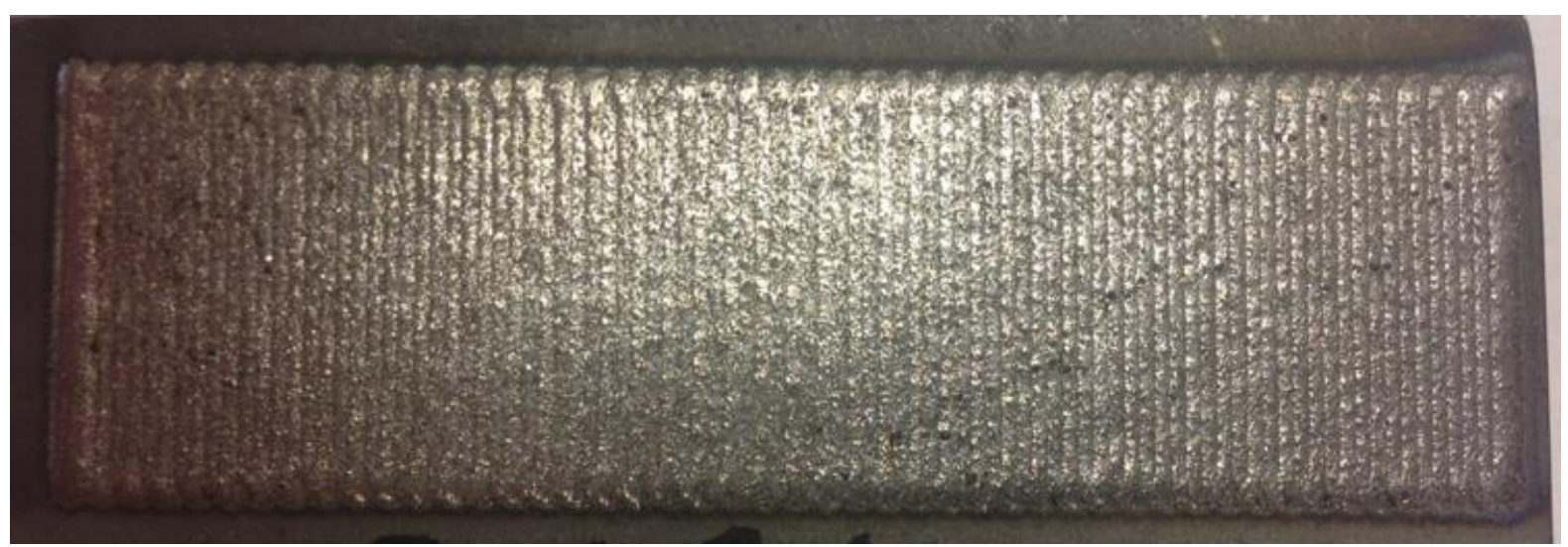

Figure 26: Alloy 1 fused coating fabricated using the POM laser deposition system.

\subsubsection{Modeling of Laser Deposition}

A thermal model has been modified that can predict the depth of substrate melting to be expected under different laser power conditions and is shown in Figure 27. An experimental test matrix has been designed to test this model and to provide feedback to improve the model. Tests were conducted with coated and uncoated substrates and attempts were made to correlate the difference in depth of penetration to the optical properties of the coating material. The new feature of the current model is to include the translation of the laser beam. By comparing the temperature evolution at locations of $0.5 \mathrm{~mm}$ and $1 \mathrm{~mm}$, the results show that the steady-state uniform conditions were attained at locations of $0.5 \mathrm{~mm}$ as shown in Figure 28.

From the temperature results, the cooling rates were calculated. The cooling rate governs the amount of crystalline material in the coating and is an important parameter for the processing. It was found that the cooling rate drops by about $50 \%$ when the sample was heated to $400{ }^{\circ} \mathrm{C}$. The maximum height of the liquid pool was also estimated from the numerical simulation results. The data on temperature evolution, cooling rates, and liquid pool depth will be used to optimize the laser processing of the nanocrystalline coatings.

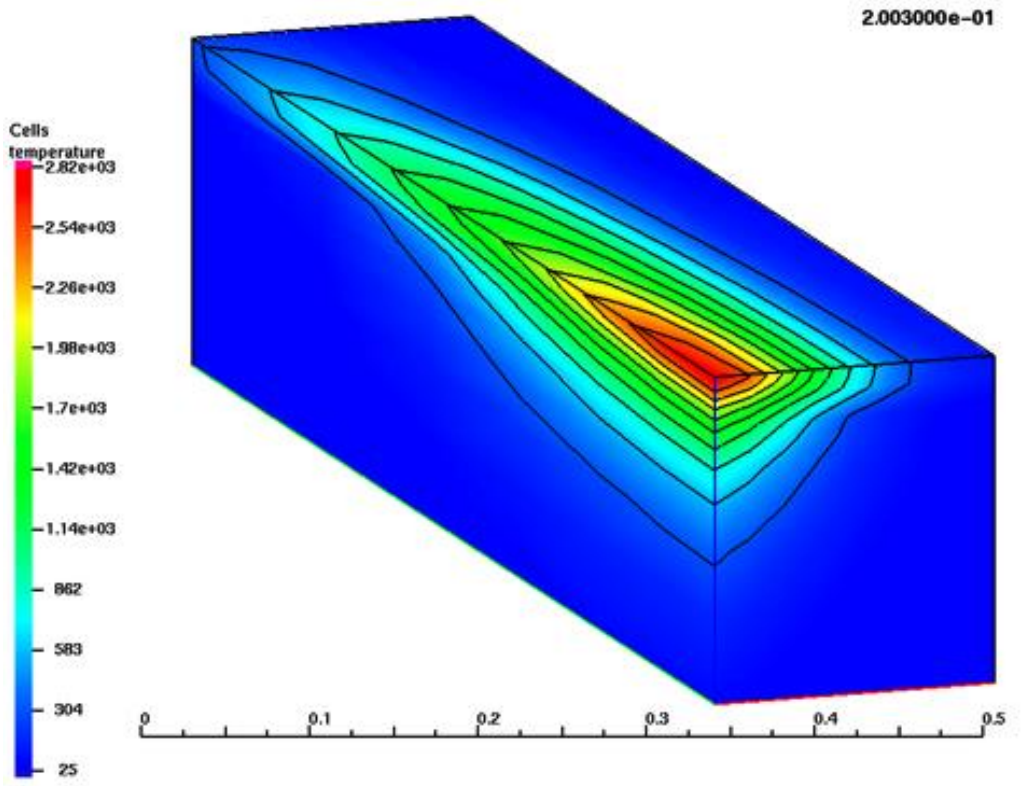

Figure 27: The distribution of the temperature 0.2 seconds after the onset of laser translation using a surface emissivity of 0.43 . The length scale is shown in $\mathrm{cm}$. 


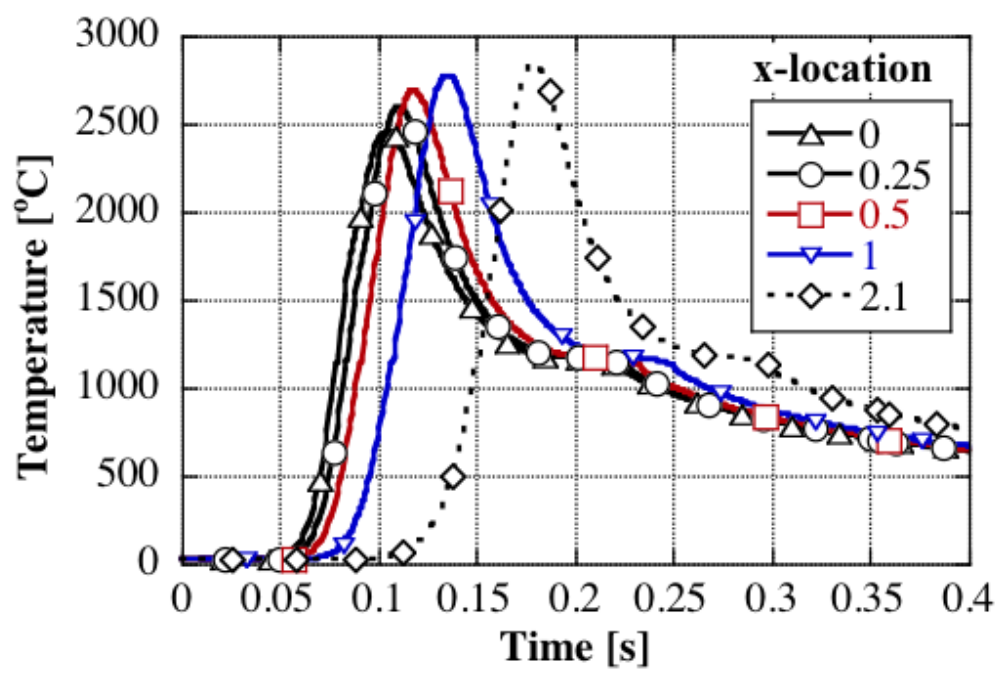

Figure 28: Temperature evolution along the $x$-axis from the sample edge for a surface emissivity of 0.43 . The length of the locations are indicated in $\mathbf{m m}$.

Reflectivity of coated but unprocessed samples of steel were measured at room temperature and is shown in Figure 29. At 1,064 nm, the wavelength of the laser, the reflectivity was $33.73 \%$. There was also a jump of approximately $1 \%$ at wavelengths of $854-860 \mathrm{~nm}$. The reflectivity data was very reproducible, as evidenced by the data shown for three different samples (Figure 29). Additional simulations were conducted with the emissivity of 0.653 and the data for the temperature evolution is shown in Figure 30.

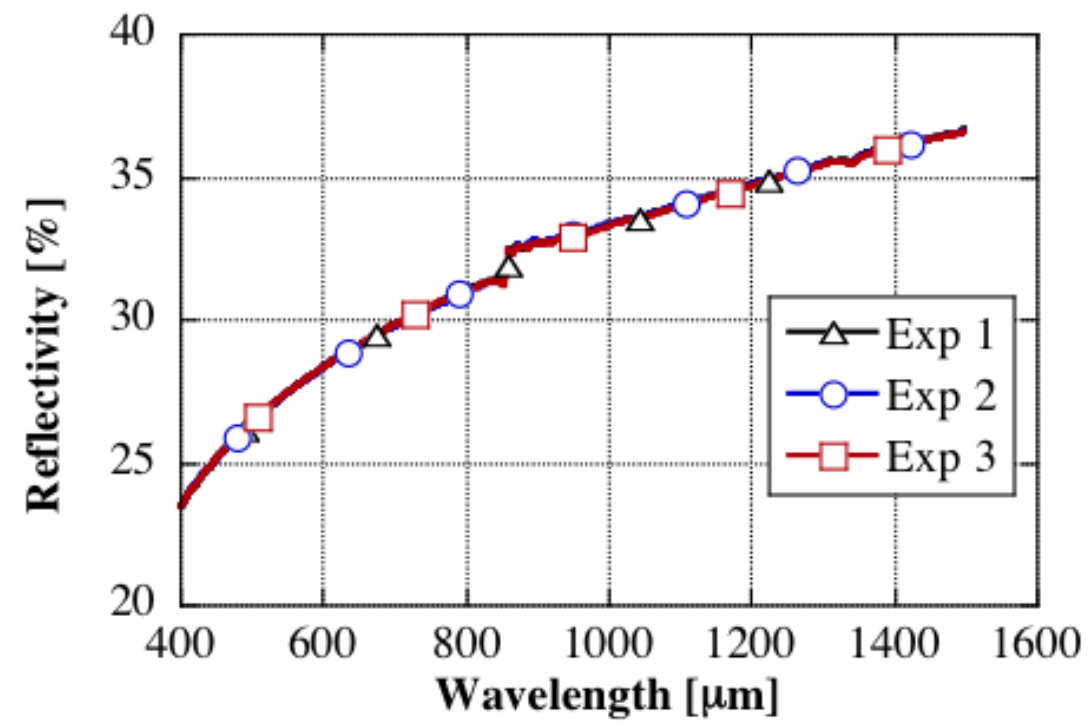

Figure 29: Measured reflectivity of samples as a function of laser wavelength. 


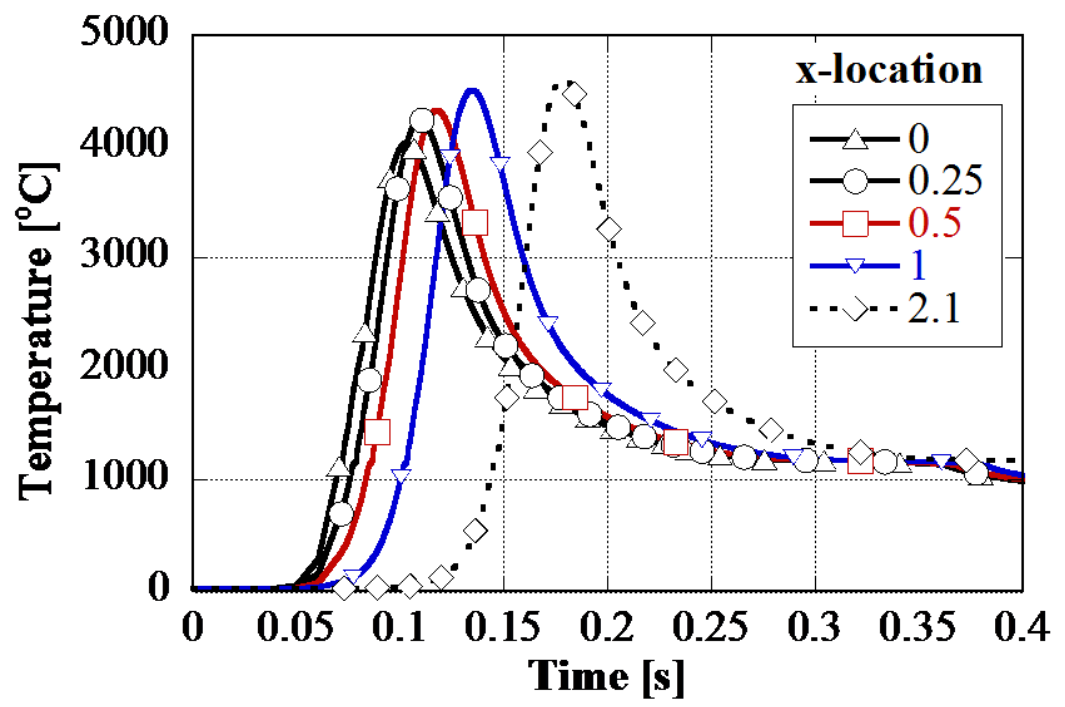

Figure 30: Temperature evolution along the $x$-axis from the sample edge for a surface emissivity of 0.653. The lengths for the locations are indicated in $\mathbf{m m}$.

From the temperature results, the cooling rates were calculated and are shown in Table 10. The cooling rate governs the amount of crystalline material in the coating and is an important parameter for the processing. It was found that the cooling rate drops by about $50 \%$ when the sample was heated to $400{ }^{\circ} \mathrm{C}$. The maximum height of the liquid pool was also estimated from the numerical simulation results (Table 11). The data on temperature evolution, cooling rates, and liquid pool depth will be used to optimize the laser processing of the nanocrystalline coatings.

Table 10: Calculated cooling rates from the improved model for laser fusing of powder materials.

\begin{tabular}{|c|c|c|}
\hline $\begin{array}{c}\text { Initial } \\
\text { temperature } \\
{\left[{ }^{\circ} \mathrm{C}\right]}\end{array}$ & $\begin{array}{c}\text { Surface } \\
\text { emissivity }\end{array}$ & $\begin{array}{c}\text { Cooling rate } \\
{\left[{ }^{\circ} \mathrm{C}\right]}\end{array}$ \\
\hline 25 & 0.43 & 8,570 \\
\hline 400 & 0.43 & 3,960 \\
\hline 25 & 0.653 & 4,530 \\
\hline
\end{tabular}

Table 11: Calculated liquid pool height as a function of preheat and surface emissivity.

\begin{tabular}{|c|c|c|}
\hline $\begin{array}{c}\text { Initial } \\
\text { temperature } \\
{\left[{ }^{\circ} \mathrm{C}\right]}\end{array}$ & $\begin{array}{c}\text { Surface } \\
\text { emissivity }\end{array}$ & $\begin{array}{c}\text { liquid pool } \\
\text { height }[\mu \mathrm{m}]\end{array}$ \\
\hline 25 & 0.43 & 550 \\
\hline 400 & 0.43 & $770-1,000$ \\
\hline 25 & 0.653 & $775-1,000$ \\
\hline
\end{tabular}

\section{Bulk Consolidation of Fe-based Powders:}

\subsubsection{Vacuum Hot Pressing}

Alloy powders were bulk consolidated using vacuum hot pressing techniques (VHP). Vacuum hot pressing is performed by placing the powder into a graphite die, evacuating the chamber housing the die, and applying a pressure to the die. A graphite die of 0.5 " and 1.0" were used to consolidate material. After powder was placed into the die, the die was loaded into the vacuum chamber and the chamber was evacuated between $10^{-4}$ to $10^{-6}$ torr. The temperature was measured using a 
thermocouple and an optical pyrometer and why a range of temperatures is given for the consolidation. The target set-point on the controller and the measured temperature are different because the thermocouple is on the outside of the graphite die wall and is therefore typically cooler than the actual measured temperature. The range of processing parameters and conditions for the VHP samples produced is shown in Table 12. Examples of bulk specimens produced via VHP are shown in Figure 31.

Table 12: VHP parameters used for consolidation. Time shows the duration the sample was held at a temperature.

\begin{tabular}{|c|c|c|c|c|c|}
\hline Alloy & Temp (setpoint) & Max $\mathrm{T}^{\circ} \mathrm{C}($ optical) & pressure & $\begin{array}{c}\text { Hold time } \\
\text { (mins) }\end{array}$ & $\begin{array}{c}\text { Density } \\
\text { (Optical) }\end{array}$ \\
\hline DOE NC-1 (130789) $(+325)$ & $1100^{\circ} \mathrm{C}$ & - & $\sim 4 \mathrm{ksi}$ & 47 & \\
\hline DOE NC-2 (130790) $(+325)$ & $1100^{\circ} \mathrm{C}$ & - & $\sim 4 \mathrm{ksi}$ & 42 & \\
\hline DOE NC-3 (130791) $(+325)$ & $1100^{\circ} \mathrm{C}$ & - & $\sim 4 \mathrm{ksi}$ & 42 & \\
\hline DOE NC-3 (130792)(+325) & $1100^{\circ} \mathrm{C}$ & - & $\sim 4 \mathrm{ksi}$ & 42 & \\
\hline DOE NC-1 $(130789)(-40,+325)$ & $1100^{\circ} \mathrm{C}$ & - & $\sim 4 \mathrm{ksi}$ & 42 & \\
\hline DOE NC-1 (130789) $(+40)$ & $1100^{\circ} \mathrm{C}$ & - & $\sim 4 \mathrm{ksi}$ & 42 & did not press \\
\hline DOE NC-4 (130793) $(-40+325)$ & $1100^{\circ} \mathrm{C}$ & - & $\sim 4 \mathrm{ksi}$ & 42 & \\
\hline DOE NC-6 (130818) $(+325)$ & $900^{\circ} \mathrm{C}$ & 1092 & $\sim 4 \mathrm{ksi}$ & 60 & 97.3 \\
\hline DOE NC-7 (130819) (+325) & $900^{\circ} \mathrm{C}$ & 1085 & $\sim 4 \mathrm{ksi}$ & 60 & 92.3 \\
\hline DOE NC-8 (130820) $(+325)$ & $900^{\circ} \mathrm{C}$ & 1087 & $\sim 4 \mathrm{ksi}$ & 60 & 95.7 \\
\hline DOE NC-9 (130821) $(+325)$ & $900^{\circ} \mathrm{C}$ & 1097 & $\sim 4 \mathrm{ksi}$ & 60 & 94.7 \\
\hline DOE NC-10 (130822) $(+325)$ & $900^{\circ} \mathrm{C}$ & 1076 & $\sim 4 \mathrm{ksi}$ & 60 & 91.6 \\
\hline DOE NC-2 (130790), (-325) & $900^{\circ} \mathrm{C}$ & 1067 & $\sim 4 \mathrm{ksi}$ & 60 & 89.5 \\
\hline DOE NC-3 (130791), (-325) & $900^{\circ} \mathrm{C}$ & 1069 & $\sim 4 \mathrm{ksi}$ & 60 & 89.2 \\
\hline DOE NC-4 (130792), (-325) & $900^{\circ} \mathrm{C}$ & 1067 & $\sim 4 \mathrm{ksi}$ & 60 & 91.1 \\
\hline DOE NC-5 (130793), (-325) & $900^{\circ} \mathrm{C}$ & 972 & $\sim 4 \mathrm{ksi}$ & 60 & 90.3 \\
\hline DOE NC-1 (130789) (-325) & $900^{\circ} \mathrm{C}$ & - & $\sim 4 \mathrm{ksi}$ & 480 & 99.9 \\
\hline DOE NC-6 (130818) (-325) & $900^{\circ} \mathrm{C}$ & - & $\sim 4 \mathrm{ksi}$ & 480 & 99.9 \\
\hline DOE NC-7 (130819) (-325) & $900^{\circ} \mathrm{C}$ & - & $\sim 4 \mathrm{ksi}$ & 480 & 99.7 \\
\hline DOE NC-8 (130820) (-325) & $900^{\circ} \mathrm{C}$ & - & $\sim 4 \mathrm{ksi}$ & 480 & 100 \\
\hline
\end{tabular}

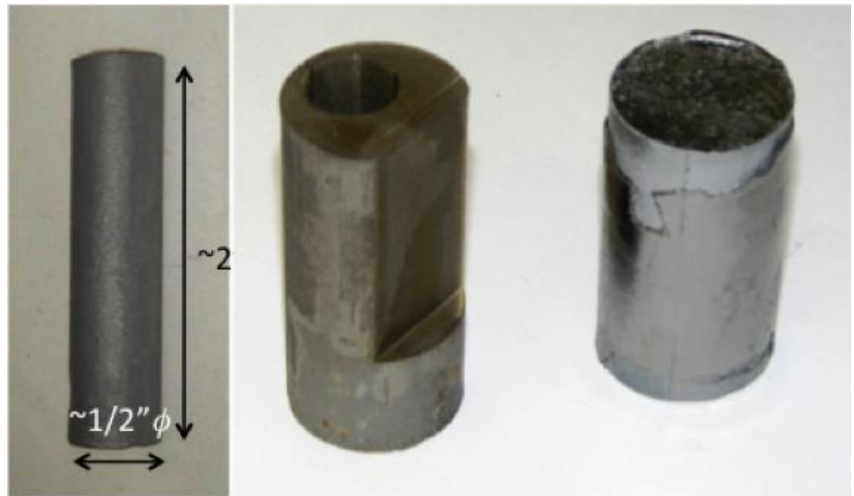

Figure 31: VHP examples of Alloy 1 using both 0.5" and 1.0" graphite die.

The first set of VHP samples were produced with +325 mesh powder. BSE images of Alloy 2 in the consolidated condition are shown in Figure 31 at various magnifications. Based on microstructural examination it was observed that many of the larger particles did not appear to deform or distort during the VHP run. This is demonstrated by the nearly spherical larger particles with a similar morphology to the particles observed in the as atomized powder (Figure 11). There is deformed material between the spherical particles that also contains a homogeneous distribution of submicron or nano sized particles. The crystalline phases present in the non-deformed powders appear to be significantly coarser than particles observed in the atomized powders. As discussed in the previous section on the atomization process, all of the powders appeared to have some level of devitrification in larger particles while small powders tended to be amorphous. It was concluded that the material between the spherical powder particles in Figure 31 could be material that was amorphous at the 
onset of the VHP process. The amorphous material would flow at lower temperatures when the glass transition temperature is reached which would occur below the onset of crystallization. As the powder is continuously heated, the amorphous material that has deformed around the larger crystalline particles begins to devitrify. Simultaneously during the VHP process, the larger powders that were crystalline after the atomization process begin to coarsen.
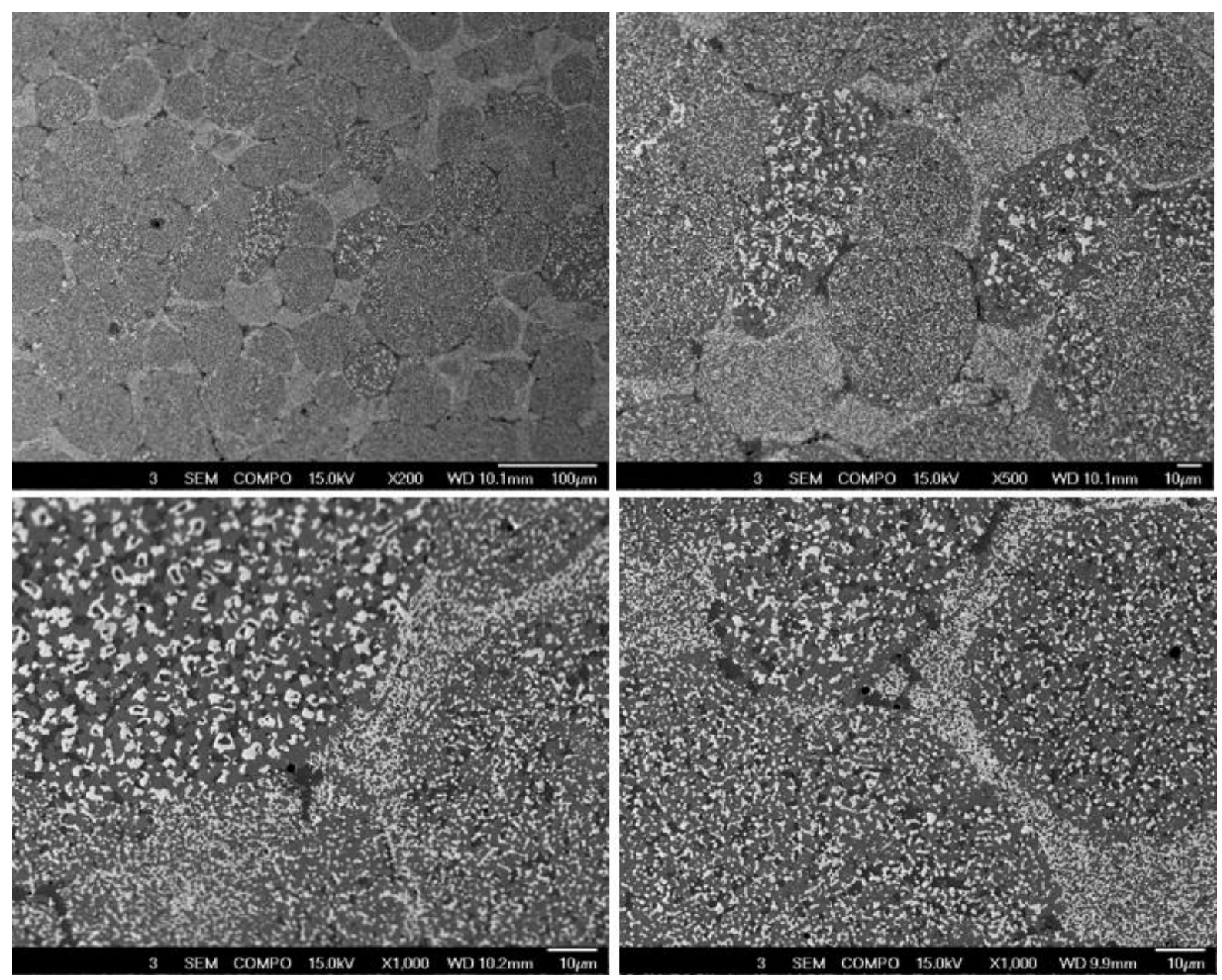

Figure 32: BSE images of VHP Alloy $2+325$ mesh powder. Some porosity was observed.

Initial VHP runs were conducted at $1100 \mathrm{C}$ and several runs were successfully completed. However, two runs at this temperature caused catastrophic failure of the die during pressing. Based on analysis of the failed run, it was determined the powder melted during the pressing processes, causing a volumetric change that resulted in increased pressure on the die wall. The maximum die pressure was exceeded and failure of the die occurred. The VHP consolidation temperature was reduced to 900C for remaining builds.

The ability to consolidate powders at $900 \mathrm{C}$ was dependent on chemistry of the powder, size distribution and hold time at temperature. In cases of +325 mesh powder held for 1 hour, the measured porosity ranged between 91 and $97 \%$. An example of the optical micrographs utilized for porosity measurements is shown for Alloy 8 vacuum hot pressed from +325 mesh powder is shown in Figure 33. Although some deformation has occurred at powder particle boundaries, a significant amount of porosity remained in the sample and it did not appear that atomic diffusion across the particle boundary occurred. Similarly, samples fabricated from the -325 mesh powder are shown in Figure 34 and show a significant amount of porosity. For Alloy 2 (left) several particles to not appear to be deformed while Alloy 3 shows that significant coarsening has occurred despite the remaining 
porosity. Measured porosity in these samples was between 10 and $11 \%$, which was measurably less than the -325 mesh powders.
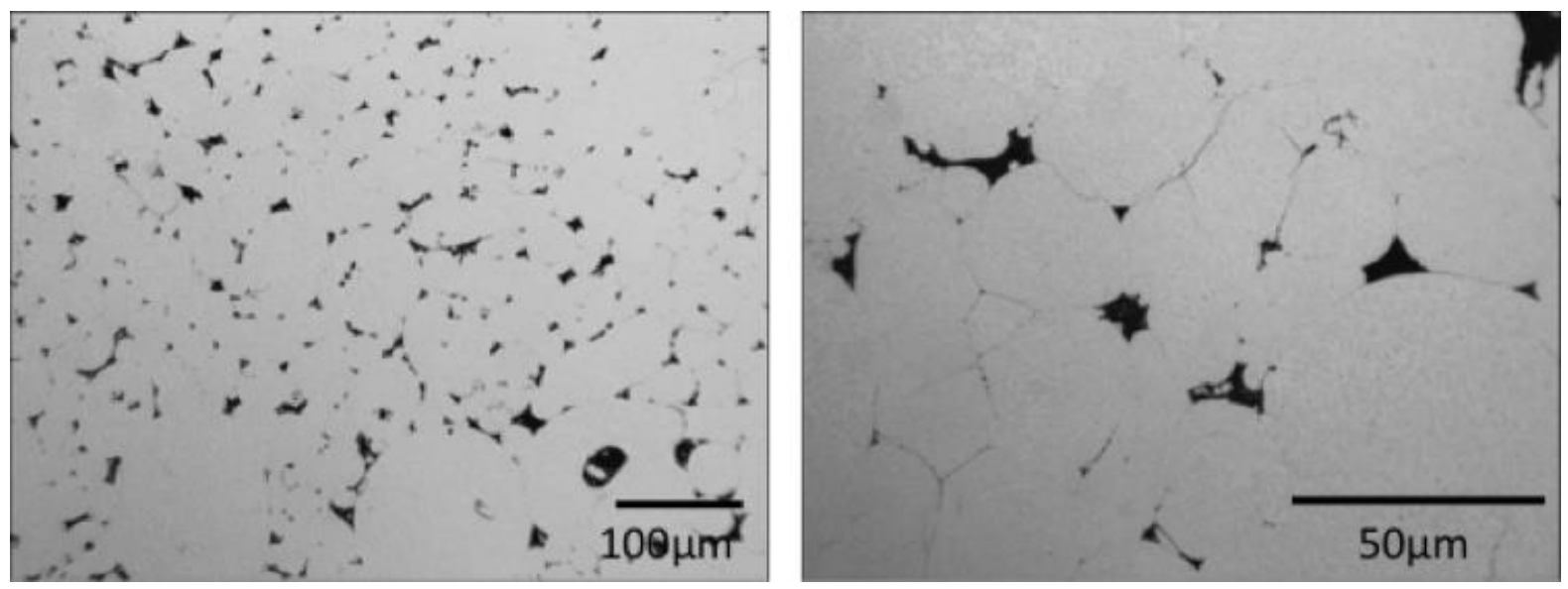

Figure 33: Alloy 8 vacuum hot pressed from +325 mesh powder at 900C and 4ksi for 1 hour.
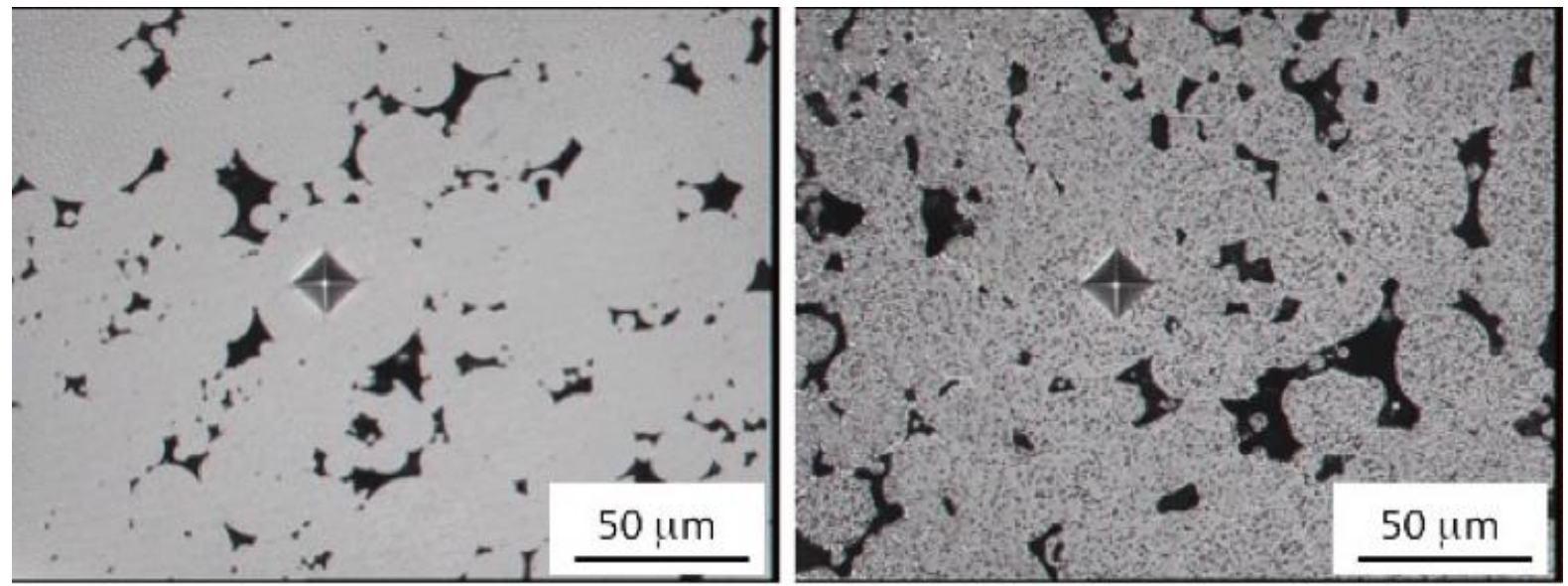

Figure 34: Alloy 2 (left) and Alloy 3 (right) vacuum hot pressed from -325 mesh powder at 900C and 4ksi for 1 hour.

Additional samples were vacuum hot pressed under similar conditions (900C and 4ksi) with an extended hold time of 8 hours (480 minutes). Example resulting microstructures are shown in Figure 35 for Alloy 8 (left) and Ally 7 (right). The extended hold time of 8 hours resulted in a significant increase in the density of the material as is shown in Table 12. Several alloys contained a small amount of measurable porosity in the range of 0.1 to $0.3 \%$ (Alloy 7 in Figure 35) while Alloy 8 (Figure 35 ) contained no observable porosity after the vacuum hot pressing process.

The results of VHP indicate a plausible path forward for the production of fully dense bulk components from Fe-based amorphous/nanocrystalline powders. However, an extended hold time of 8 hours was required to produce fully dense components. Additional work could be conducted for each alloy to determine the exact time required to produce fully dense material. Hold times between 1 and 8 hours were not evaluated experimentally to determine a density vs. hold time function. This would be beneficial for production of commercial components using this methodology. 


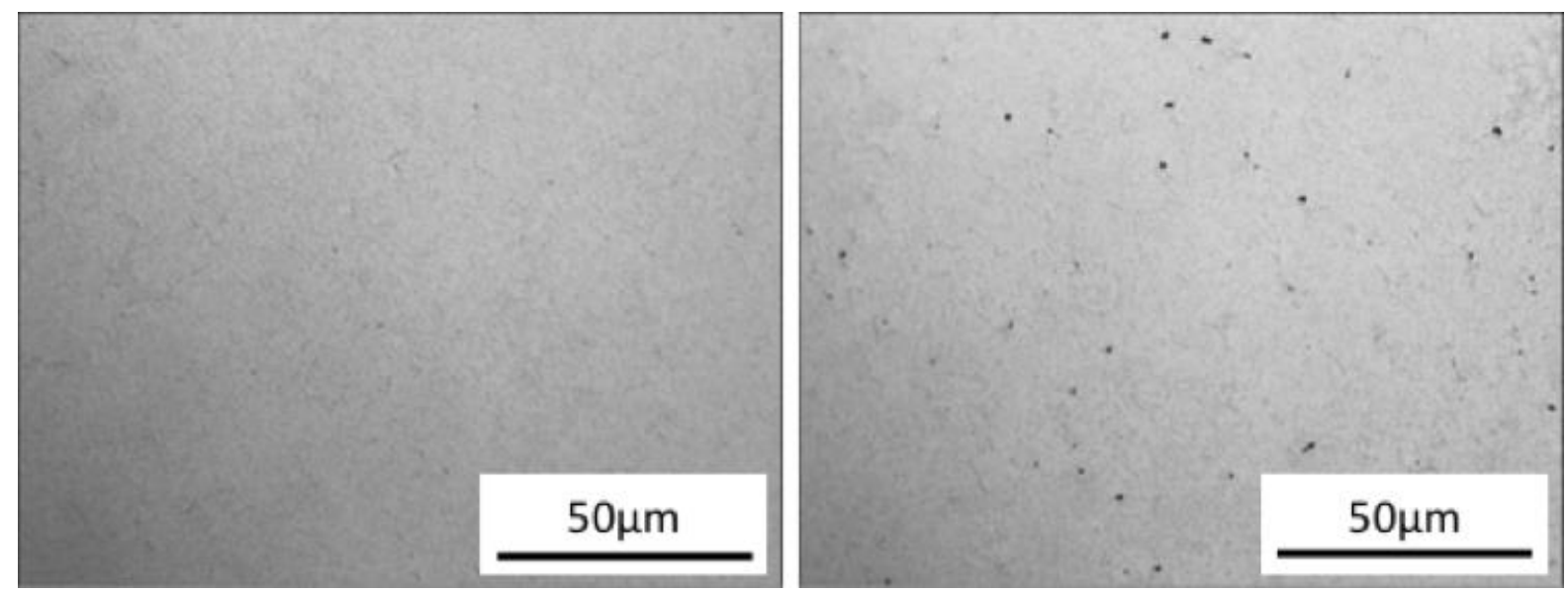

Figure 35: Alloy 8 (left) and Alloy 7 (right) vacuum hot pressed from -325 mesh powder at 900C and 4ksi for 8 hours.

\subsubsection{Dynaforge Process}

Dynaforge is a powder metallurgy rapid consolidation process that makes fully dense, near-net-shape components from tailored high-performance alloys and other specialty materials. The components can be manufactured from a single alloy or from multiple metal compositions. Gas-atomized metal alloy powder is loaded into a container, degassed and sealed, heated to a suitable temperature, transferred to a hydraulic press and densified with very high quasi-isostatic pressures in a viscous fluid. Fulldensity consolidation occurs within a matter of seconds. Densification occurs at higher pressures and more rapidly than in any other commercial $\mathrm{P} / \mathrm{M}$ consolidation process.

Additionally, the Dynaforge process often results in unique mechanical properties not attainable with other processes. This capability comes from the fact that the Dynaforge process does not rely on a diffusion reaction, but rather on shear deformation at powder particle interfaces. This deformation, created by exceptionally high forging pressures, yields fresh material surfaces that readily bond during the consolidation cycle. Equally important is the fact that consolidation is a solid-state process (no melting) which allows many metal powders to retain unique as-atomized microstructures in the densified component.

It was expected that the Dynaforge process could result in unique microstructures that differ from those produced in the VHP or HIP process because the hold time at temperature is significantly reduced when compared to these processes. Because the powders utilized in the Dynaforge process in this project were amorphous or nanocrystalline, it was expected that devitrification of the amorphous phase could be minimized or eliminated and the coarsening of phases could be reduced over VHP because the hold time at temperature is less. The expected result would be a bulk material with amorphous or nanocrystalline phase homogeneously distributed in the material.

Samples were Dynaforged at Carpenter Powder Products at a temperature of 1950F. Samples of Alloy 1-5 were consolidated using gas atomized powder which was not screened for various particle size distribution, utilizing all powder below -40 mesh. The samples were sectioned using a wire EDM and polished for metallurgical analysis. Many of the Dynaforged samples showed evidence of cracking during the EDM process as shown in Figure 36. Sample 4 demonstrated so much cracking that a wear sample could not be extracted for examination. Alloy 3 and Alloy 5 were the only alloys that did not demonstrate cracking. 

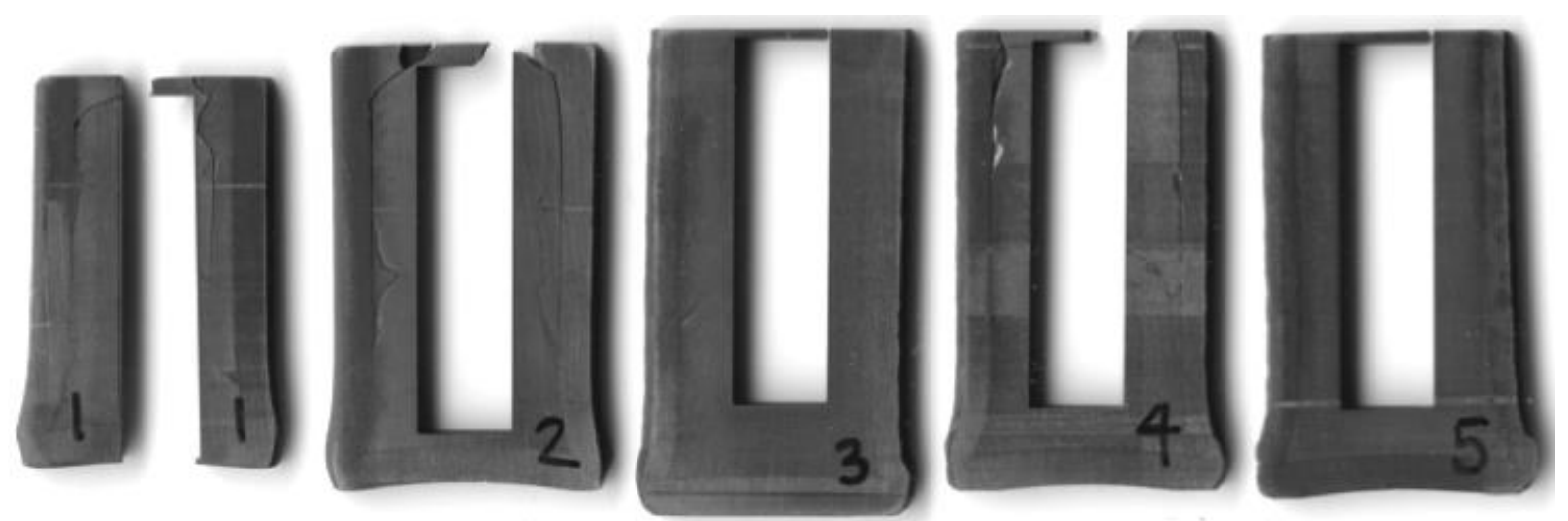

Figure 36: Dynaforged samples of Alloy 1-5 sectioned using EDM. Evidence of cracking was observed in Alloy 1, Alloy 2 and Alloy 4. Alloy 4 showed significant cracking such that a wear sample could not be produced for testing.

An example microstructure is shown in Figure 37 of Alloy 2 fabricated using the Dynaforge process. The optical micrograph in the top left corner shows significant cracking of the sample as well as small amounts of porosity in the sample. The sample was fabricated using all powder under 40 mesh, implying both larger particles of devitrified material and smaller amorphous powders were used based on previous powder analysis. The powder particle distribution can clearly be observed using BSE images. Distinct microstructural regions are evident and appear to be the size and shape of prior powder particle boundaries. This similar result has been observed in the vacuum hot pressed samples of similar composition. A similar argument is used to explain the microstructural variation observed.

It is interesting to note that during the Dynaforge process, porosity appears to be located at the center of the devitrified as-atomized powder. This result may indicate that the powder contains some amount of porosity. In typical gas atomization using argon, porosity can be observed in powder and can be attributed to trapped gas from the process where the argon gas would not react with the metal, and did not have sufficient time to escape. The entrapped gas is usually found in the center of the particle. The air bubbles may not compress, evolve, or coalesce during the short time frames associated with the Dynaforging process. However, it would be expected that gas entrapped during the atomization process would be spherical in shape. For the observed pores in this Dynaforged sample (figure 37), the porosity appears in the center of the powder particle, but the shape of the pore is very irregular. If the porosity is not from argon, it could be attributed to strain induced shrinkage, which results as the powder is cooled from the liquid state. The limited analysis of the as-fabricated powder did not show evidence of porosity at the center of powder particles. Additional experiments would be required to determine the cause of porosity in Dynaforge materials.

It should also be noted that the shape of the devitried powder used in the Dynaforged sample fabrication does not change morphology as a result of processing. This indicates that the previously crystalline powder does not deform via shear during the process. Based on the amount of consolidation, it is expected that the amorphous based material does shear during Dynaforge. However, it is unknown if the material is devitrified prior to deforming or devitrifies after the consolidation process has occurred. The morphology, scale and distribution of the carbide and boride phases in the Dynaforged material are similar to those observed from vacuum hot pressing. Therefore, there does not appear to be a significant advantage of the Dynaforge process over VHP based on microstructural observations.

Additional samples were fabricated using the Dynaforge process from Alloy 6-10 for both the +325 and -325 mesh powders. The apparent density for these samples was measured using optical microscopy. All samples fabricated using -325 mesh powders resulted in $99.9 \%$ dense material excluding Alloy 8 which demonstrated $100 \%$ dense material. All values calculated for +325 mesh 
powder were between 99.6 and $99.9 \%$ dense. These results indicate that $100 \%$ dense material can be fabricated using the Dynaforge process and that Dynaforge is more effective than VHP in producing pore free materials.
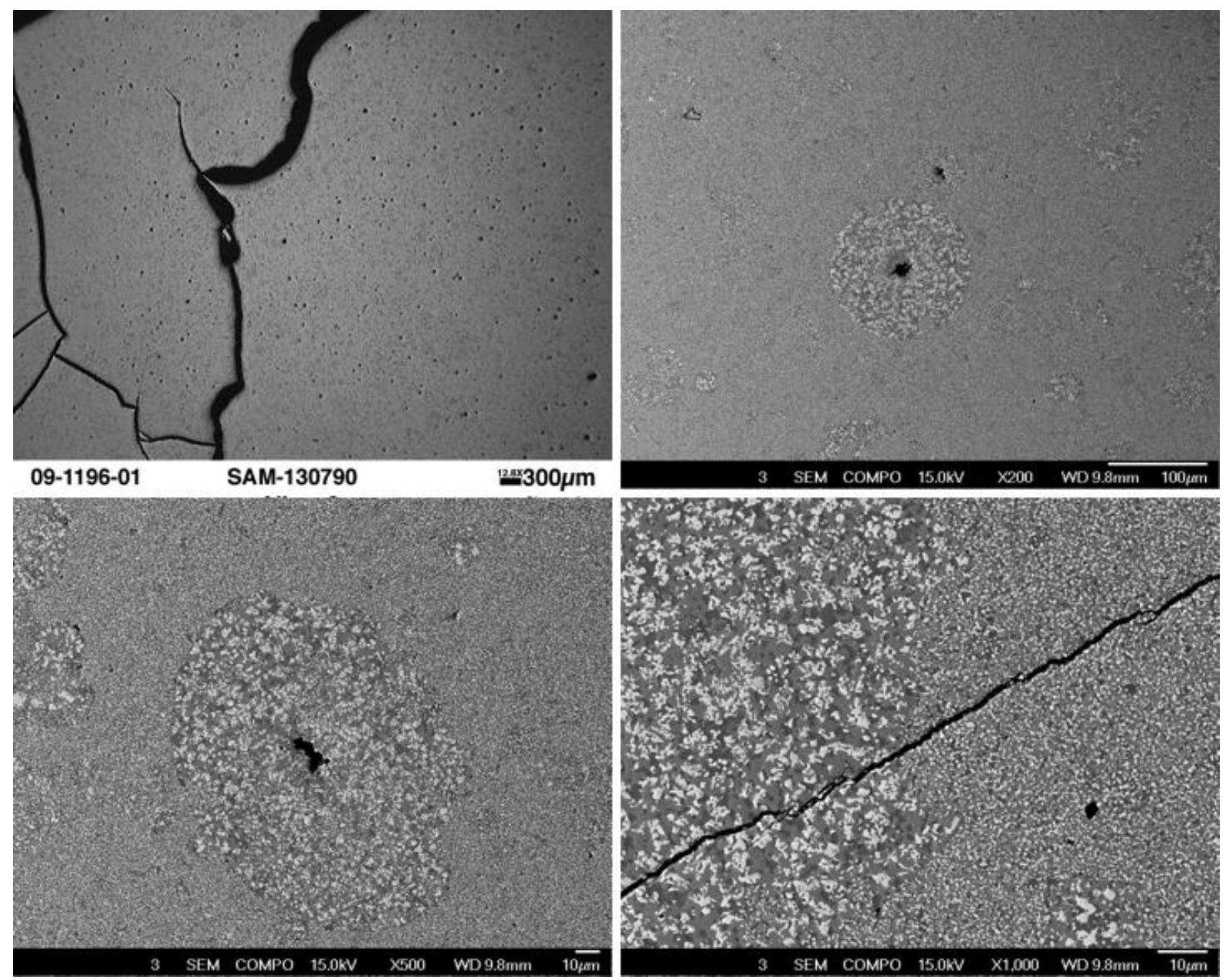

Figure 37: Optical microstructure (top left) and BSE images of Alloy 2 (-40 mesh) after Dynaforge at 1950F. Significant cracking was observed in the sample.

\subsubsection{Hot Isostatic Pressing (HIP)}

Samples of the various powder compositions of alloy 1-10 were hot isostatically pressed using -325 mesh powder. +325 mesh powder was not utilized for bulk consolidation via HIP because the microstructure of the +325 mesh powder was determined to be crystalline. In addition, the POM laser deposition technology was determined to be the more industrial deployable laser deposition technology and utilization of -325 for bulk consolidation would increase atomization process yield and decrease powder costs. The powder was placed into steel with $\sim 1$ inch outside diameter cans and evacuated. Two sets of samples were produced; one had a HIP temperature of $1950^{\circ} \mathrm{F}\left(1065.6^{\circ} \mathrm{C}\right)$ and the other set had a HIP temperature of $2125^{\circ} \mathrm{F}\left(1162.8^{\circ} \mathrm{C}\right)$. Samples were held at temperature for 4 hours. Process notes indicate that sample NC4B appeared to melt during the HIP cycle, indicating the melting temperature of this alloy was close to $2125^{\circ} \mathrm{F}$. In addition, alloy NC8 HIPed at $2125^{\circ} \mathrm{F}$ did not pull down to appropriate vacuum levels. However, the material also appeared to be fully dense, indicating a high probability of melting near the HIP temperature. The sample labels are shown in Table 13 and samples are shown in Figure 38. 
Table 13: Alloys and labels for the HIP'ed samples.

\begin{tabular}{|c|c|c|c|}
\hline Alloy & Heat & Mesh & $\begin{array}{c}\text { HIP } \\
\text { Temperature }\end{array}$ \\
\hline NC1 & 130789 & -325 & $\begin{array}{l}\mathrm{A}=1950 \mathrm{~F} \\
\mathrm{~B}=2125 \mathrm{~F}\end{array}$ \\
\hline NC2 & 130790 & -325 & $\begin{array}{l}\mathrm{A}=1950 \mathrm{~F} \\
\mathrm{~B}=2125 \mathrm{~F}\end{array}$ \\
\hline NC3 & 130791 & -325 & $\begin{array}{l}\mathrm{A}=1950 \mathrm{~F} \\
\mathrm{~B}=2125 \mathrm{~F}\end{array}$ \\
\hline NC4 & 130792 & -325 & $\begin{array}{l}\mathrm{A}=1950 \mathrm{~F} \\
\mathrm{~B}=2125 \mathrm{~F}\end{array}$ \\
\hline NC5 & 130793 & -325 & $\begin{array}{l}\mathrm{A}=1950 \mathrm{~F} \\
\mathrm{~B}=2125 \mathrm{~F}\end{array}$ \\
\hline NC7 & 130818 & -325 & $\begin{array}{l}\mathrm{A}=1950 \mathrm{~F} \\
\mathrm{~B}=2125 \mathrm{~F}\end{array}$ \\
\hline NC8 & 130819 & -325 & $\begin{array}{l}\mathrm{A}=1950 \mathrm{~F} \\
\mathrm{~B}=2125 \mathrm{~F}\end{array}$ \\
\hline NC9 & 130820 & -325 & $\begin{array}{l}\mathrm{A}=1950 \mathrm{~F} \\
\mathrm{~B}=2125 \mathrm{~F}\end{array}$ \\
\hline NC10 & 130822 & -325 & $\begin{array}{l}\mathrm{A}=1950 \mathrm{~F} \\
\mathrm{~B}=2125 \mathrm{~F}\end{array}$ \\
\hline
\end{tabular}

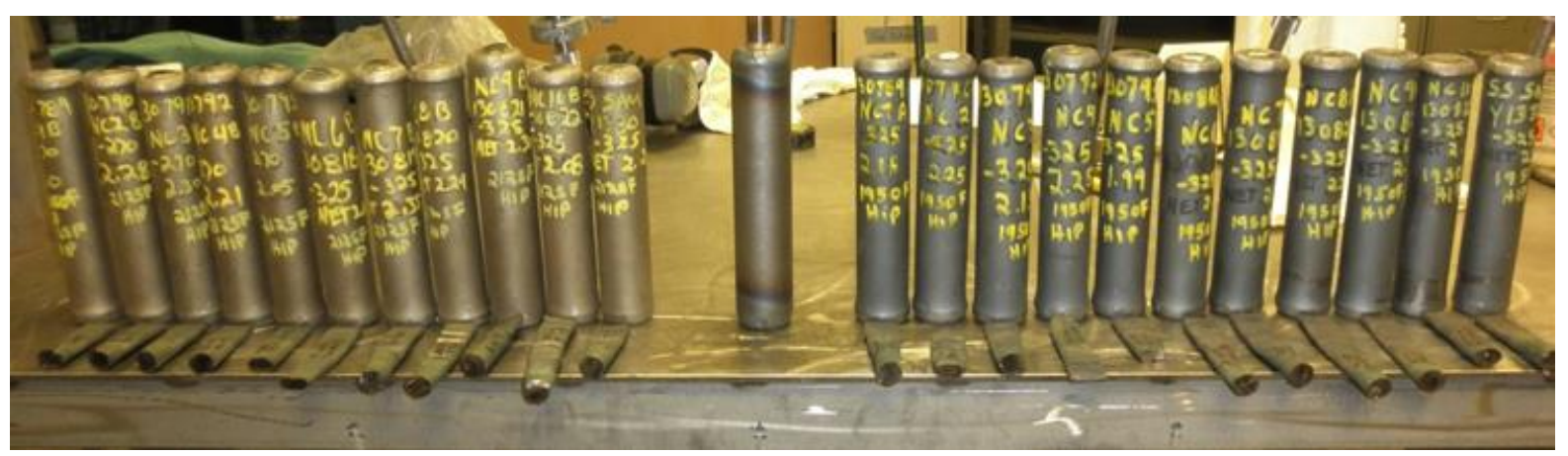

Figure 38: HIP samples from Alloy 1-10 at 1950F and 2125F.

The HIP material was sectioned using a wire EDM. Depending on the sample, the HIP'ed material did delaminate from the HIP can or the sample bonded to the can. In either case, a small sample was extracted from the center of the HIP sample. Samples were then mounted in epoxy and polished using $\mathrm{SiC}$ abrasive paper and final polished with colloidal silica. The resulting microstructures were examined using both optical and scanning electron microscopy. Energy dispersive spectroscopy was utilized to examine the composition of phases present after the HIP cycle.

The microstructure of Alloy 3 HIP'ed at $1950^{\circ} \mathrm{F}$ is shown in Figure 39 using optical microscopy (top) and BSE imaging (bottom). From the optical images, it appears the sample may contain porosity however BSE imaging showed the material was fully dense. The contrast in the optical image is due to a specific phase formed during devitrification. Increase magnifications images taken using BSE are shown in Figure 40 along with EDS analysis in Figure 41. It should be noted that EDS analysis may be inaccurate in terms of actual composition due to the size of the particles being analyzed. Chemical analysis using EDS is typically off by several percent even if the samples are properly standardized. It was expected that one of the phases present would 
be an Fe based matrix phase although the concentration of $\mathrm{C}$ measured suggests a carbide phase is present.
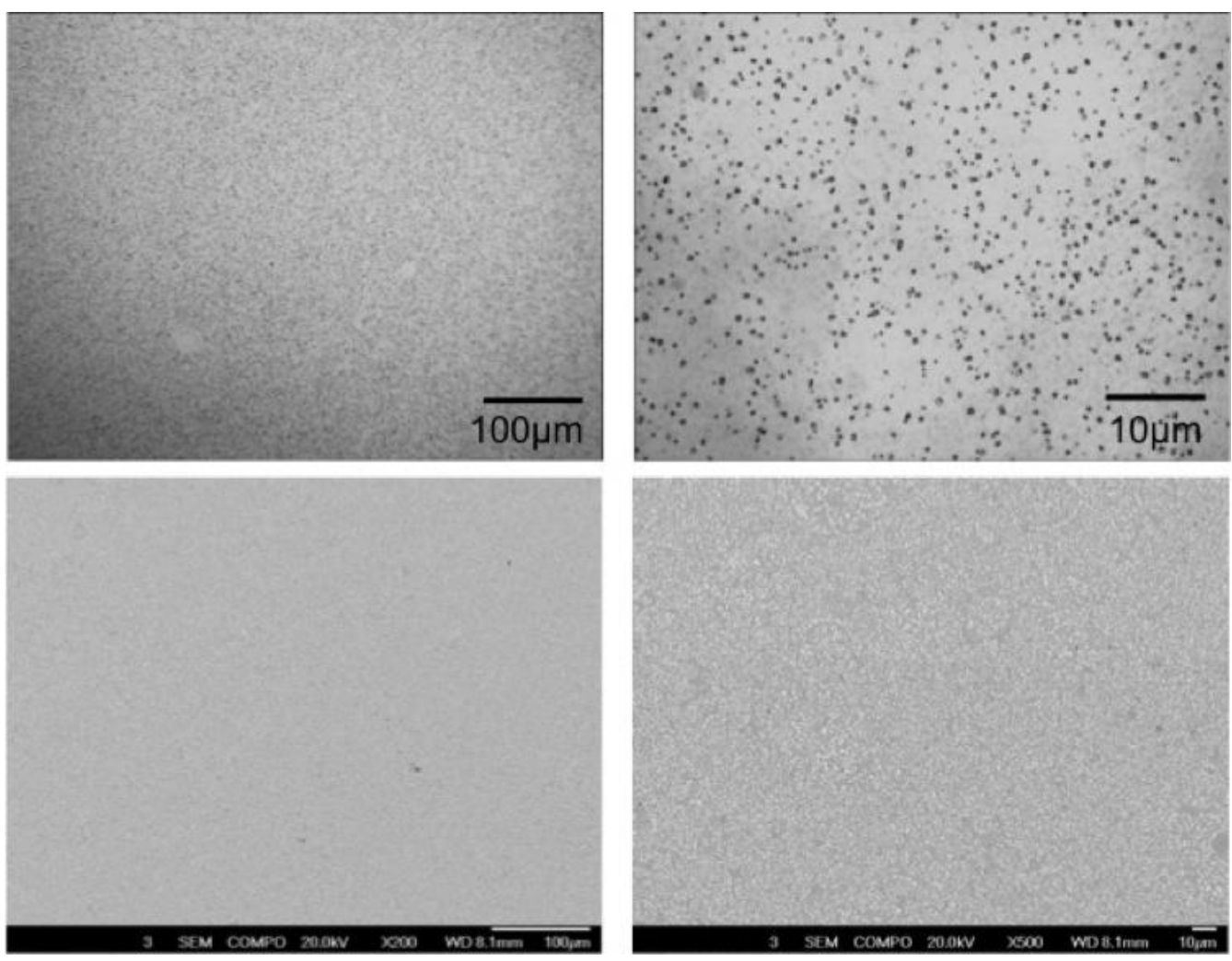

Figure 39: Alloy NC3 powder in the $\mathbf{- 3 2 5}$ mesh size range after $\mathrm{HIP}$ at $1950 \mathrm{~F}$ shown at various magnifications using Optical (top) and BSE imaging (bottom). 

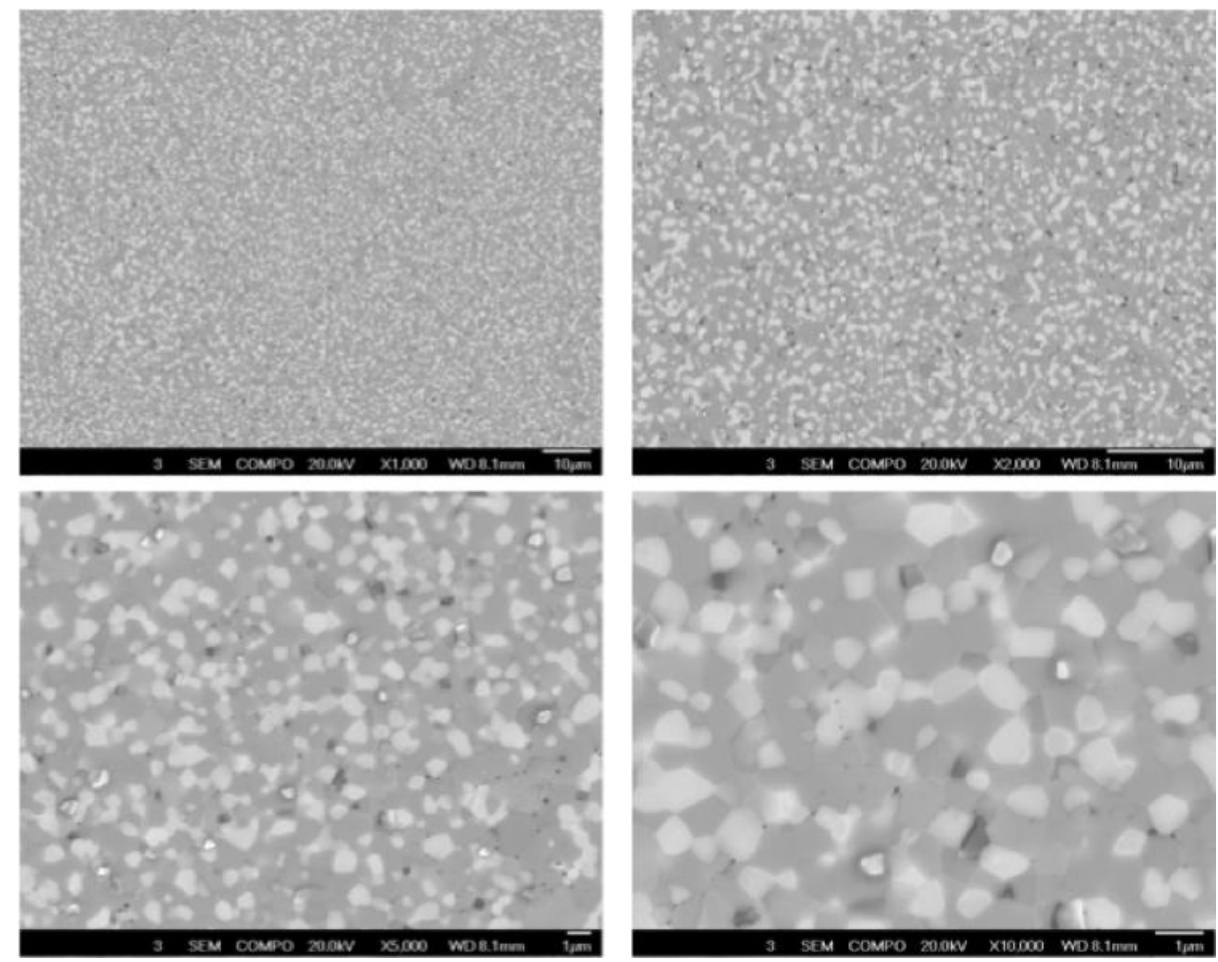

Figure 40: Increased magnification of BSE images of Alloy 3 powder in the size range of -325 mesh HIP'ed at $1950 \mathrm{~F}$

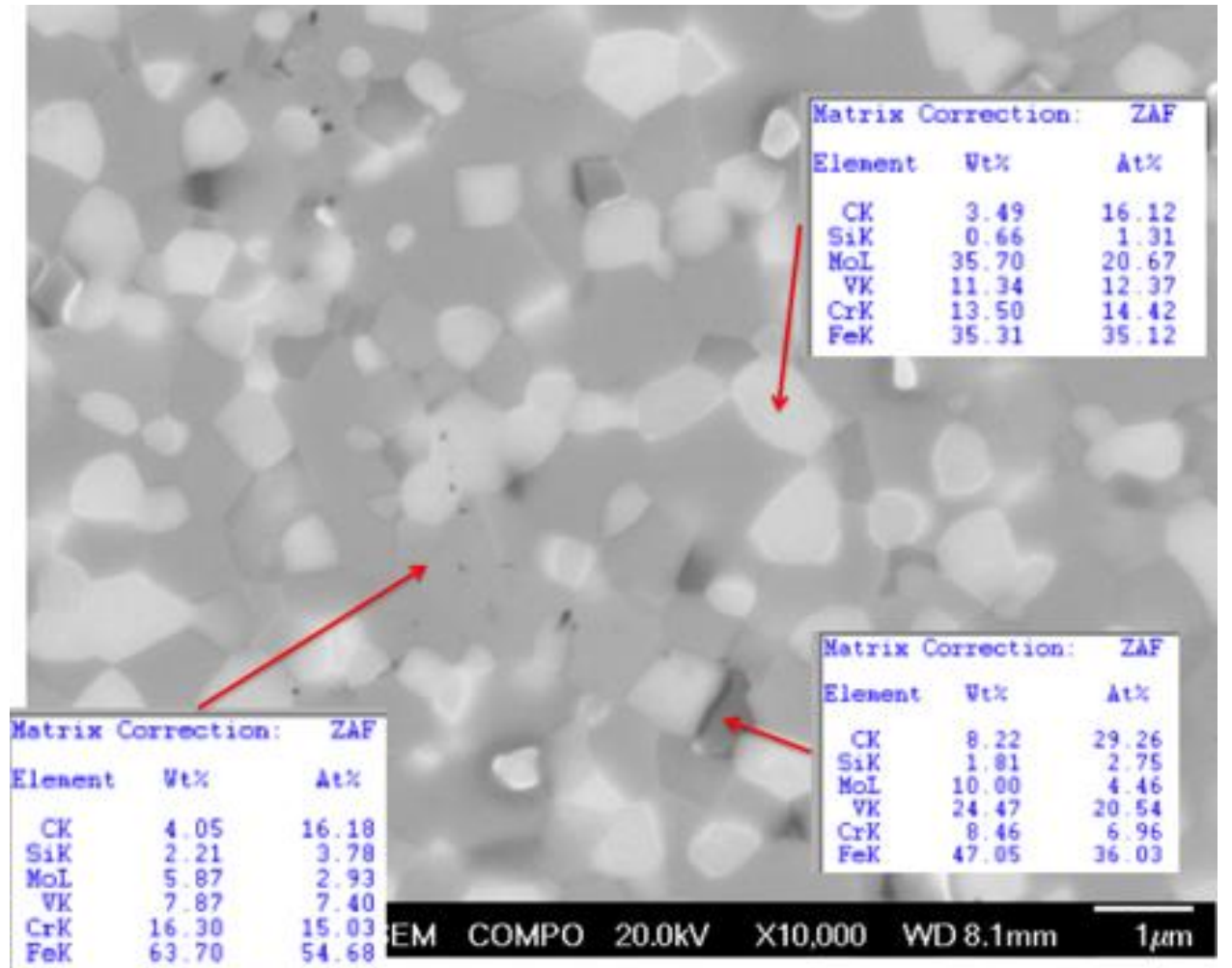

Figure 41:EDS mapping showing elemental distribution on -325 mesh powder of alloy 3 HIP'ed at 1950F.

For comparison, both optical images (top) and BSE images (bottom) in Figure 42 are shown. In contrast to Alloy 3, Alloy5 has clear boundaries evident using optical microscopy. It is expected that 
these boundaries are representative of the original powder particle size used during consolidation. The grain size appears to be on the order of 5-20 $\mu \mathrm{m}$, similar to the size distribution to the -325 powder of alloy 5. It was expected that the boundaries evident would be similar to a grain boundary precipitated material and be a stress concentration leading to decreased mechanical properties. From the increased magnification BSE images shown in Figure 43, it can be seen that the prior particle boundaries are decorated with a nearly continuous layer of precipitates. EDS analysis demonstrated the particles at the boundary to be Fe-19.4C-10.9Y-10Cr by wt\%.
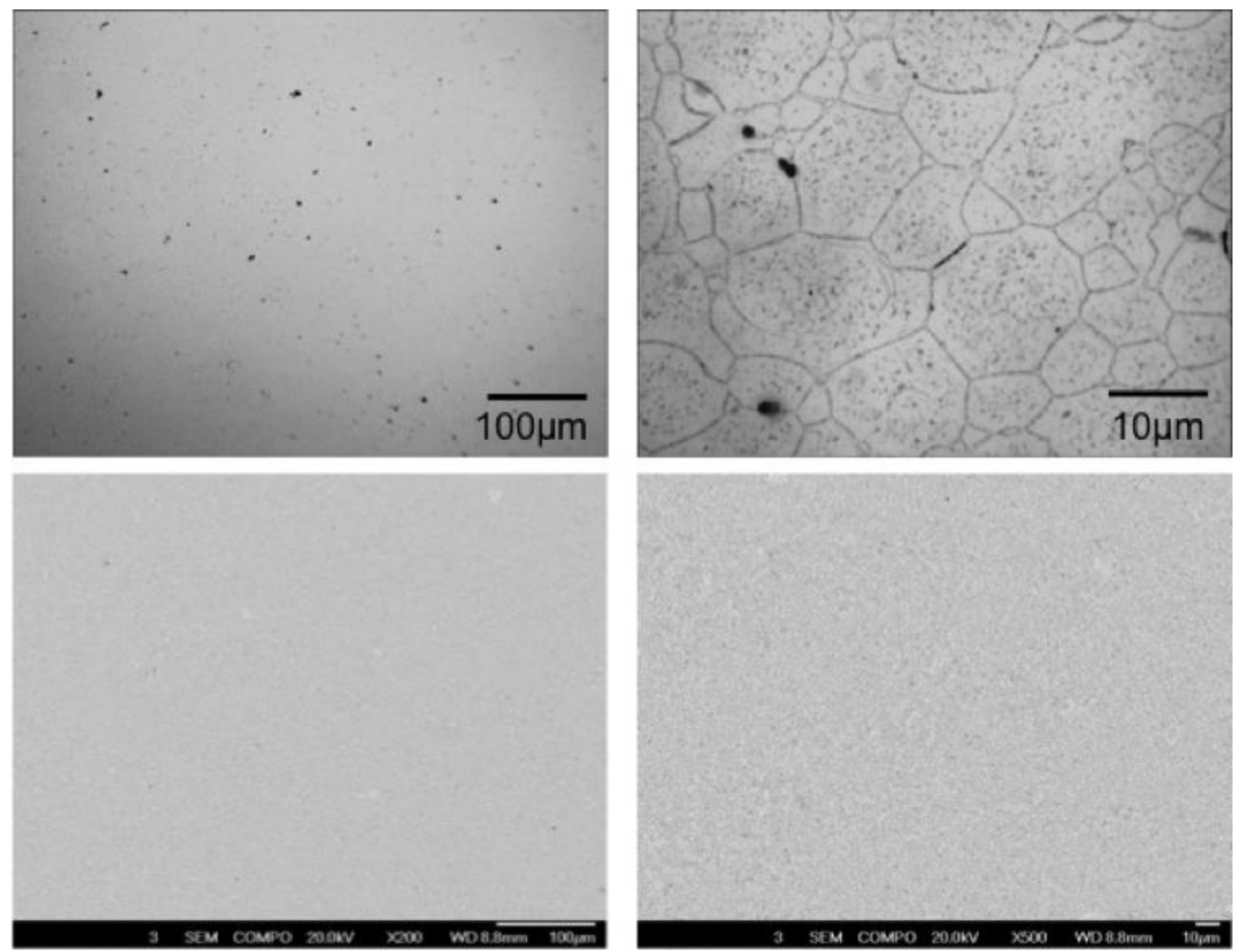

Figure 42: -325 mesh alloy 5 powder consolidated via HIP at 1950F using optical imaging (top) and BSE imaging (bottom). 

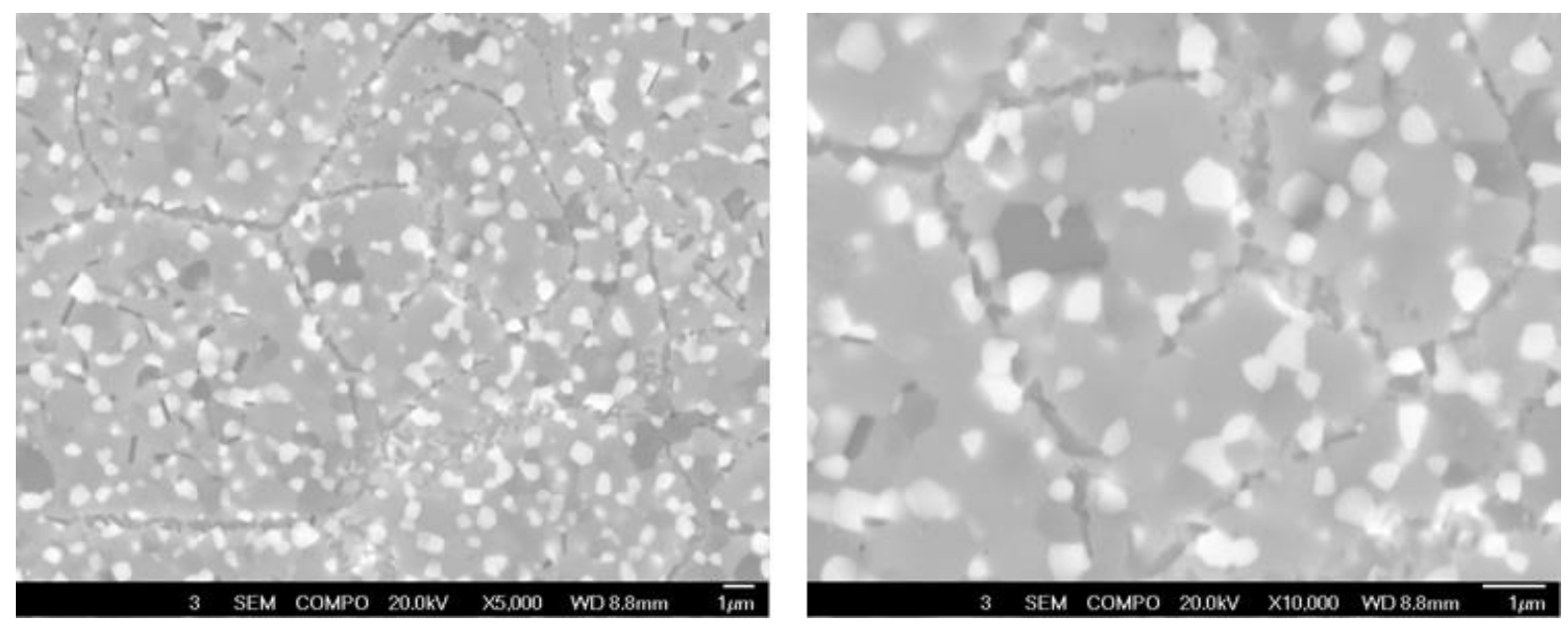

Figure 43: Increased magnification BSE images of -325 mesh powder of Alloy 5 HIP'ed at 1950F

Figure 44 are BSE micrographs of -325 mesh Alloy 8 powder consolidated using HIP at 1950F. Three phases were evenly and homogeneously distributed through the entire sample. No particle segregation is evident along the prior particle boundaries, indicating the HIP temperature of $1950 \mathrm{~F}$ was sufficient to allow for sintering and diffusion to occur uniformly. It is likely that Alloy 8 has a higher tendency to remain amorphous compared to Alloy 5. Based on kinetic theory of devitrification, it can be determined that the particles were fully consolidated prior to crystallization in Alloy 8. For Alloy 5, it is expected that devitrification occurred prior to consolidation of the powders into bulk material. However, it would be expected based on the size of the crystalline particles in Alloy 8, the rate of coarsening is greater in Alloy 8 compared to Alloy 5.

Figure 45, Figure 46, and Figure 47 are BSE images of -325 mesh powder consolidated via HIP at $2125 \mathrm{~F}$. When compared to the microstructure of material consolidated at 1950F, the samples HIP'ed at $2125 \mathrm{~F}$ show a coarser microstructure and those at $1950 \mathrm{~F}$. This result is expected due to the high diffusional mobility of atoms at increased temperature and is consistent with coarsening observed at elevated temperatures. The microstructure shown in Figure 46 (top) of alloy 2 shows the formation of a eutectic microstructure. Eutectic microstructures are formed during the solidification process and indicate that the temperature of $2125 \mathrm{~F}$ was above the melting point for Alloy 4 . However, no eutectic microstructures were observed in Alloy 4 HIP'ed at 1950F, demonstrating the melting temperature of Alloy 4 lies somewhere between $1950 \mathrm{~F}$ and $2125 \mathrm{~F}$. Additional evidence of eutectic formation is shown in Figure 47 (bottom) for Alloy 10. Similar to Alloy 4, it was determined that the melting temperature of Alloy 10 lies between 1950F and 2125F.

The size scale of the microstructures of materials HIP'ed at $2125 \mathrm{~F}$ are in the micron or submicron range. However, in most cases, the precipitates are still on the order of several hundred to a thousand nanometers. The precipitates are homogeneously distributed throughout the microstructure. Although some coarsening does occur at the higher HIP temperature, it is not expected that the coarser structure will limit the potential uses for bulk fabrication of materials produced from amorphous or nanocrystalline materials. 

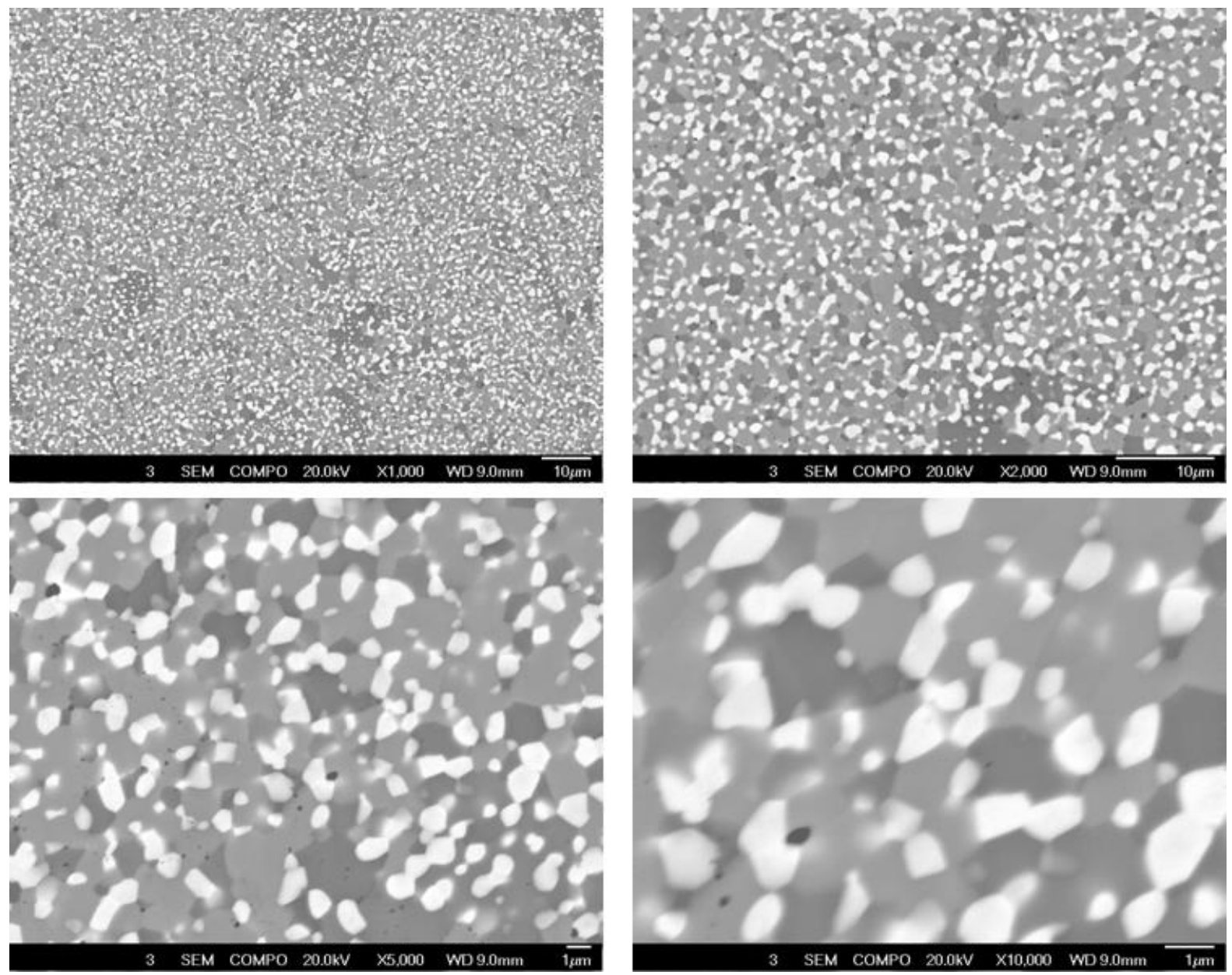

Figure 44: BSE images of -325 mesh Alloy 8 powder HIP'ed at 1950F. 


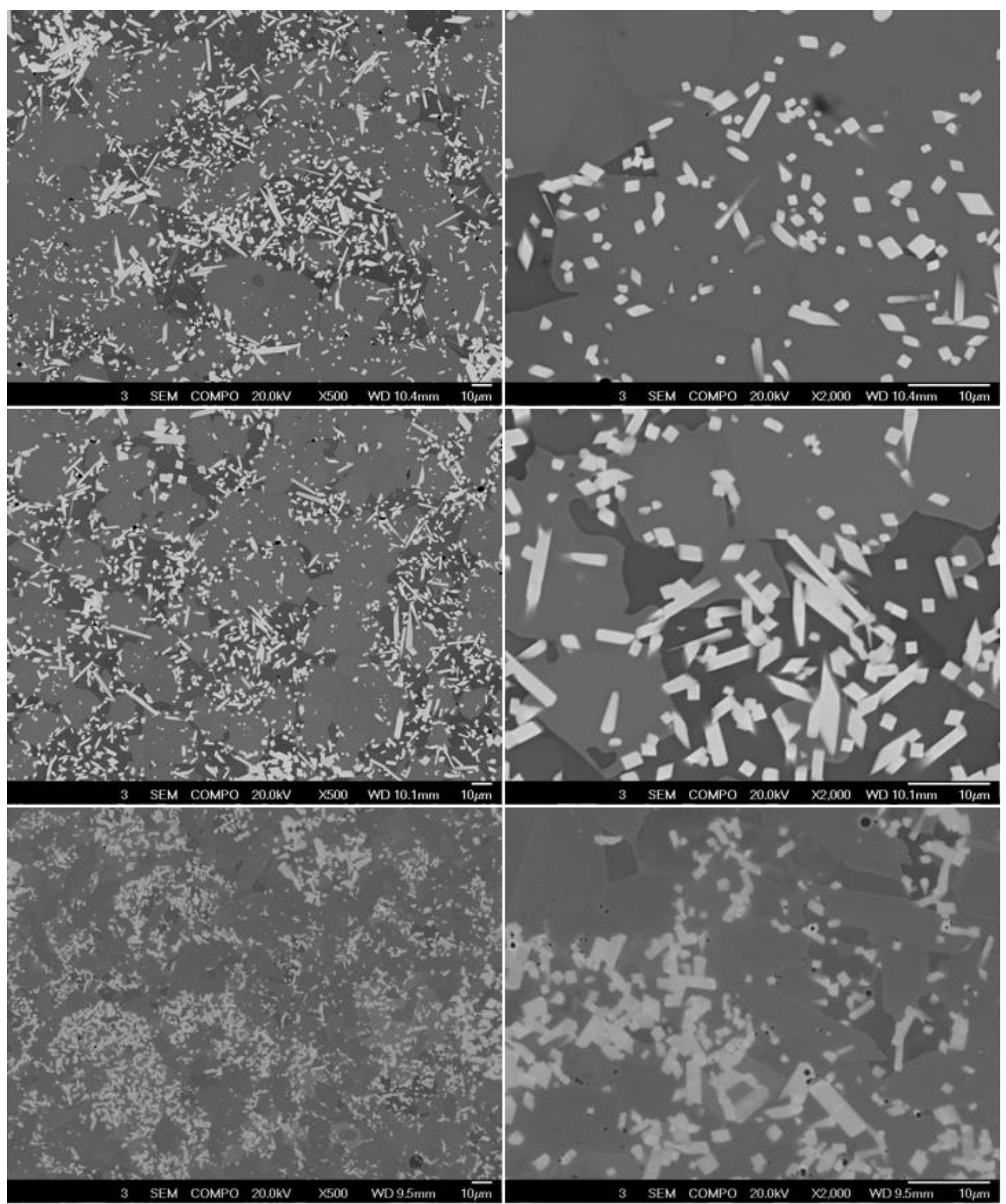

Figure 45: BSE images of Alloy 1 (top), Alloy 2 (middle) and Alloy 3 (bottom). Samples were fabricated from -325 mesh powder HIP'ed at 2125F. 


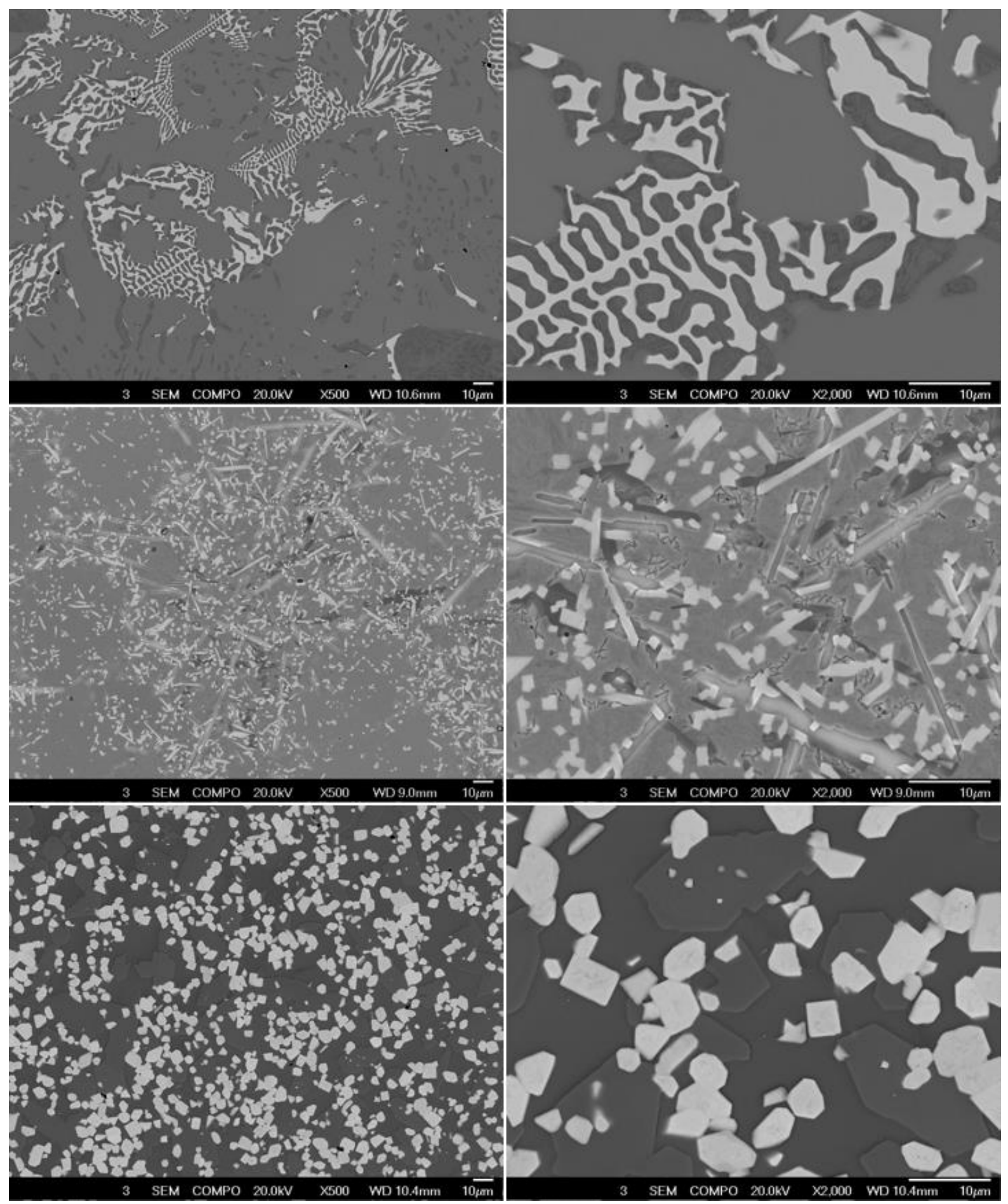

Figure 46: BSE image of Alloy 4 (top), Alloy 5 (middle) and Alloy 6 (bottom). Samples were fabricated from -325 mesh powder HIP'ed at $2125 \mathrm{~F}$. 


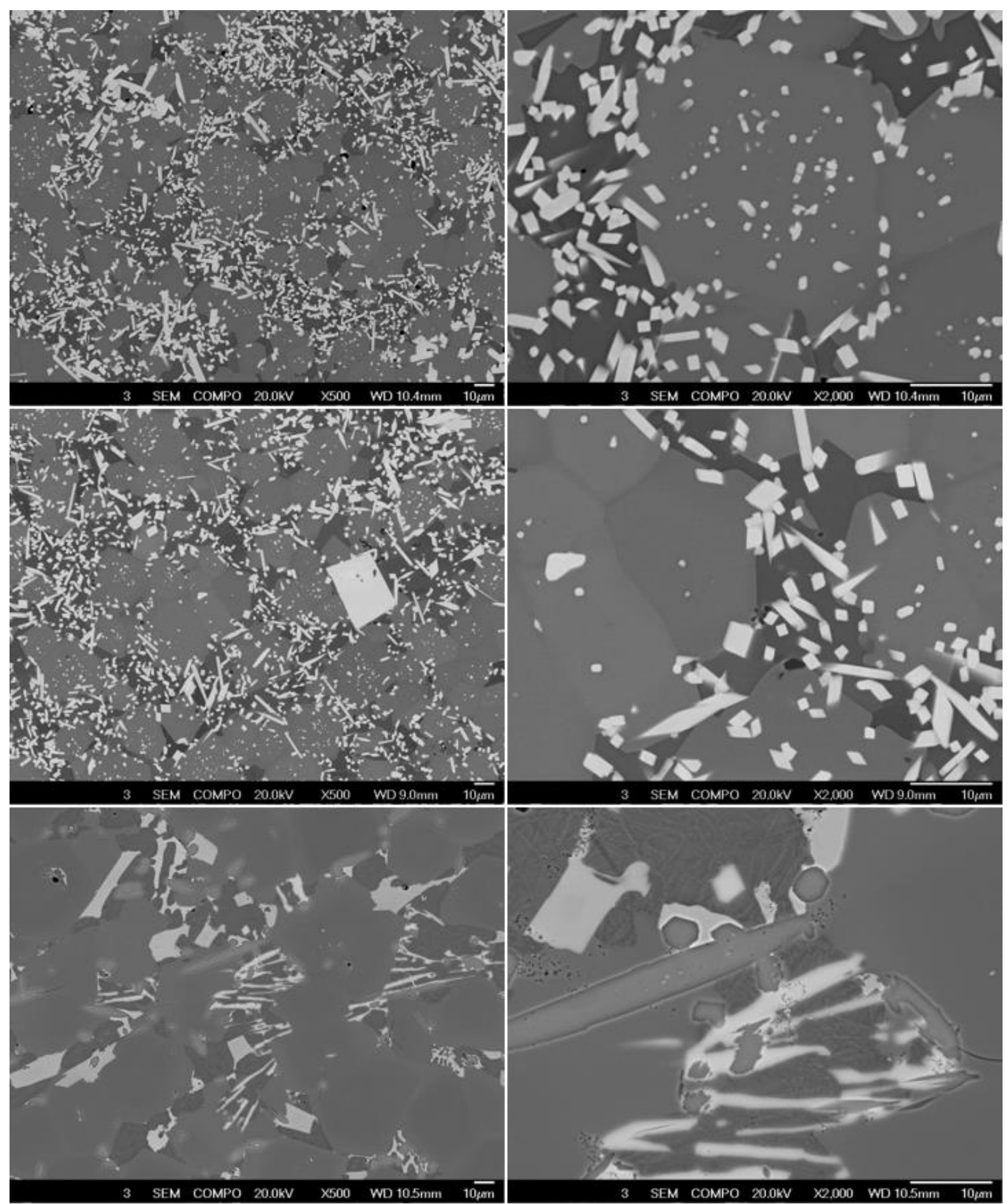

Figure 47: BSE images of Alloy 7 (top), Alloy 8 (middle) and Alloy 10 (bottom). Samples were fabricated from -325 mesh powder HIP'ed at 2125F.

\subsection{ABRASIVE WEAR AND OTHER MECHANICAL PROPERTIES}

Abrasive loop contact measurements were conducted to analyze how the materials performed in abrasive wear studies in a laboratory environment. Results of the laboratory abrasive loop studies were extrapolated to how components would perform in field evaluations. It was expected that laboratory results would directly correlate to field evaluations. Therefore, alloys and processing conditions that demonstrated resistance to abrasive loop testing in the laboratory were chosen for field 
evaluations. The loop abrasion tests give a good indication of in field performance, although it should be noted that several wear mechanisms may be active during actual field evaluations. ASTM G174 (Standard Test Method for Measuring Abrasive Resistance of Materials by Abrasive Loop Contact) was used to conduct low stress microabrasion tests of candidate alloys. The test uses a $200 \mathrm{~g}$ weight pressing down on the flat face of a rectangular coupon $8 \mathrm{~mm}$ wide $\times 32 \mathrm{~mm}$ long x $3 \mathrm{~mm}$ thick. A continuous band of $30 \mu \mathrm{m}$ grit size alumina media travels between three pulleys in a triangular arrangement such that the test specimen presses down upon the topmost pulley (apex of the triangle). Test length is 60 minutes and wear is determined by the width of the mark on the test specimen. A photo of the wear specimen area of the commercial apparatus (made by Bud Labs, Rochester, NY) is shown in Figure 48.

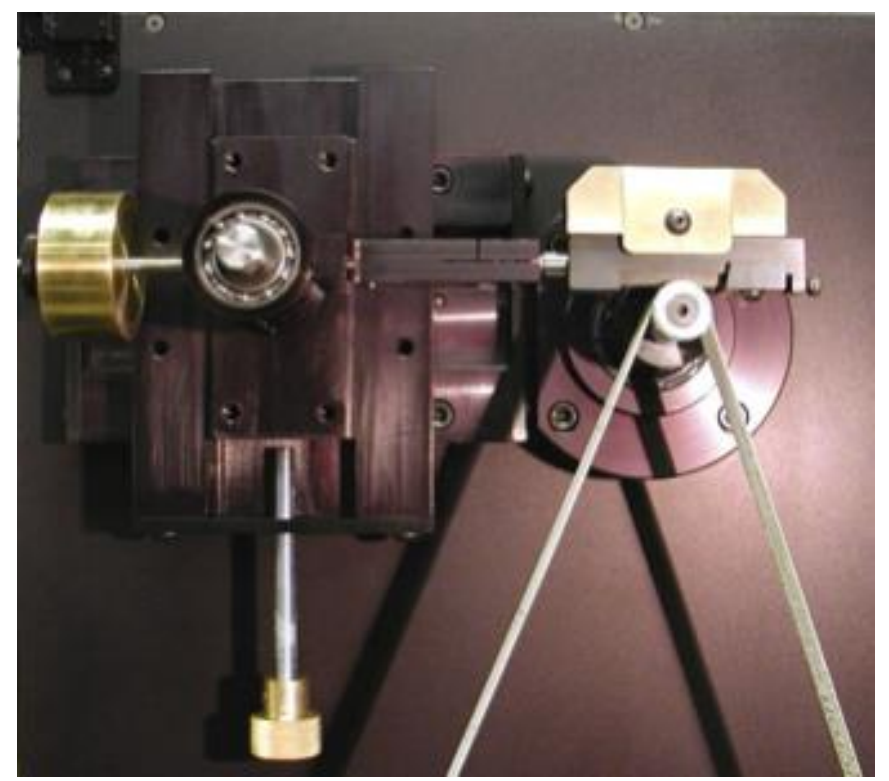

Figure 48: Close-up of the loop abrasion apparatus showing the top pulley and abrasive strip. The test specimen is a flat rectangular piece $3 \mathrm{~mm}$ thick, clamped just above the pulley.

The test is periodically interrupted in order to measure the size of the wear scar. This is performed across the face of the sample and is presented as the average scar width. This value changes as a function of time, although only the final value is reported after the test duration of 1 hour. The average scar width is converted to wear volumetric based on a geometric constraint of the testing apparatus. The wear factor is a unit less number based on the volume of the wear scar and sample thickness and is designed to allow comparison between slightly dissimilar specimen geometries. The results of the loop abrasion tests are shown in Table 14. The table includes wear results from both substrates H13 and 4340 and they have average wear factors of $5.104 \times 10^{-3}$ and $7.582 \times 10^{-3}$ for H13 and 4340 respectively. A value for tungsten carbide-cobalt sample was also measured and determined to be $6.09 \times 10^{-6}$ (LC220).

The bulk samples fabricated through HIP at $2125 \mathrm{~F}$ demonstrated the highest resistance to abrasive loop wear for the bulk processing methodologies evaluated (HIP, VHP, and Dynaforge). Alloy 8 demonstrated an abrasive loop wear factor of $7.5 \times 10^{-5}$ and was the most wear resistant of all alloys tested. This was over an order of magnitude improvement in wear factor compared to the industrial concrete aggregate mixing paddle supplied by Vulcan materials $\left(8.382 \times 10^{-4}\right)$.

It was difficult to measure the abrasive wear factor for laser fused coatings due to the geometrical constraint between the testing geometry and the coated sample. For a single layer of coated material, the layer thickness of the coating was typically between $200 \mu \mathrm{m}$ and $400 \mu \mathrm{m}$. During the abrasive loop test, the full thickness of the coating was penetrated during the first half of the test cycle, and 
continued testing resulted in significant wear of the base material. Therefore, an accurate value of the wear factor for the coating could not be determined/calculated. In order to obtain an accurate value for laser coated materials, additional layers of coating were fused to the substrate material. As can be seen in Table 14 for Alloy NC1, additional layers improved the wear factor from $4.80 \times 10^{-3}, 1.74 \times 10$ ${ }^{3}$, to $7.34 \mathrm{z} 10^{-4}$ for 1,2 and 3 layers respectively. It is expected that the improvement in wear factor was a direct result of the test not penetrating into the softer substrate material, however some improvement may have been realized due to chemical differences in the final surface coating associated with limited dissolution between the coating and previous layer.

Table 14: Abrasive Loop wear testing for NC samples in various processed conditions. Wear factor is unitless with the magnitude indicating resistance to abrasive wear. Lower number indicates improved wear resistance.

\begin{tabular}{|c|c|c|c|c|c|}
\hline Material & $\begin{array}{c}\text { Sample } \\
\text { Width (mm) }\end{array}$ & $\begin{array}{l}\text { Ave. Scar } \\
\text { Width } \\
\text { (mm) }\end{array}$ & $\begin{array}{l}\text { Volume } \\
\text { (cu.mm) }\end{array}$ & Wear Factor & $\begin{array}{c}\text { Average } \\
\text { Wear Factor }\end{array}$ \\
\hline H13 & 7.849 & 4.851 & 9.444 & $5.441 \mathrm{E}-03$ & \multirow{3}{*}{ 5.104E-03 } \\
\hline H13 & 7.849 & 4.694 & 8.541 & $4.921 \mathrm{E}-03$ & \\
\hline H13 & 7.849 & 4.703 & 8.591 & $4.950 \mathrm{E}-03$ & \\
\hline 4340 & 7.849 & 5.362 & 12.836 & $7.395 \mathrm{E}-03$ & \multirow{3}{*}{$7.582 \mathrm{E}-03$} \\
\hline 4340 & 7.849 & 5.368 & 12.881 & $7.421 \mathrm{E}-03$ & \\
\hline 4340 & 7.849 & 5.485 & 13.763 & $7.929 \mathrm{E}-03$ & \\
\hline NC 1-2 (1 Layer) & 7.950 & 4.637 & 8.335 & $4.800 \mathrm{E}-03$ & $4.800 \mathrm{E}-03$ \\
\hline NC 1-2(3 Layers) & 8.030 & 2.667 & 1.575 & $9.070 \mathrm{E}-04$ & \multirow{2}{*}{$7.340 \mathrm{E}-04$} \\
\hline NC 1-2(3 Layers) & 8.030 & 2.274 & 0.974 & $5.610 \mathrm{E}-04$ & \\
\hline NC 1-2(2 Layers) & 8.000 & 3.750 & 4.397 & $2.530 \mathrm{E}-03$ & \multirow{2}{*}{$1.740 \mathrm{E}-03$} \\
\hline NC 1-2(2 Layers) & 8.000 & 2.708 & 1.643 & $9.460 \mathrm{E}-04$ & \\
\hline $\mathrm{NC} 1$ & 8.030 & 1.526 & 0.293 & $1.690 \mathrm{E}-04$ & \multirow{2}{*}{$1.530 \mathrm{E}-04$} \\
\hline $\mathrm{NC} 1$ & 8.030 & 1.423 & 0.238 & $1.370 \mathrm{E}-04$ & \\
\hline NC 1-2 B (2Layers) & 8.000 & 2.383 & 1.117 & $6.440 \mathrm{E}-04$ & \multirow{2}{*}{$3.420 \mathrm{E}-04$} \\
\hline NC 1-2 B (2Layers) & 8.000 & 2.007 & 0.666 & $3.840 \mathrm{E}-04$ & \\
\hline VHP NC 6 & 7.900 & 1.629 & 0.351 & $2.023 \mathrm{E}-04$ & \multirow{4}{*}{$1.981 \mathrm{E}-04$} \\
\hline VHP NC 6 & 7.900 & 1.653 & 0.367 & $2.114 \mathrm{E}-04$ & \\
\hline VHP NC 6 & 7.900 & 1.608 & 0.338 & $1.946 \mathrm{E}-04$ & \\
\hline VHP NC 6 & 7.900 & 1.579 & 0.320 & $1.842 \mathrm{E}-04$ & \\
\hline VHP NC 8 & 7.900 & 1.701 & 0.400 & $2.304 \mathrm{E}-04$ & \multirow{4}{*}{ 2.157E-04 } \\
\hline VHP NC 8 & 7.900 & 1.659 & 0.371 & $2.137 \mathrm{E}-04$ & \\
\hline VHP NC 8 & 7.900 & 1.644 & 0.361 & $2.080 \mathrm{E}-04$ & \\
\hline VHP NC 8 & 7.900 & 1.651 & 0.366 & $2.107 \mathrm{E}-04$ & \\
\hline VHP NC $18 \mathrm{hr}$ & 7.950 & 1.622 & 0.349 & $2.010 \mathrm{E}-04$ & \multirow{4}{*}{$1.851 \mathrm{E}-04$} \\
\hline VHP NC $18 \mathrm{hr}$ & 7.950 & 1.629 & 0.353 & $2.036 \mathrm{E}-04$ & \\
\hline VHP NC $18 \mathrm{hr}$ & 7.950 & 1.518 & 0.286 & $1.647 \mathrm{E}-04$ & \\
\hline VHP NC $18 \mathrm{hr}$ & 7.950 & 1.537 & 0.297 & $1.710 \mathrm{E}-04$ & \\
\hline VHP NC 9 & 8.000 & 1.901 & 0.566 & $3.260 \mathrm{E}-04$ & \multirow{4}{*}{$2.564 \mathrm{E}-04$} \\
\hline VHP NC 9 & 8.000 & 1.669 & 0.383 & $2.204 \mathrm{E}-04$ & \\
\hline VHP NC 9 & 8.000 & 1.691 & 0.398 & $2.292 \mathrm{E}-04$ & \\
\hline VHP NC 9 & 8.000 & 1.740 & 0.434 & $2.498 \mathrm{E}-04$ & \\
\hline VHP NC 7 & 8.000 & 1.752 & 0.443 & $2.550 \mathrm{E}-04$ & \multirow{3}{*}{ 2.277E-04 } \\
\hline VHP NC 7 & 8.000 & 1.630 & 0.356 & $2.053 \mathrm{E}-04$ & \\
\hline VHP NC 7 & 8.000 & 1.675 & 0.387 & $2.228 \mathrm{E}-04$ & \\
\hline VHP NC 2 & 8.000 & 1.872 & 0.540 & $3.113 \mathrm{E}-04$ & \multirow{4}{*}{$3.510 \mathrm{E}-04$} \\
\hline VHP NC 2 & 8.000 & 2.043 & 0.703 & $4.049 \mathrm{E}-04$ & \\
\hline VHP NC 2 & 8.000 & 1.942 & 0.603 & $3.476 \mathrm{E}-04$ & \\
\hline VHP NC 2 & 8.000 & 1.928 & 0.590 & 3.401E-04 & \\
\hline
\end{tabular}




\begin{tabular}{|c|c|c|c|c|c|}
\hline Material & $\begin{array}{c}\text { Sample } \\
\text { Width (mm) }\end{array}$ & $\begin{array}{l}\text { Ave. Scar } \\
\text { Width } \\
(\mathrm{mm})\end{array}$ & $\begin{array}{l}\text { Volume } \\
\text { (cu.mm) }\end{array}$ & Wear Factor & $\begin{array}{c}\text { Average } \\
\text { Wear Factor }\end{array}$ \\
\hline VHP NC 3 & 8.000 & 1.813 & 0.491 & $2.827 \mathrm{E}-04$ & \multirow{2}{*}{$2.755 \mathrm{E}-04$} \\
\hline VHP NC 3 & 8.000 & 1.782 & 0.466 & $2.684 \mathrm{E}-04$ & \\
\hline VHP NC 5 & 8.000 & 1.975 & 0.635 & $3.657 \mathrm{E}-04$ & \multirow{4}{*}{$4.079 \mathrm{E}-04$} \\
\hline VHP NC 5 & 8.000 & 2.050 & 0.710 & 4.091E-04 & \\
\hline VHP NC 5 & 8.000 & 2.139 & 0.807 & $4.649 \mathrm{E}-04$ & \\
\hline VHP NC 5 & 8.000 & 2.021 & 0.680 & 3.919E-04 & \\
\hline VHP NC 4 & 8.000 & 2.292 & 0.994 & 5.724E-04 & \multirow{4}{*}{$5.175 \mathrm{E}-04$} \\
\hline VHP NC 4 & 8.000 & 2.217 & 0.899 & $5.178 \mathrm{E}-04$ & \\
\hline VHP NC 4 & 8.000 & 2.188 & 0.864 & 4.977E-04 & \\
\hline VHP NC 4 & 8.000 & 2.165 & 0.837 & 4.821E-04 & \\
\hline VHP NC $68 \mathrm{hr}$ & 8.000 & 1.820 & 0.496 & $2.860 \mathrm{E}-04$ & \multirow{4}{*}{$2.713 \mathrm{E}-04$} \\
\hline VHP NC $68 \mathrm{hr}$ & 8.000 & 1.870 & 0.539 & 3.103E-04 & \\
\hline VHP NC $68 \mathrm{hr}$ & 8.000 & 1.704 & 0.407 & $2.346 \mathrm{E}-04$ & \\
\hline VHP NC $68 \mathrm{hr}$ & 8.000 & 1.751 & 0.442 & $2.546 \mathrm{E}-04$ & \\
\hline VHP NC7 8hr & 8.000 & 1.752 & 0.443 & $2.550 \mathrm{E}-04$ & \multirow{4}{*}{$2.362 \mathrm{E}-04$} \\
\hline VHP NC7 8hr & 8.000 & 1.694 & 0.400 & $2.305 \mathrm{E}-04$ & \\
\hline VHP NC7 8hr & 8.000 & 1.654 & 0.372 & $2.145 \mathrm{E}-04$ & \\
\hline VHP NC7 8hr & 8.000 & 1.728 & 0.425 & $2.447 \mathrm{E}-04$ & \\
\hline VHP NC8 8hr & 8.000 & 1.654 & 0.372 & $2.145 \mathrm{E}-04$ & \multirow{4}{*}{$2.051 \mathrm{E}-04$} \\
\hline VHP NC8 8hr & 8.000 & 1.587 & 0.329 & 1.894E-04 & \\
\hline VHP NC8 8hr & 8.000 & 1.631 & 0.357 & $2.057 \mathrm{E}-04$ & \\
\hline VHP NC8 8hr & 8.000 & 1.645 & 0.366 & $2.110 \mathrm{E}-04$ & \\
\hline 4340 & 8.000 & 5.717 & 15.937 & 9.181E-03 & \multirow{3}{*}{$9.116 \mathrm{E}-03$} \\
\hline 4340 & 8.000 & 5.666 & 15.503 & $8.931 \mathrm{E}-03$ & \\
\hline 4340 & 8.000 & 5.728 & 16.031 & $9.236 \mathrm{E}-03$ & \\
\hline 1045 & 8.000 & 5.674 & 15.570 & $8.970 \mathrm{E}-03$ & \multirow{3}{*}{$8.360 \mathrm{E}-03$} \\
\hline 1045 & 8.000 & 5.500 & 14.147 & $8.150 \mathrm{E}-03$ & \\
\hline 1045 & 8.000 & 5.458 & 13.817 & $7.960 \mathrm{E}-03$ & \\
\hline Dyna NC $8-325$ & 8.000 & 1.742 & 0.435 & $2.507 \mathrm{E}-04$ & \multirow{3}{*}{$2.411 \mathrm{E}-04$} \\
\hline Dyna NC $8-325$ & 8.000 & 1.727 & 0.424 & 2.442E-04 & \\
\hline Dyna NC $8-325$ & 8.000 & 1.689 & 0.397 & $2.284 \mathrm{E}-04$ & \\
\hline Vulcan Paddle & 8.458 & 2.538 & 1.428 & $8.228 \mathrm{E}-04$ & \multirow{3}{*}{$8.382 \mathrm{E}-04$} \\
\hline Vulcan Paddle & 8.458 & 2.591 & 1.520 & $8.758 \mathrm{E}-04$ & \\
\hline Vulcan Paddle & 8.458 & 2.531 & 1.416 & 8.160E-04 & \\
\hline Vulcan Teeth & 8.940 & 1.851 & 0.584 & $3.362 \mathrm{E}-04$ & \multirow{3}{*}{$3.675 \mathrm{E}-04$} \\
\hline Vulcan Teeth & 8.940 & 1.950 & 0.683 & 3.933E-04 & \\
\hline Vulcan Teeth & 8.940 & 1.916 & 0.647 & $3.730 \mathrm{E}-04$ & \\
\hline NC3A (-325) HIP 1950 & 8.080 & 1.340 & 0.200 & $1.151 \mathrm{E}-04$ & \multirow{2}{*}{$1.118 \mathrm{E}-04$} \\
\hline NC3A (-325) HIP 1950 & 8.080 & 1.314 & 0.188 & $1.085 \mathrm{E}-04$ & \\
\hline NC5A (-325) HIP 1950 & 8.080 & 1.784 & 0.472 & $2.720 \mathrm{E}-04$ & \multirow{2}{*}{$2.722 \mathrm{E}-04$} \\
\hline NC5A (-325) HIP 1950 & 8.080 & 1.785 & 0.473 & $2.724 \mathrm{E}-04$ & \\
\hline NC8A (-325) HIP 1950 & 8.280 & 1.355 & 0.212 & $1.219 \mathrm{E}-04$ & \multirow{2}{*}{$1.259 \mathrm{E}-04$} \\
\hline NC8A (-325) HIP 1950 & 8.280 & 1.384 & 0.226 & 1.299E-04 & \\
\hline NC3B (-325) HIP 2125 & 8.100 & 1.227 & 0.154 & $8.854 \mathrm{E}-05$ & \multirow{3}{*}{$8.700 \mathrm{E}-05$} \\
\hline NC3B (-325) HIP 2125 & 8.100 & 1.187 & 0.139 & $8.000 \mathrm{E}-05$ & \\
\hline NC3B (-325) HIP 2125 & 8.100 & 1.248 & 0.162 & $9.300 \mathrm{E}-05$ & \\
\hline NC5B (-325) HIP 2125 & 8.100 & 1.367 & 0.217 & $1.250 \mathrm{E}-04$ & \multirow{2}{*}{$1.330 \mathrm{E}-04$} \\
\hline NC5B (-325) HIP 2125 & 8.100 & 1.430 & 0.243 & 1.400E-04 & \\
\hline NC8B (-325) HIP 2125 & 8.100 & 1.184 & 0.138 & $8.000 \mathrm{E}-05$ & $7.500 \mathrm{E}-05$ \\
\hline
\end{tabular}




\begin{tabular}{|l|c|c|c|c|c|}
\hline \multicolumn{1}{|c|}{ Material } & $\begin{array}{c}\text { Sample } \\
\text { Width (mm) }\end{array}$ & $\begin{array}{c}\text { Ave. Scar } \\
\text { Width } \\
(\mathrm{mm})\end{array}$ & $\begin{array}{c}\text { Volume } \\
\text { (cu.mm) }\end{array}$ & Wear Factor & $\begin{array}{c}\text { Average } \\
\text { Wear Factor }\end{array}$ \\
\cline { 1 - 5 } NC8B (-325) HIP 2125 & 8.100 & 1.137 & 0.122 & $7.000 \mathrm{E}-05$ & \\
\cline { 1 - 5 } LC 220 & 8.630 & 0.498 & 0.011 & $6.300 \mathrm{E}-06$ & \multirow{2}{*}{$6.090 \mathrm{E}-06$} \\
\hline LC 220 & 8.630 & 0.487 & 0.010 & $5.890 \mathrm{E}-06$ & \\
\hline
\end{tabular}

Hardness measurements were utilized to give an indication of the performance of the coating and bulk-processed materials and give an estimate for the resistance to plastic deformation under an applied load. The Vickers Hardness (HV) scale was used because the values obtained for hardness were not in the range of other typically utilized hardness scales (Rockwell Hardness). It was expected a higher hardness value would lead to an improvement in the abrasive wear resistance.

Samples were cross-sectioned, mounted in epoxy, and polished using $\mathrm{SiC}$ abrasive paper to 1200 grit followed by final polishing with $0.05 \mu \mathrm{m}$ colloidal silica. This allows for a smooth, flat surface in which to take the hardness measurement. Hardness measurements were taken on a Buehler Omnimet ${ }^{\mathrm{TM}}$ MHT automated microindentation hardness testing system. An array of several indents was taken for each sample depending on sample configuration. An example array of microindents is shown in Figure 49 and an associated report is shown in Table 15. A complete list of microhardness values is shown in Table 16 for bulk-consolidated materials.

As a function of processing condition, the VHP and Dynaforged material showed the highest overall hardness values with HIP material having lower hardness values. It was determined that the hold time associated with the HIP process resulted in coarsening of the microstructure as discussed in the previous section, which resulted in lower overall hardness values. Alloy 10 had the highest hardness of all alloys regardless of bulk processing condition. Alloy NC8 demonstrated the second highest hardness value of the HIP processed material (1216 HV).

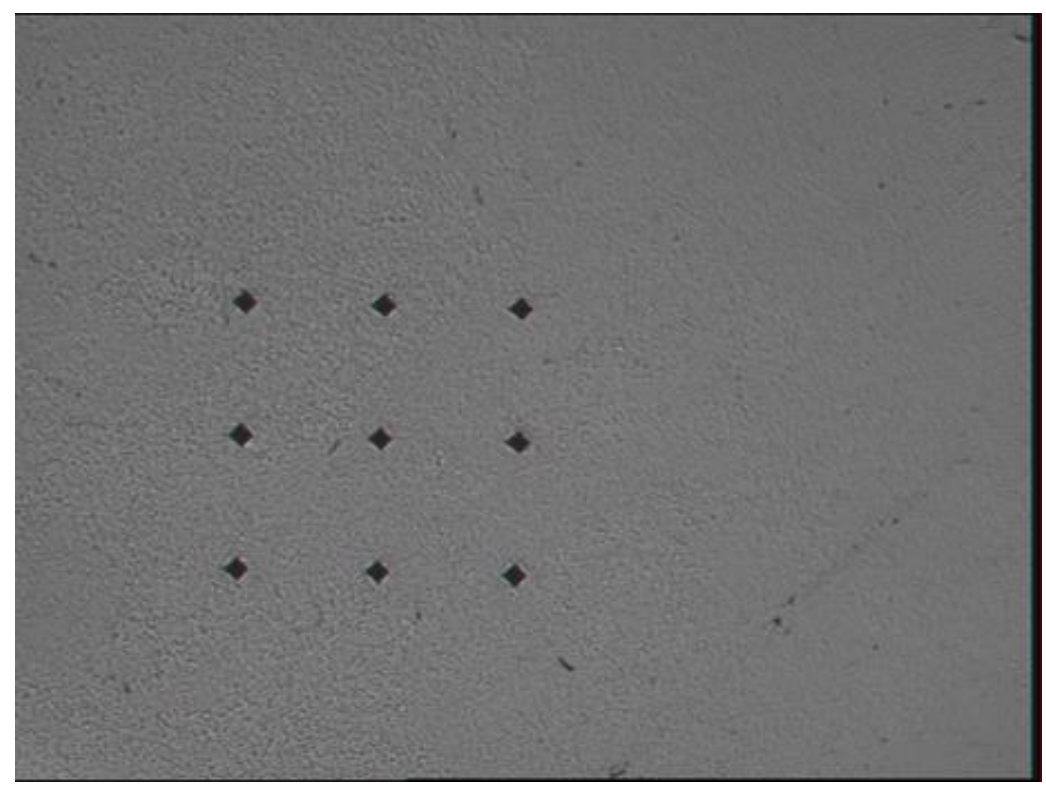

Figure 49: Microindentation array on Dynaforged NC9 (+325 Mesh) sample. The size of the indent is measured corner to corner to achieve an associated hardness value. 
Table 15: Hardness report generated using the Buehler Omnimet MHT machine for NC9 Dynaforged from +325 Mesh powder.

\section{Buehler Omnimet MHT Report}

\section{BUEHLER}

\begin{tabular}{|c|c|c|c|c|}
\hline $\begin{array}{l}\text { Sample ID: } \\
\text { Invoice: } \\
\text { Material specification: } \\
\text { Comment: } \\
\text { Work order: } \\
\text { Detail: } \\
\text { Material: } \\
\text { Depth: }\end{array}$ & $\begin{array}{l}\text { Dyna NC9 +325 } \\
\text { : } \\
\text { D1: }\end{array}$ & $\begin{array}{l}\text { Work order: } \\
\text { Part number: } \\
\text { Registration date: } \\
\text { Registered by: } \\
\text { Part number: } \\
\text { Customer: } \\
\text { D2: }\end{array}$ & $\begin{array}{l}\text { 7/19/10 } \\
\text { Andrew } \\
\text { Hardness: }\end{array}$ & Load: \\
\hline $\begin{array}{l}0.00 \mathrm{~mm} \\
0.00 \mathrm{~mm} \\
0.00 \mathrm{~mm} \\
0.10 \mathrm{~mm} \\
0.10 \mathrm{~mm} \\
0.10 \mathrm{~mm} \\
0.20 \mathrm{~mm} \\
0.20 \mathrm{~mm} \\
0.20 \mathrm{~mm}\end{array}$ & $\begin{array}{l}18.26 \mu \mathrm{m} \\
17.06 \mu \mathrm{m} \\
18.26 \mu \mathrm{m} \\
17.54 \mu \mathrm{m} \\
17.06 \mu \mathrm{m} \\
18.02 \mu \mathrm{m} \\
17.78 \mu \mathrm{m} \\
18.02 \mu \mathrm{m} \\
17.06 \mu \mathrm{m}\end{array}$ & $\begin{array}{l}18.04 \mu \mathrm{m} \\
16.79 \mu \mathrm{m} \\
17.04 \mu \mathrm{m} \\
17.29 \mu \mathrm{m} \\
17.29 \mu \mathrm{m} \\
17.54 \mu \mathrm{m} \\
17.04 \mu \mathrm{m} \\
17.29 \mu \mathrm{m} \\
17.29 \mu \mathrm{m}\end{array}$ & $\begin{array}{l}1125 \mathrm{HV} \\
1295 \mathrm{HV} \\
1190 \mathrm{HV} \\
1223 \mathrm{HV} \\
1257 \mathrm{HV} \\
1173 \mathrm{HV} \\
1223 \mathrm{HV} \\
1190 \mathrm{HV} \\
1257 \mathrm{HV}\end{array}$ & $\begin{array}{l}200 \mathrm{gf} \\
200 \mathrm{gf} \\
200 \mathrm{gf} \\
200 \mathrm{gf} \\
200 \mathrm{gf} \\
200 \mathrm{gf} \\
200 \mathrm{gf} \\
200 \mathrm{gf} \\
200 \mathrm{gf}\end{array}$ \\
\hline $\begin{array}{l}\text { Max Hardness: } \\
\text { Min Hardness: } \\
\text { Mean Hardness: } \\
\text { Stddev Hardness: }\end{array}$ & $\begin{array}{l}1295 \mathrm{HV} \\
1125 \mathrm{HV} \\
1215 \mathrm{HV} \\
51 \mathrm{HV}\end{array}$ & & & \\
\hline
\end{tabular}

Table 16: Microhardness indentation results for bulk consolidated materials using VHP, HIP and Dynaforge.

\begin{tabular}{|l|c|c|c|c|c|}
\hline \multicolumn{7}{|c|}{ Micro Indentation Hardness (Vickers Hardness, HV) } \\
\hline Sample & Mean & Min & Max & Std dev & Indents \\
\hline Dynaforge NC6 (-325) & 1078 & 1039 & 1111 & 29 & $9(3 \times 3)$ \\
\hline Dynaforge NC6 (+325) & 1080 & 1039 & 1125 & 28 & $9(3 \times 3)$ \\
\hline Dynaforge NC7 (-325) & 1242 & 1188 & 1276 & 25 & $9(3 \times 3)$ \\
\hline Dynaforge NC7 (+325) & 1237 & 1205 & 1276 & 29 & $9(3 \times 3)$ \\
\hline Dynaforge NC8 (-325) & 1272 & 1125 & 1332 & 65 & $9(3 \times 3)$ \\
\hline Dynaforge NC8 (+325) & 1279 & 1190 & 1334 & 51 & $9(3 \times 3)$ \\
\hline Dynaforge NC9 (-325) & 1254 & 1206 & 1295 & 36 & $9(3 \times 3)$ \\
\hline Dynaforge NC9 (+325) & 1215 & 1125 & 1295 & 51 & $9(3 \times 3)$ \\
\hline Dynaforge NC10 (-325) & 1342 & 1312 & 1393 & 30 & $9(3 \times 3)$ \\
\hline Dynaforge NC10 (+325) & 1347 & 1258 & 1414 & 57 & $9(3 \times 3)$ \\
\hline VHP NC2 (-325) & 1299 & 1258 & 1314 & 24 & 5 \\
\hline VHP NC3 (-325) & 1299 & 824 & 1294 & 170 & 5 \\
\hline VHP NC4 (-325) & 1388 & 1189 & 1506 & 125 & 5 \\
\hline VHP NC5 (-325) & 1219 & 1111 & 1276 & 69 & 5 \\
\hline VHP NC6 (+325) & 1132 & 1068 & 1276 & 66 & $9(3 \times 3)$ \\
\hline VHP NC7 (+325) & 1225 & 1157 & 1313 & 55 & $6(3 \times 3)$ \\
\hline VHP NC8 (+325) & 1275 & 1224 & 1332 & 37 & $8(3 \times 3)$ \\
\hline VHP NC9 (+325) & 1249 & 1053 & 1374 & 106 & $9(3 \times 3)$ \\
\hline VHP NC10 (+325) & 1349 & 1332 & 1393 & 26 & 5 \\
\hline NC1 (-325) HIP 2125F & 1178 & 778 & 1552 & 283 & $9(3 \times 3)$ \\
\hline NC2 (-325) HIP 2125F & 1005 & 744 & 1204 & 146 & $9(3 \times 3)$ \\
\hline NC3 (-325) HIP 1950F & 1191 & 1156 & 1240 & 26 & $9(3 \times 3)$ \\
\hline NC3 (-325) HIP 2125F & 788 & 788 & 1012 & 103 & $9(3 \times 3)$ \\
\hline NC4 (-325) HIP 2125F & 978 & 697 & 1141 & 170 & $9(3 \times 3)$ \\
\hline NC5 (-325) HIP 1950F & 939 & 736 & 1053 & 92 & $9(3 \times 3)$ \\
\hline
\end{tabular}




\begin{tabular}{|l|c|c|c|c|c|}
\hline \multicolumn{7}{|c|}{ Micro Indentation Hardness (Vickers Hardness, HV) } \\
\hline Sample & Mean & Min & Max & Std dev & Indents \\
\hline NC5 (-325) HIP 2125F & 953 & 654 & 1205 & 197 & $9(3 \times 3)$ \\
\hline NC6 (-325) HIP 2125F & 793 & 690 & 976 & 108 & $9(3 \times 3)$ \\
\hline NC7 (-325) HIP 2125F & 1064 & 853 & 1458 & 208 & $9(3 \times 3)$ \\
\hline NC8 (-325) HIP 1950F & 1216 & 1126 & 1352 & 70 & $9(3 \times 3)$ \\
\hline NC8 (-325) HIP 2125F & 1034 & 786 & 1294 & 222 & $9(3 \times 3)$ \\
\hline NC10 (-325) HIP 2125F & 1060 & 797 & 1276 & 194 & $9(3 \times 3)$ \\
\hline
\end{tabular}

Both compression and tensile testing was conducted on bulk samples consolidated via the various processing methodologies described previously. However, mechanical testing was only conducted on samples with a high probability of producing the desired combination of mechanical properties, and samples which contained a significant amount of porosity or other processing defects (cracking, etc.) after the consolidation process were not tested.

Compression testing was conducted on small-scale specimens of samples fabricated from HIP at $2125 \mathrm{~F}$ using atomized -325 mesh powders. The sample geometry used in compression was cylindrical with a gauge diameter of 0.044 inches by 0.098 inches in length $(1 \mathrm{~mm} \times 2.5 \mathrm{~mm})$. Samples were fabricated from HIP'ed samples using a wire EDM machine and lightly polished using 600 grit $\mathrm{SiC}$ paper. Samples were tested using an Instron 4465 testing apparatus with a maximum load of $1000 \mathrm{lbs}$. The crosshead displacement rate was 0.020 inches per minute. An example stress strain curve for Alloy 6 and Alloy 1 fabricated via HIP at 2125F is shown in Figure 50 and Figure 51 respectively. The elastic modulus of the sample is shown as a straight line on the stress strain curve and was used to determine the maximum strain achieved at failure. Table 17 shows the results of all compression testing conduced on samples fabricated using HIP at 2125F. Samples from Alloy 9 were not evaluated because Alloy 9 melted during the HIP cycle at $2125 \mathrm{~F}$ as previously reported.

The compressive stress strain behavior shown in Figure 51 is typical, with samples showing very little compressive ductility. This is evident by fracture/failure occurring along the elastic modulus and is typical of brittle materials. However, it should be noted that several of the alloys such as that shown in Alloy 6 in Figure 50 demonstrate significant plastic deformation after yielding. The improvement in plastic deformation associated with alloy 6 is significant when compared to other Fe based amorphous glass materials that are typically very brittle and demonstrate little or no measureable plastic deformation.

Tensile samples were machined using the SS3 geometry and tested samples are shown in Figure 52. Many of the samples did not fail in the gauge section of the sample. This failure mechanism can potentially result from the brittle nature of the material when testing with conventional "dog bone" geometry. However, conventional geometry specimens could not be fabricated due to the amount of material available from the bulk-fabricated specimen. The specimens tested did not show discernible tensile elongation. It is believed this is partially due to the brittle nature inherent in Fe based amorphous materials. In addition, the testing conditions were not optimized and the surface of the mechanical test specimens were not finished machined or polished to a level where amorphous based brittle material can be accurately measured. Therefore, additional tensile testing was not conducted on samples, and the focus of mechanical testing was placed on the compression behavior.

0.18T Disc Tension Compacts to determine the fracture toughness of each sample. 10 samples have been machined for each condition for to determine statistical variations. Samples were extracted from both the VHP and Dynaforged bulk materials. However, the results of the fracture toughness were not reliable. It was believed that porosity in the sample resulted in inaccurate data in the fracture toughness testing. In many cases, the sample failed during the pre-crack initiation cycle necessary to perform the compact tension test. Therefore, no results were obtained for fracture toughness. 


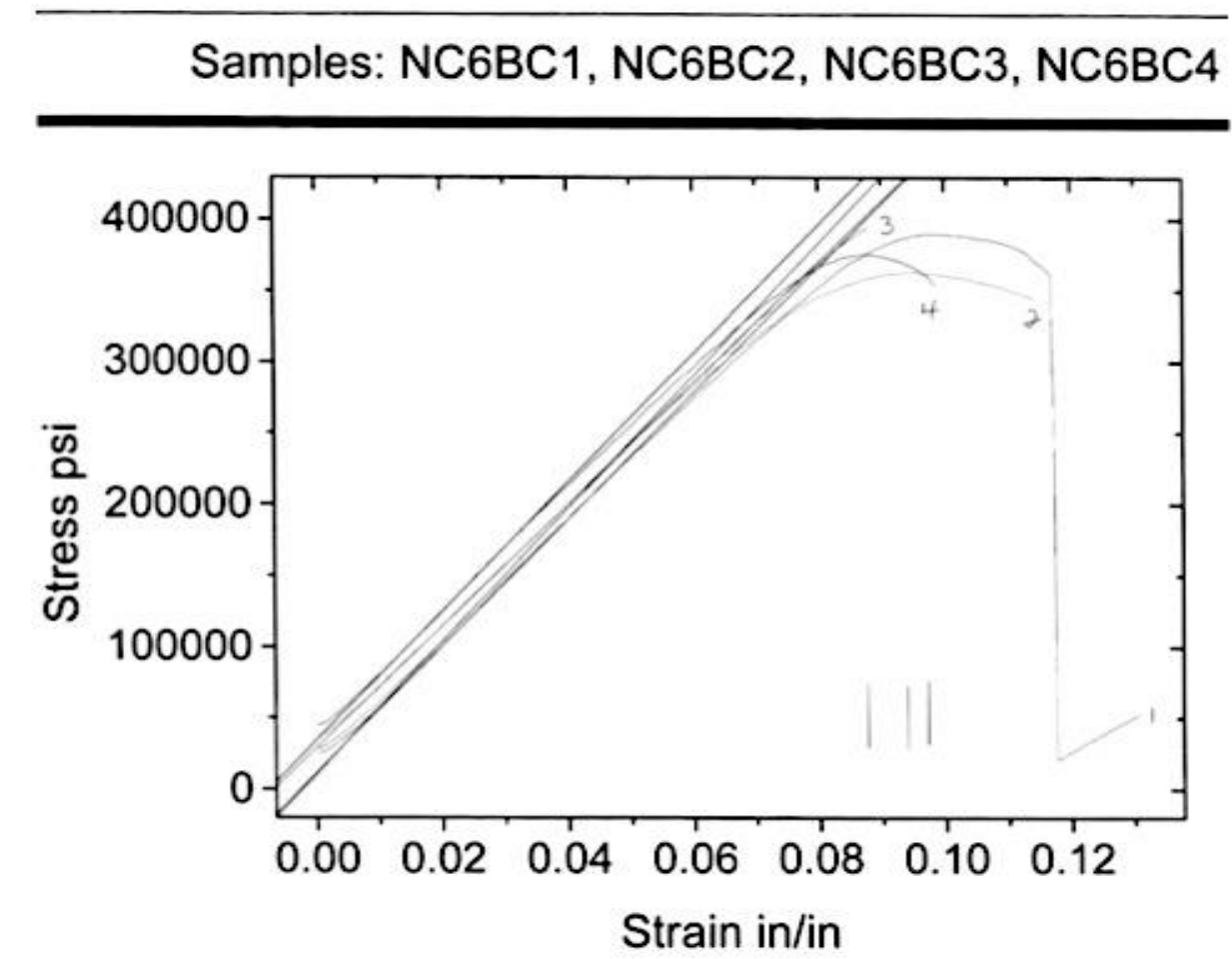

Figure 50: Example Stress-Strain Compression curve for Alloy 6 fabricated from -325 Mesh powder using HIP at 2125F.

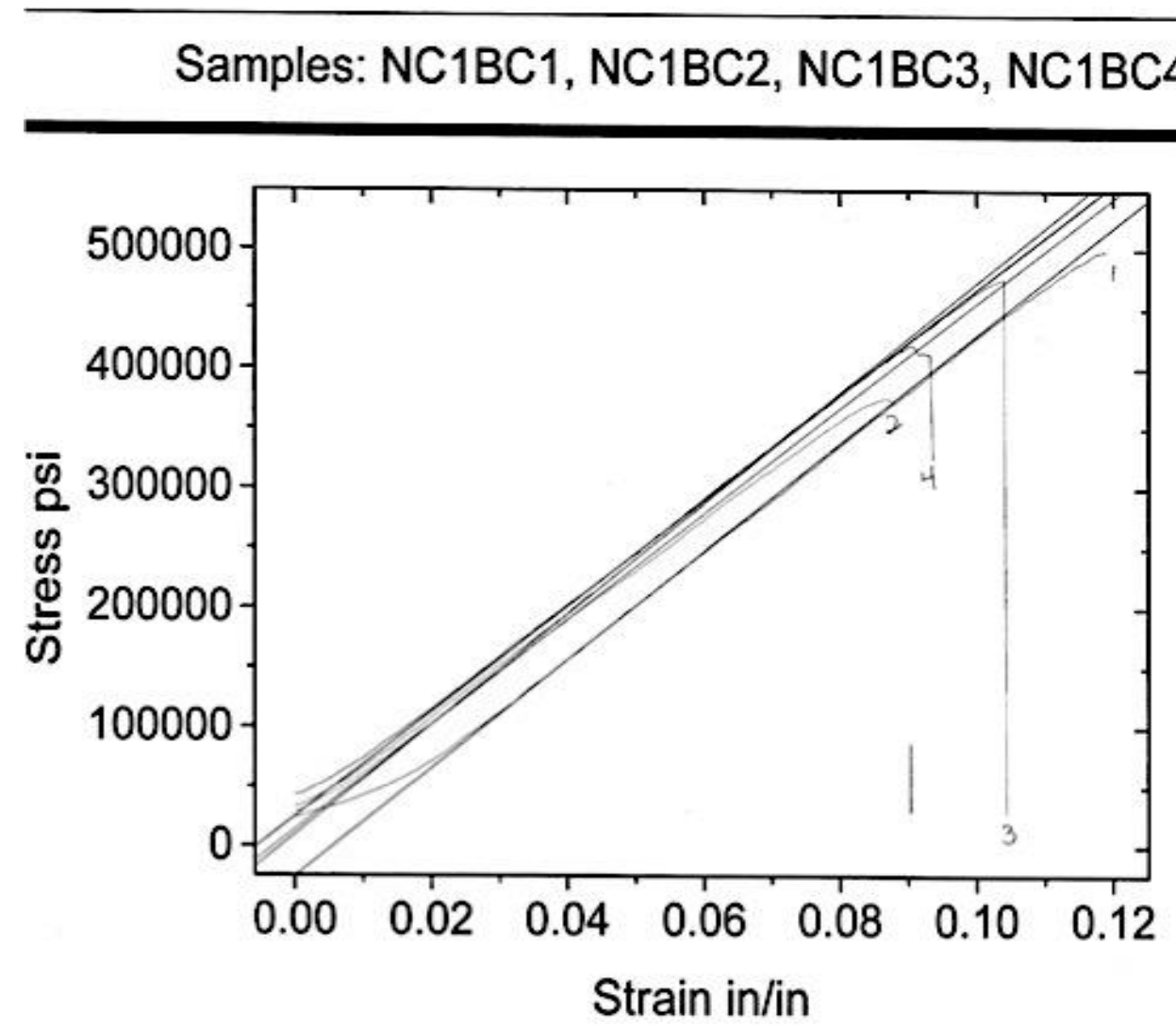

Figure 51: Example Stress-Strain Compression curve for Alloy 1 fabricated from -325 mesh powder using HIP at 2125F. 
Table 17: Tabulated results of compression testing on samples HIP'ed at 2125F. Sample 9 was not tested due to melting at $2125 \mathrm{~F}$ during the HIP cycle

\begin{tabular}{|l|r|r|r|r|}
\hline \multicolumn{1}{|c|}{ Specimen Number } & $\begin{array}{c}\text { Max Stress } \\
\text { (psi) }\end{array}$ & $\begin{array}{c}\text { Max Load } \\
\text { (lbs.) }\end{array}$ & $\begin{array}{c}\text { Max Strain } \\
(\%)\end{array}$ & $\begin{array}{c}\text { Max } \\
\text { Displacement } \\
\text { (in) }\end{array}$ \\
\hline Alloy 1 HIP 2125F & 499000 & 758.7 & 10.91 & 0.105 \\
\hline Alloy 1 HIP 2125F & 375000 & 570.2 & 8.738 & 0.0083 \\
\hline Alloy 1 HIP 2125F & 475300 & 722.7 & 10.63 & 0.0102 \\
\hline Alloy 1 HIP 2125F & 420200 & 638.9 & 10.03 & 0.0095 \\
\hline Alloy 2 HIP 2125F & 425500 & 647 & 9.897 & 0.0094 \\
\hline Alloy 2 HIP 2125F & 468900 & 713 & 11.08 & 0.0101 \\
\hline Alloy 2 HIP 2125F & 468700 & 712.7 & 10.67 & 0.0098 \\
\hline Alloy 2 HIP 2125F & 378700 & 575.8 & 9.634 & 0.0089 \\
\hline Alloy 3 HIP 2125F & 332600 & 528.9 & 8.909 & 0.0086 \\
\hline Alloy 3 HIP 2125F & 281100 & 447 & 9.082 & 0.0089 \\
\hline Alloy 4 HIP 2125F & 429200 & 652.6 & 9.963 & 0.0091 \\
\hline Alloy 4 HIP 2125F & 363200 & 552.2 & 9.288 & 0.00852 \\
\hline Alloy 4 HIP 2125F & 368800 & 560.8 & 9.594 & 0.0086 \\
\hline Alloy 4 HIP 2125F & 387400 & 589 & 9.322 & 0.0086 \\
\hline Alloy 5 HIP 2125F & 376700 & 626.8 & 9.597 & 0.0086 \\
\hline Alloy 5 HIP 2125F & 356500 & 592.5 & 9.479 & 0.0091 \\
\hline Alloy 6 HIP 2125F & 390400 & 593.6 & 10.37 & 0.0103 \\
\hline Alloy 6 HIP 2125F & 363200 & 552.2 & 9.878 & 0.0097 \\
\hline Alloy 6 HIP 2125F & 394400 & 599.7 & 9.332 & 0.0092 \\
\hline Alloy 6 HIP 2125F & 375700 & 571.3 & 9.866 & 0.0078 \\
\hline Alloy 7 HIP 2125F & 439300 & 667.9 & 10.11 & 0.0098 \\
\hline Alloy 7 HIP 2125F & 450600 & 685.1 & 10.97 & 0.0104 \\
\hline Alloy 7 HIP 2125F & 482200 & 733.2 & 11.48 & 0.0109 \\
\hline Alloy 7 HIP 2125F & 473200 & 719.5 & 11.03 & 0.0105 \\
\hline Alloy 8 HIP 2125F & 355600 & 565.6 & 9.008 & 0.0086 \\
\hline Alloy 8 HIP 2125F & 346500 & 551.1 & 9.422 & 0.009 \\
\hline Alloy 10 HIP 2125F & 369500 & 561.9 & 8.76 & 0.0082 \\
\hline Alloy 10 HIP 2125F & 424500 & 645.4 & 9.789 & 0.0093 \\
\hline Alloy 10 HIP 2125F & 413700 & 629 & 9.605 & 0.0091 \\
\hline Alloy 10 HIP 2125F & 423700 & 644.3 & 9.372 & 0.0089 \\
\hline
\end{tabular}

Table 18: Tensile properties of bulk samples fabricated from HIP at various conditions.

\begin{tabular}{|c|c|c|c|c|c|}
\hline $\begin{array}{l}\text { Specimen } \\
\text { Number }\end{array}$ & $\begin{array}{l}\text { Yield } \\
\text { (PSI) }\end{array}$ & $\begin{array}{l}\text { Ultimate } \\
\text { (PSI) }\end{array}$ & $\begin{array}{l}\text { Elongation } \\
(\%)\end{array}$ & $\begin{array}{l}.2 \% \text { Elongation } \\
(\%)\end{array}$ & $\begin{array}{l}\text { Total Plastic } \\
\text { Strain (\%) }\end{array}$ \\
\hline NC3 HIP 1950F & 76460 & 76460 & 2.017 & 2.017 & 0 \\
\hline NC3 HIP 1950F & 84750 & 84750 & 3.333 & 3.36 & 0 \\
\hline NC3 HIP 1950F & 108600 & 108600 & 3 & 2.92 & 0 \\
\hline NC3 HIP 1950F & 103600 & 103600 & 3 & 2.923 & 0 \\
\hline NC3 HIP 2125F & 67510 & 67510 & 2.333 & 2.24 & 0 \\
\hline NC3 HIP 2125F & 60980 & 60980 & 2 & 1.897 & 0 \\
\hline NC5 HIP 1950F & 90690 & 90690 & 2.333 & 2.263 & 0 \\
\hline NC5 HIP 1950F & 87820 & 87820 & 2.667 & 2.25 & 0 \\
\hline NC5 HIP 1950F & 90200 & 90200 & 2.667 & 2.57 & 0 \\
\hline NC5 HIP 1950F & 95760 & 95760 & 2.667 & 2.77 & 0 \\
\hline NC5 HIP 2125F & 53570 & 53570 & 1.667 & 1.527 & 0 \\
\hline NC5 HIP 2125F & 56980 & 56980 & 1.667 & 1.76 & 0 \\
\hline NC6 HIP 2125F & 69130 & 69130 & 2 & 1.987 & 0.013 \\
\hline NC6 HIP 2125F & 76700 & 76700 & 2.333 & 2.24 & 0.093 \\
\hline NC6 HIP 2125F & 68410 & 68410 & 2 & 1.913 & 0.087 \\
\hline
\end{tabular}




\begin{tabular}{|l|r|r|r|r|r|}
\hline $\begin{array}{l}\text { Specimen } \\
\text { Number }\end{array}$ & $\begin{array}{l}\text { Yield } \\
(\mathrm{PSI})\end{array}$ & $\begin{array}{l}\text { Ultimate } \\
(\mathrm{PSI})\end{array}$ & $\begin{array}{l}\text { Elongation } \\
(\%)\end{array}$ & $\begin{array}{l}.2 \% \text { Elongation } \\
(\%)\end{array}$ & $\begin{array}{l}\text { Total Plastic } \\
\text { Strain (\%) }\end{array}$ \\
\hline NC6 HIP 2125F & 39300 & 39300 & 1.333 & 1.25 & 0.083 \\
\hline NC8 HIP 2125F & 39680 & 39680 & 1.333 & 1.3 & 0 \\
\hline NC8 HIP 2125F & 42080 & 42080 & 1.333 & 1.23 & 0 \\
\hline NC8 HIP 2125F & 38950 & 38950 & 1 & 1 & 0 \\
\hline NC8 HIP 2125F & 37220 & 37220 & 1 & 1 & 0 \\
\hline
\end{tabular}

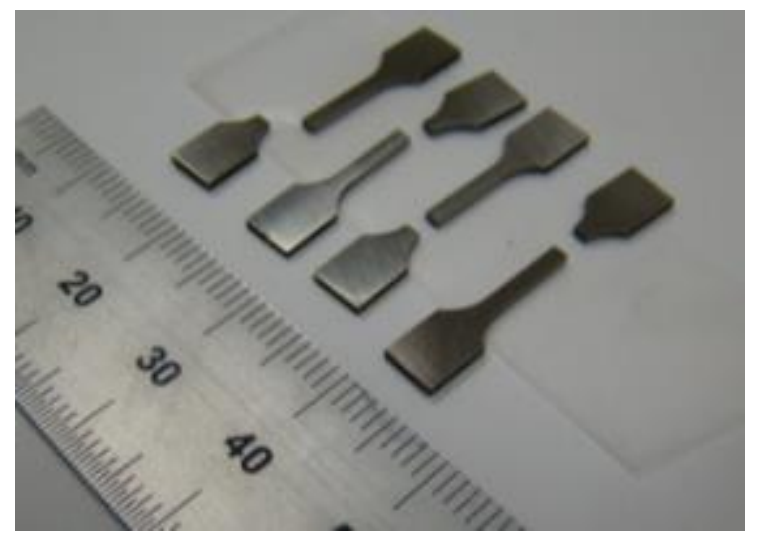

Figure 52: Tested tensile samples using the SS3 tensile geometry. Samples had a tendency to not break in the gauge section of the sample.

\subsection{FIELD EVALUATION OF NANOCOMPOSITE COATINGS}

In mid-summer of 2009, ORNL initiated discussions with Vulcan Materials to assess interest and potential applications of the nanocomposite coatings in rock quarrying activities. In this meeting and subsequent field visits, it was determined that there were a number of applications where wear resistant coatings that could be applied to tool steels would have the potential to decrease wear and decrease budgetary requirements for the replacement of tool steel components. Several specific components were targeted including the teeth on dozer buckets used to transport and scoop rock, the impact plates and blow bars in the rock impact crushers used in the crushing production line to make aggregate, and the paddles in the aggregate mixers that are used to mix and finely break down rock for fine aggregate. ORNL staff spent the better part of a day in the field evaluating the potential components that could be coated and field evaluated. Rock mixing paddles were down-selected for field evaluation by Vulcan Materials and ORNL due to the ability to visually inspect the coatings during field evaluation, the abrasive wear and impact degradation that is observed in this application, and the lower risk to equipment and down time. Other parts were also inspected and compared in wear, but the predominant research would be performed on the rock mixing paddles.
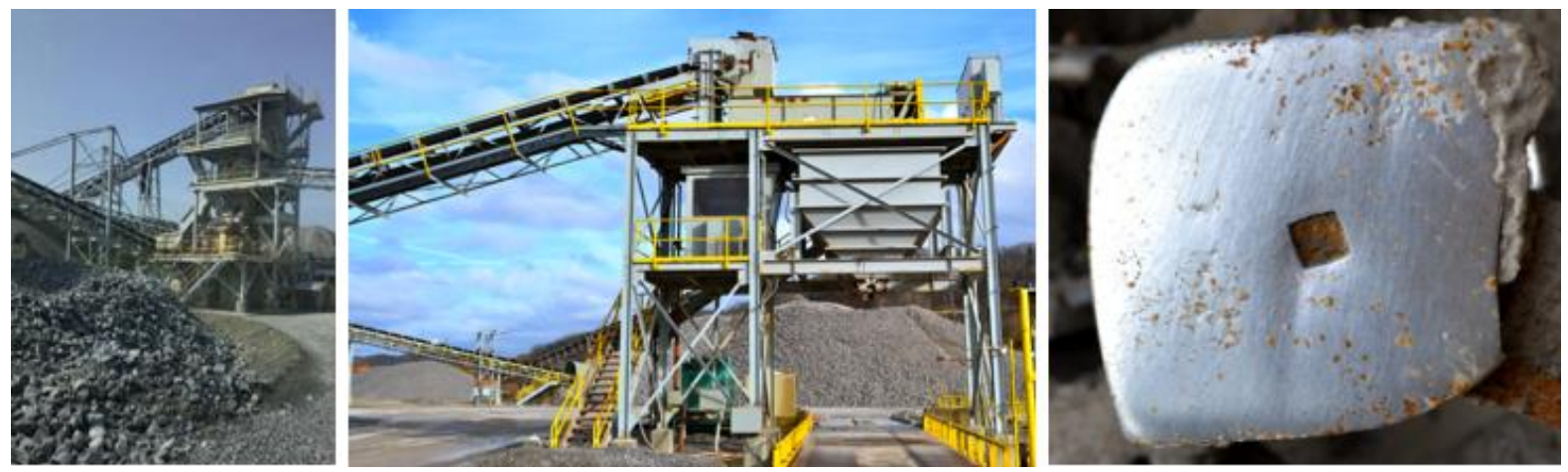

Figure 53. Vulcan Materials Dixie Lee Rock Quarry (left), fine aggregate rock mixing machine (center), and a worn mixing paddle (right). 
ORNL performed microstructure and hardness testing on the existing paddles. The paddles are a high $\mathrm{Cr}$ steel casting with average hardness values of approximately $650 \mathrm{HV}$. Abrasive wear loop tests, in accordance with ASTM G174, were performed on the casting. 8.38X10 ${ }^{-4}$ (smaller is better) was the average wear factor found after three tests with a load of $201 \mathrm{~g}, 680$ revolutions, tape thickness of 0.19 $\mathrm{mm}$, and a total distance of abrasive tape travel of $880.6 \mathrm{~m}$. The sample width of the bar taken from the casting was $8.458 \mathrm{~mm}$. In comparing to other tools steels, the average wear factor was close to an order of magnitude lower than $\mathrm{H} 13,4340$, and $1045,5.10 \times 10^{-3}, 9.12 \times 10^{-3}$, and $8.36 \times 10^{-3}$, respectively. In comparing the wear resistance to the NC compositions, the wear factor was close to an order of magnitude greater than NC8 hot isostatically pressed at $2125^{\circ} \mathrm{F}, 8.73 \times 10^{-5}$.
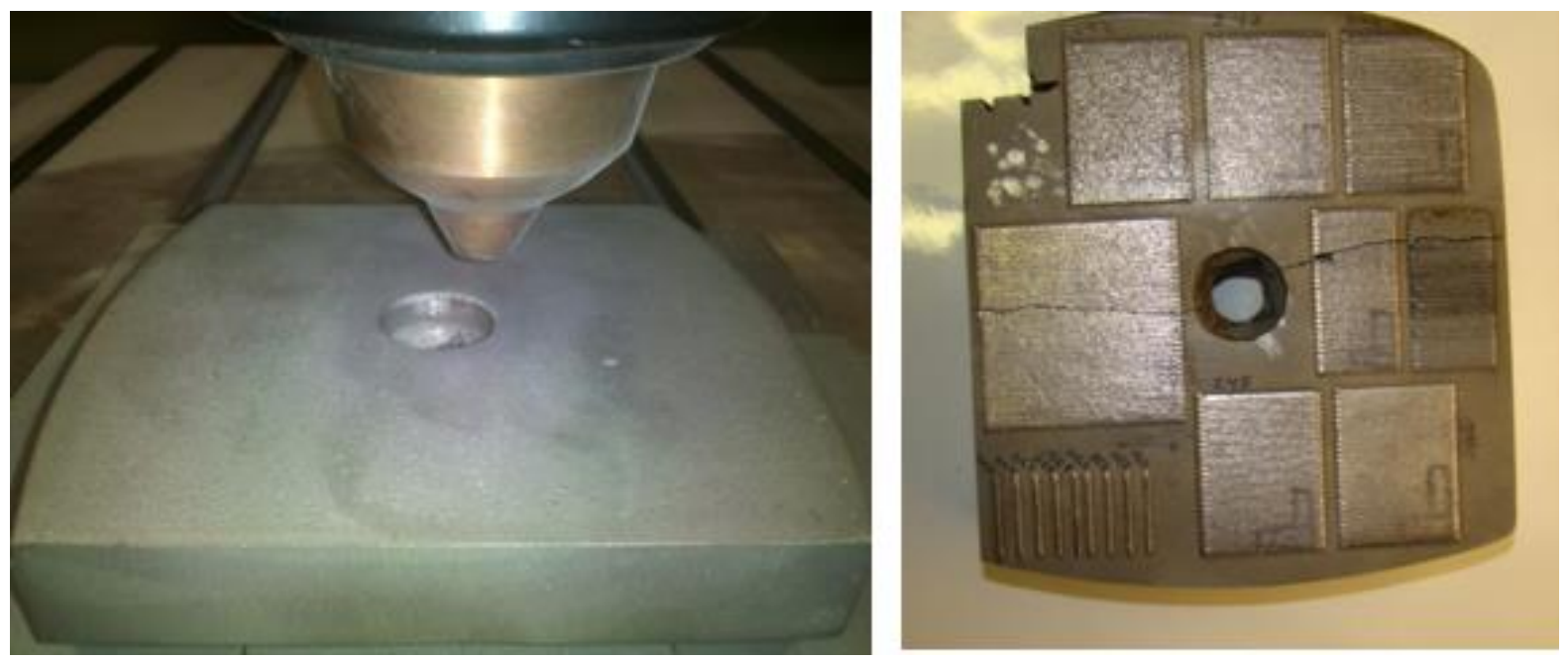

Figure 54. Laser fusing setup of the mixing paddle in the POM laser (left). Various laser fusing trials for 7 powders on paddle.

Laser fusing trials were then performed using the POM DMD ${ }^{\mathrm{TM}}$ free form laser and seven of the nine nanocrystalline powders ( $\mathrm{NC} 1, \mathrm{NC} 3, \mathrm{NC} 4, \mathrm{NC} 6, \mathrm{NC} 7, \mathrm{NC} 8$, and NC9). The powders were directly fused to the paddle as shown in Figure 21. The integrities of the coatings were tested by subjecting the paddle to a ball ping hammer. The paddle substrate experienced deformation where impacted. The coated areas when hit with the hammer did not experience deformation. The paddle was subjected to such severe hits that the paddle broke during the impact evaluation; however, the coatings stayed intact except for one small area. Metallography specimens were taken from the unimpacted areas of the sample. Micrographs and hardness profiles were performed. Results are shown in Figure 55. The coatings ranged between $0.4 \mathrm{~mm}$ and $0.65 \mathrm{~mm}$ in thickness. Each of the coatings increased the hardness at the surface, but coatings NC7 and NC8 had the largest increase in hardness. The hardness for the NC8 coating was increased by $88 \%$ compared to the substrate, resulting in Vicker's Hardness of 1223 HV. A slight decrease in strength was observed in the heataffected zone. 

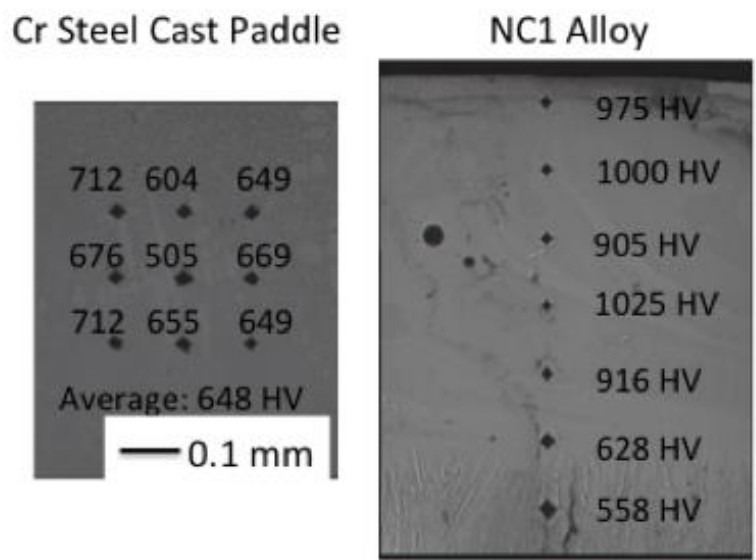

NC6 Alloy
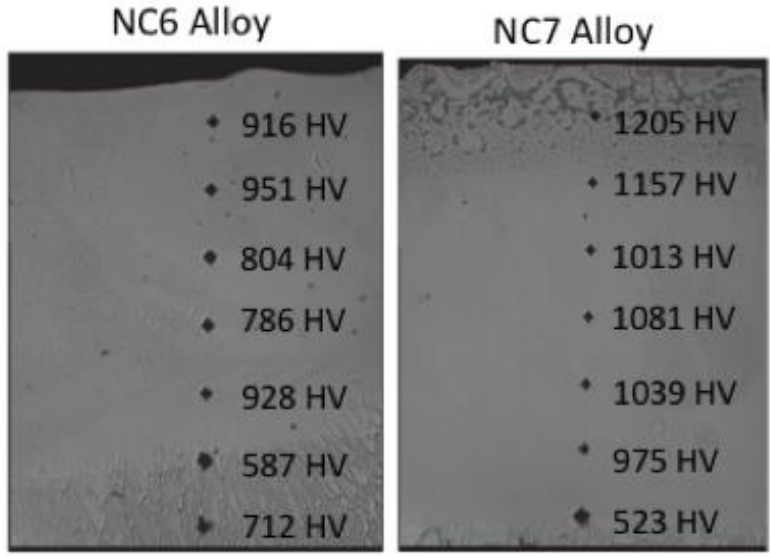
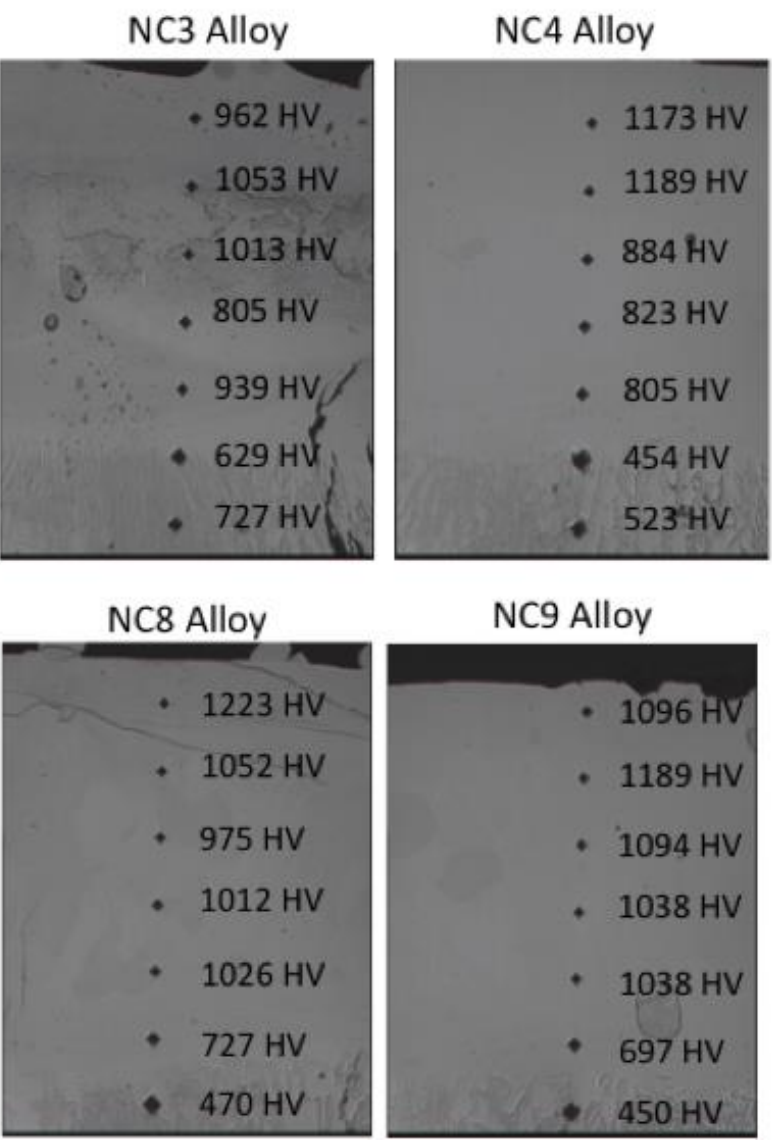

Figure 55. Hardness profiles of the chromium steel cast paddle compared to the hardness profiles of the nanocomposite coatings deposited on the paddle.

NC8 was down selected for performing the laser fusing of paddles for field trials based on the hardness profiles and previous performance in abrasive loop tests. A $+325 \mathrm{M}$ cut of the powder was once again laser fused to the $\mathrm{Cr}$ Steel paddles using the POM DMD ${ }^{\mathrm{TM}}$ free form laser. Six paddles were fused in total for field evaluations. Coating thicknesses were not individually measured, but the same procedure was used as the laboratory trial samples, and is therefore expected to be between 0.4 and $0.7 \mathrm{~mm}$ in thickness. The large face of the paddles and two sides were coated.
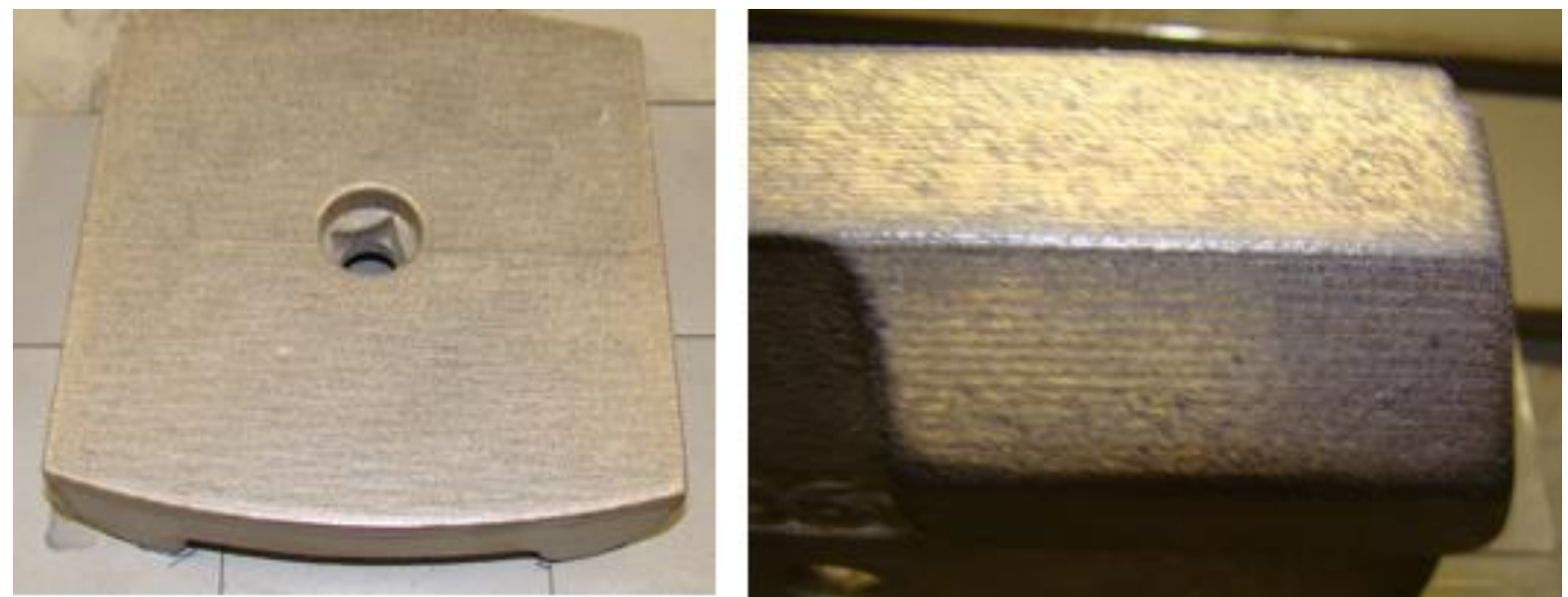

Figure 56. Laser fused nanocomposite coating on mixing paddles showing front face (left) and sides (right). 
The 6 paddles were delivered to the quarry site, and installed in the equipment in late 2010. Adjacent uncoated paddles were installed at the same time. The coated paddles were tested in the field for over 2 years. A field inspection was performed in January 2012 (a little over one year of field performance) to visually inspect the paddles. The coatings were still intact and performing well at this interim inspection. The uncoated paddle installed at the same time underwent minor abrasion, but seemed to be in very good shape. The condition of the uncoated paddle was much better than anticipated based on early discussions where paddles could be replaced every six months. However, replacement of the paddles is highly dependent on the frequency of use and demand of fine aggregate.
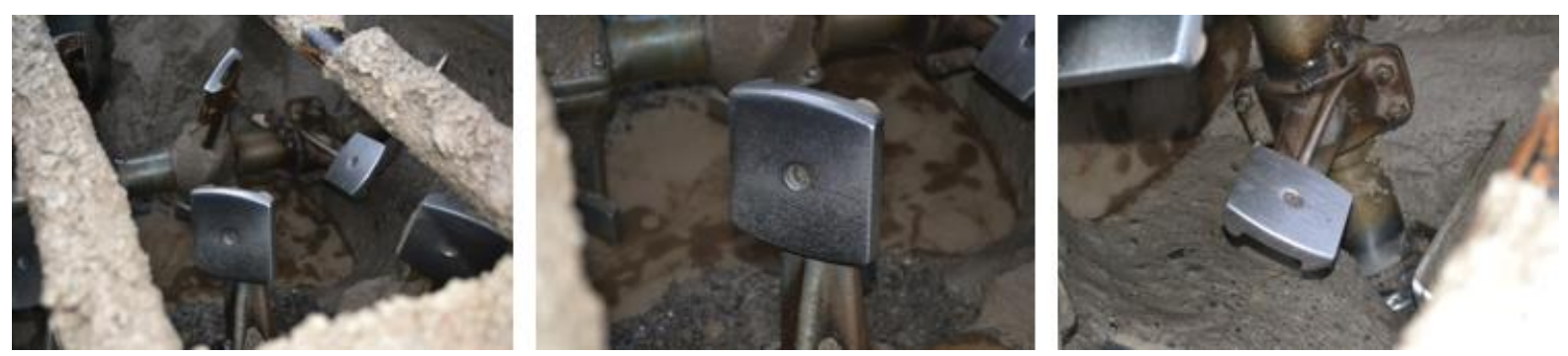

Figure 57. Annual inspection of paddles (left). The nanocomposite coatings were still intact and appeared to be in good shape (center). The uncoated paddle installed at the same time exhibited visual signs of light abrasion, but were in good condition (right).

After two years, the paddles were still in service, and in good condition. Two coated and two uncoated paddles were removed from the equipment. The workload on the equipment was extremely high. Vulcan requested that the other four paddles remain in service. The two coated paddles removed were good specimens of all in service. Less than 1 millimeter of wear occurred to the paddles. The coating was still present on each of the three faces originally fused (large face and two sides). Approximately half the coating was still visible on the largest face of the paddles fused. Due to the extremely low wear of the paddles over the two-year evaluation, no statistical differences in wear rate of coated and uncoated paddles were observed. Thicker coatings on more wear prone applications are suggested for any future evaluations. 


\section{COMMERCIALIZATION}

Three areas of technology development occurred in this project, glassy powder atomization, laser deposition of nanocomposite coatings, and solid state consolidation of bulk components. Each development area progressed, but are at different points of maturity. In order to accurately capture the current commercialization state, a description of the current status will be shared of each area, and then future requirements for maturation and implementation will be discussed.

\subsection{POWDER}

In total for this project, over 2,600 pounds and ten compositions of glassy powder were developed and atomized. One composition was scaled up to large, commercial gas atomization equipment and $1,278 \mathrm{lbs}$ fabricated. Processes losses for the commercial run were less than $4 \%$, and over $90 \%$ of the powder fell into the size categories required for powder metallurgy or laser deposition. Carpenter has exhibited the ability to produce powders commercially upon request. There have been several industrial enquires in the use of the powder, and independent evaluations for its use. If these evaluations are successful, commercial atomization runs can be performed to meet these demands. The commercial equipment, labor, and materials are available.

\subsection{POWDER METALLURGY}

Powder metallurgy of components is performed today using other powder feedstocks. The spherical nature of the gas-atomized powders allow for ease in flow and can filling. This procedure is well suited for making simple geometries such as rods or bearings. Several geometries were hot pressed to show the ability to make different shapes, as shown in figure 58.

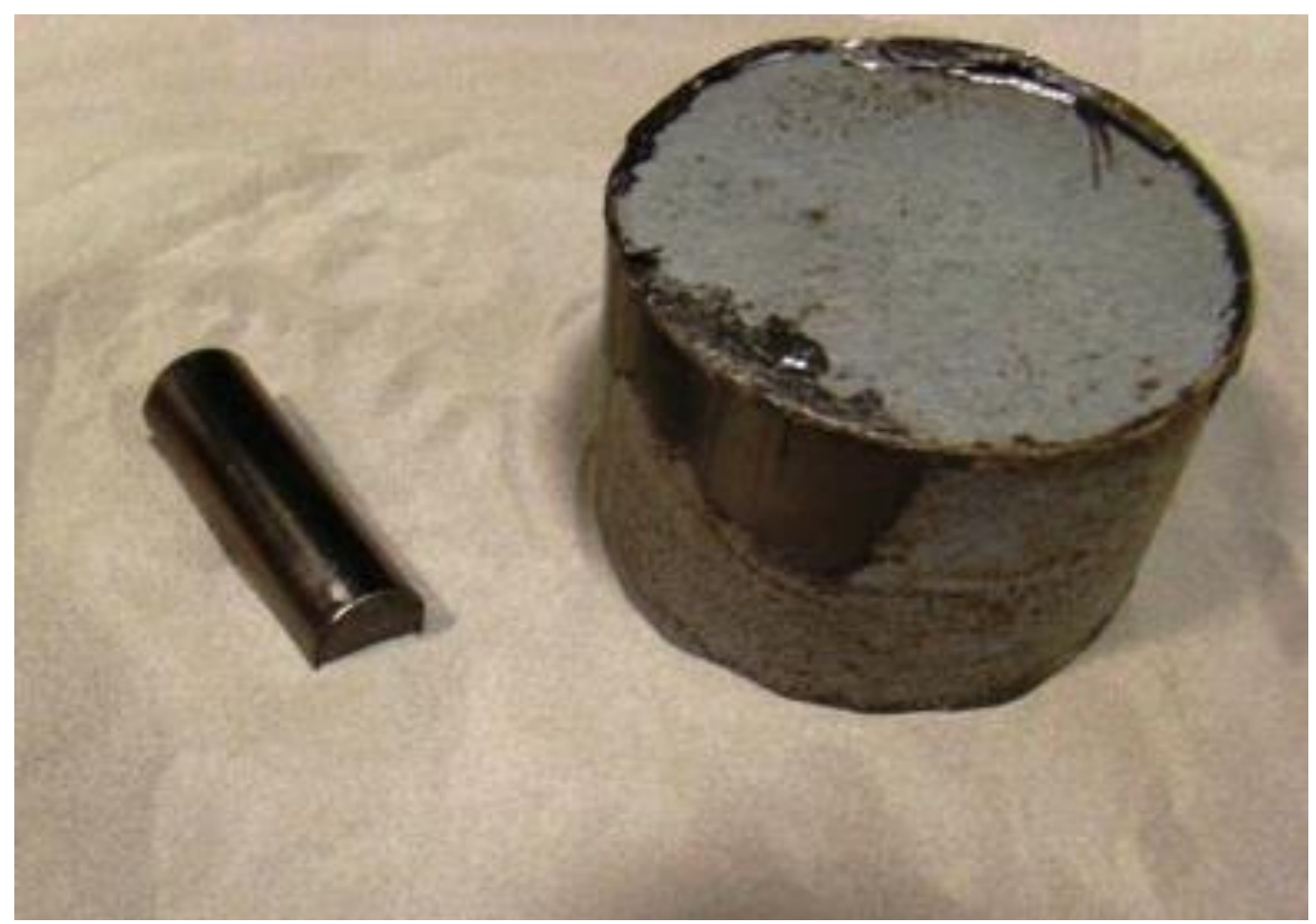

Figure 58. Consolidation of multiple sizes from $1 / 2$ " diameter to 2 " diameter. 
The use of a mandrel would allow for the fabrication of tubes and pipes. Hot isostatic pressing houses are available that are independently operated and consolidate powder on a toll basis. Carpenter won an R\&D 100 Award in 2011for the Dynaforging process, and that process is currently commercially available. Complex geometries or net shapes are not as mature for these nanocomposite alloys, but similar procedures as those found in the consolidation of tungsten carbide cobalt could be used. Some development would need to be performed on optimizing parameters to make net shapes. Net shape fabrication of components is important due to the difficulty and expense in machining the Fe-based nanocomposites developed in this project. As part of this project, a cylinder was machined into a bit for a mine pick or drill head, exhibiting the ability to machine. However, the machining was costly and went through multiple grinding bits.

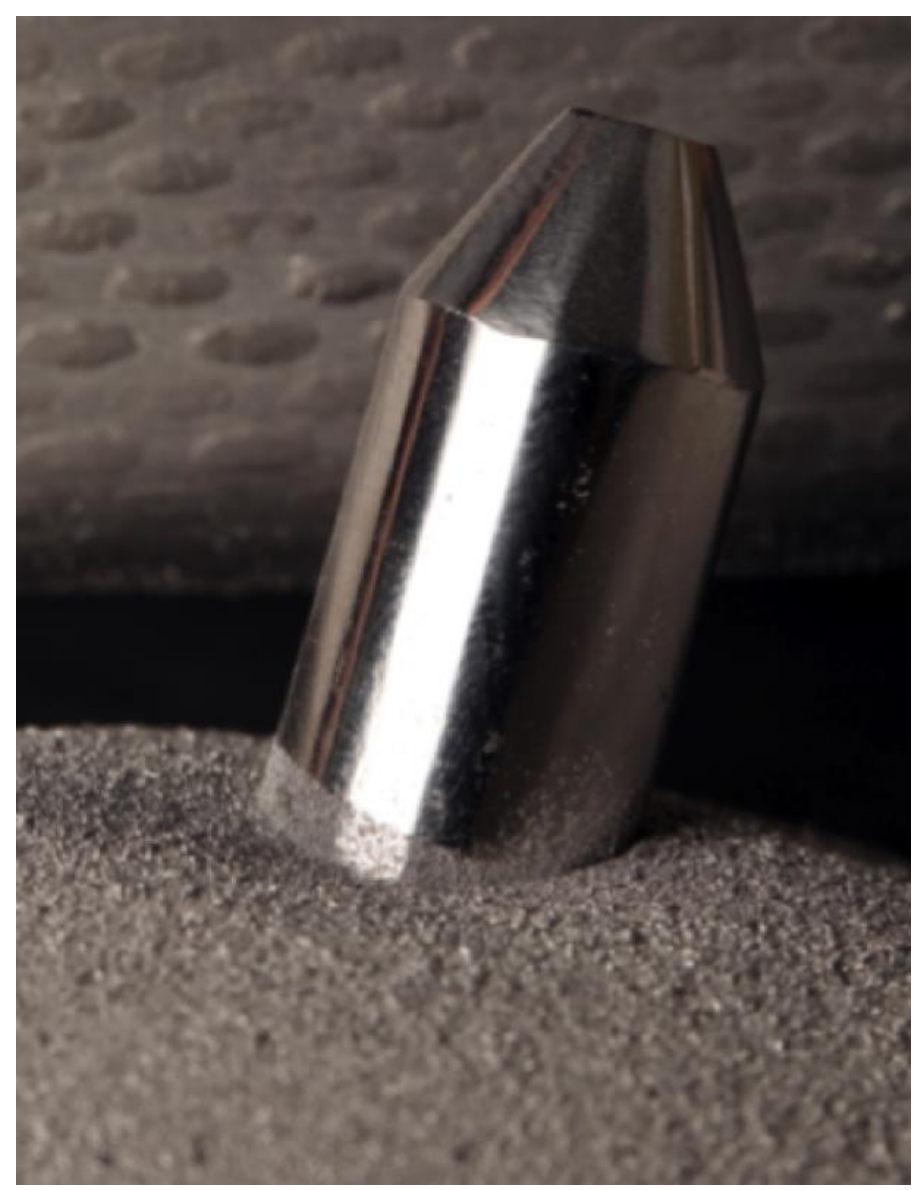

Figure 59: Machined bit from NC1 composition.

\subsection{LASER DEPOSITION}

Other shapes and geometries were performed with nanocrystalline coatings from this process. These samples did not undergo field evaluation, but exhibited the ability to coat various geometries. The coating of complex geometries takes operator time for providing the machine code similar to computer numeric control machining. Laser cladding outfits currently make commercial runs at the laser fusing of coatings to components. The laser and powder parameters could be transferred to a company, but have not been at this point since a specific component has not been chosen for commercial implementation or a business case made. As part of this project, ORNL fused other components as well to demonstrate the ability to fuse varying geometries and tool steels, as an example shown in figure 60. 

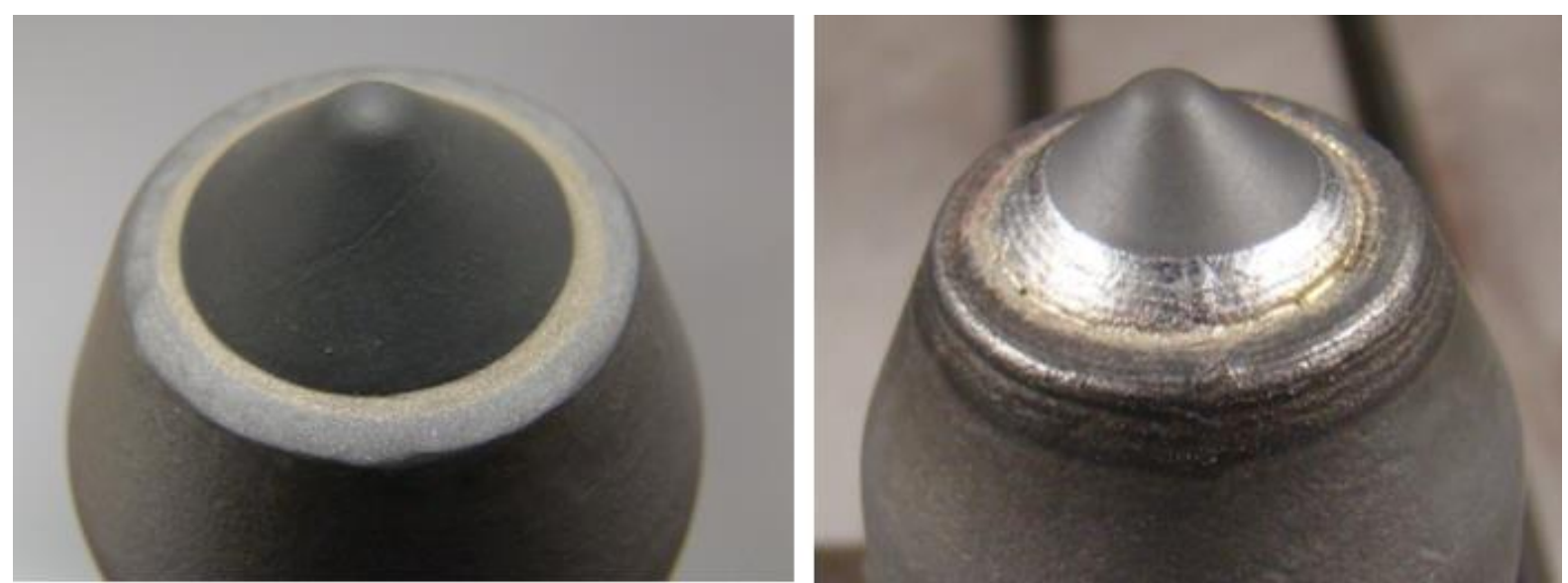

Figure 60. Conical Tool before and after laser coating with Alloy 8. Coating of the shoulder of the conical tool results in increased wear performance and maintains the integrity of the $\mathrm{WC} / \mathrm{Co}$ insert. The coating did not effect or crack the insert during the deposition process.

Several activities are currently ongoing as a follow up to this project. ORNL has provided powder to three commercial entities to evaluate laser or other fusing activity to make coatings for a range of applications including down hole, drilling, and heavy equipment. The development of the laser fused coatings and preliminary results in tunnel boring applications led to the receiving of an R\&D100 Award in 2012(figure 61). The award was based on patent no. 7,939,142 B2 awarded May 10, 2011 for the "In-Situ Composite Formation of Damage Tolerant Coatings Utilizing Laser".

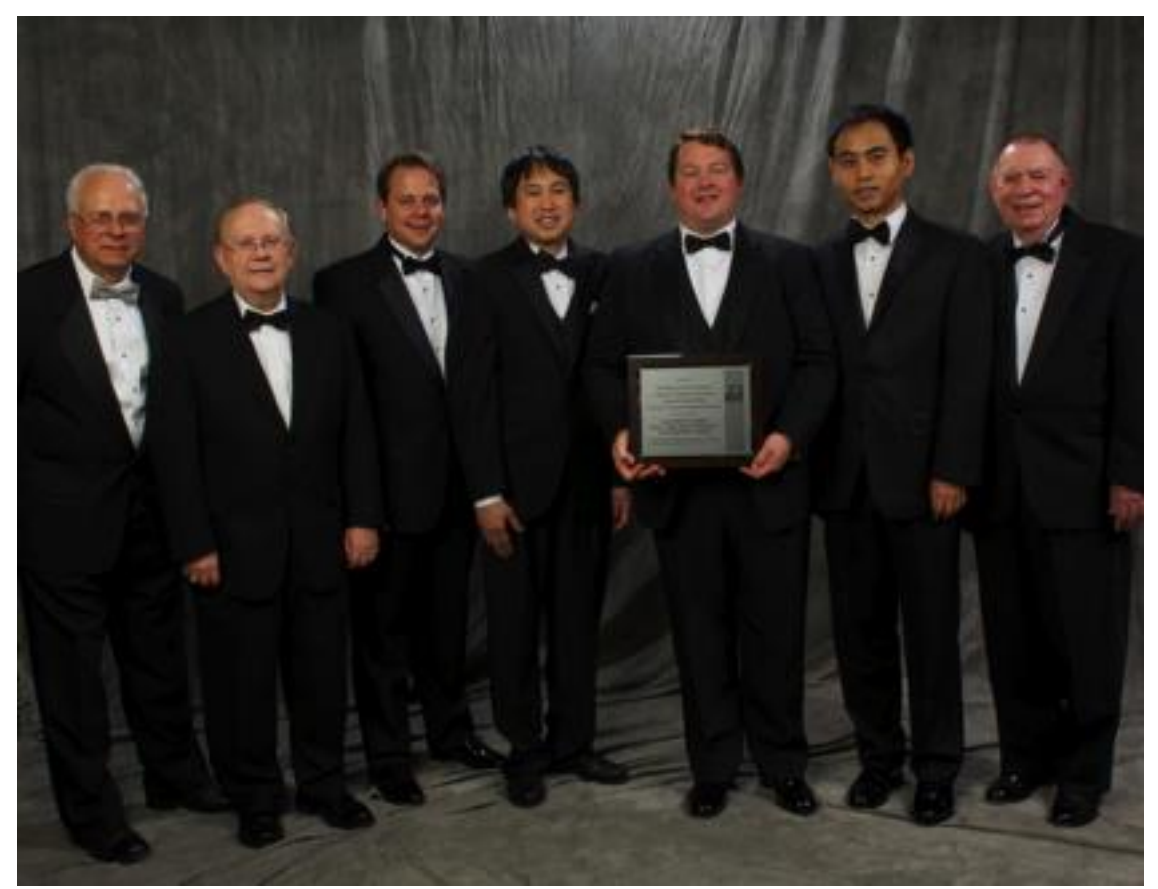

Figure 61. Nanocomposites team won an R\&D 100 Award entitled "NanoSHIELD" for the development laser fusing of amorphous powders to fabricate "Super Hard InExpensive Laser Deposited" nanocomposite coatings. 


\section{CONCLUSIONS}

The following technical accomplishments were met in the project:

1) Over 2,600 pounds of amorphous or nanocrystalline powder was atomized: ORNL worked with Carpenter Powder Products to produce ten different Fe-based nanocomposite powders. Research heats of approximately $250 \mathrm{lbs}$. were produced for each composition. The chemical composition of atomized powder matched the desired target chemistry. The amorphous content of the powder was dependent on powder particle size with many of the compositions showing amorphous behavior at -325 mesh. Amorphous nature of the powder was dependent on both powder chemistry and powder size.

2) Commercial gas atomization run successfully performed:

Carpenter Powder Products produced a commercial size atomization run of Alloy 8 totaling $1278 \mathrm{lbs}$. net charge weight. The powder yield for the atomization demonstrated only $4 \%$ material loss, with $96 \%$ powder production efficiency. This is significantly improved from previous gas atomization runs of Fe-based powders. The chemistry of the powder was low in Mo and W due to high melting temperature and density of these elements. Information learned from this atomization run will enable Carpenter Powder Products to atomize on specification powder in subsequent atomization runs.

3) NanoComposite coatings were successfully fabricated through laser deposition: Two different laser deposition technologies, a 4kW Nd:YAG laser and a $1 \mathrm{~kW}$ diode laser on a POM DMD ${ }^{\mathrm{TM}}$, were utilized to fuse the Fe-based powders to various steel substrates. The POM laser deposition technology produced more uniform coatings with less cracking than the $4 \mathrm{~kW} \mathrm{Nd:YAG} \mathrm{laser} \mathrm{system.} \mathrm{Preheating} \mathrm{of} \mathrm{the} \mathrm{substrate} \mathrm{improved} \mathrm{resistance} \mathrm{of} \mathrm{the}$ coating to cracking during deposition.

4) Bulk NanoComposite materials were successfully produced:

Three powder consolidation technologies, vacuum hot pressing (VHP), hot isostatic pressing (HIP), and the Dynaforge ${ }^{\mathrm{TM}}$ process, were utilized to produce bulk NanoComposite material. HIP at $2125 \mathrm{~F}$ yielded fully consolidated material with the best balance of mechanical properties and wear resistance.

5) Fe-based NanoComposite materials produced as coatings and bulk components demonstrated improved mechanical performance for high wear applications: Abrasive loop wear testing on NanoComposite materials demonstrated a nearly two orders of magnitude in abrasive loop wear factor compared to conventional substrate materials, $5.104 \mathrm{x}$ $10^{-3}$ for $\mathrm{H} 13$ and $7.500 \times 10^{-5}$ for Alloy 8 in the HIP'ed condition. In addition to wear, the NanoComposite materials exhibited limited, but measurable compressive ductility.

6) NanoComposite materials were fused to industrial components and field evaluated:

Various compositions of NanoComposite materials were fused to industrial aggregate mixing paddles. The paddles were installed at Vulcan Materials Company in the Dixie Lee Facility and evaluated for performance during field evaluations. Due to limited wear of components, lifetime improvements could not be measured or quantified. 


\section{RECOMMENDATIONS}

The project has demonstrated the ability to produce Fe-based nanocomposite powder materials on a commercial/industrial size scale at Carpenter Powder Products. The project team has demonstrated the ability to utilize these alloy powders in laser fusing processes to create coatings with high hardness values and increased wear resistance. Bulk components have been fabricated and mechanical properties have been assessed for processing methodologies including HIP, VHP and the Dynaforge Process. Coating performance has been evaluated on an industrial aggregate mixing paddle at Vulcan Materials Company. The industrial application chosen was not aggressive enough to determine the true impact of the coating on resistance to wear and improved component performance.

Future projects should concentrate on applications with more aggressive or complex wear behavior. In addition to abrasive wear, erosive wear, fretting wear, and surface fatigue could be studied. Complex stress states including combinations of impact, corrosion, environment, temperature in combination of wear should be examined. In many down hole applications such as those observed in commercial drilling or geothermal well formation, the environmental impacts can play a significant role in addition to the wear environment. Alloy composition modifications may be necessary in order to improve the corrosion resistance or mechanical performance of these materials. Although ten different alloys were studied in this project, many additional alloy combinations may be beneficial for specifically targeted applications. Because Fe-based nanocomposite materials are a relatively new class of materials, additional information will be needed in terms of mechanical properties, coarsening behavior at elevated temperatures, and corrosion properties of the material to allow industry to broadly accept this class of materials as an alternative to high value coating such as tungsten carbide cobalt based materials or other nickel based materials. 


\section{REFERENCES / BIBLIOGRAPHY}

1 G.E. Dieter, Mechanical Metallurgy, McGraw-Hill, pp. 184-240, 1984.

2 R.W. Hertzberg, Deformation and Fracture Mechanics of Engineering Materials, 3 rd Ed., John Wiley \& Sons, pp. 132-136, 1989.

3 C.C. Koch and C. Suryanarayana, "Nanocrystalline Materials" in Microstructure and Properties of Materials, Vol. 2, J.C.M. Li, Ed, World Scientific Publishing, pp. 359-403, 2000.

4 C. C. Koch, "Bulk Behavior of Nanostructured Materials" in Nanostructure Science and Technology, A Worldwide Study, R.W. Siegel, E. Hu, M.C. Roco, Eds., Kluwer Academic Publishers, pp. 93-111, 1999.

5 P. Holister, C.R. Vas, T. Harper, "Nanocrystalline Materials": Technology White Papers nr.4, Cientifica, Ltd., pp. 1-12, 2003.

6 B.S. Murty, M.K. Datta, and S.K. Pabi, "Structure and thermal stability of nanocrystalline materials", Sadhana, Vol. 28, Parts 1\& 2, pp. 23-45, 2003.

7 C. Suryanarayana, "The Structure and Properties of Nanocrystalline Materials: Issues and Concerns", JOM, Vol. 54, No. 9, pp. 24-27, 2002.

8 R.W. Siegel, Nanostructured Mater., 4 [1], 121-138, (1994).

9 G.W. Nieman et al., J. Mater. Res., 61012 (1991).

10 M.J. Mayo et al., J. Mater. Res., 51073 (1990).

11 M.J. Mayo et al., J. Mater. Res., 7973 (1992).

12 D.W. Matson et al., Energy \& Fuels, 8 [1] 10-18 (1994).

13 R. Dagani, Chem. \& Eng'g News, 18-24, November 23, (1992).

14 Summary of the Workshop on Structural Naomaterials, R. Dowding and D. Durham (eds.)

National Materials Advisory Board, NRC, National Academy Press, Washington, D. C., 2001.

15 H. Conrad and J. Narayan, Script. Met. 42, 1025 (2000).

16 A. Inoue, Acta Mater. 48 (2000) p 281

17 Surface Engineering for Corrosion and Wear. J.R. Davis Ed. ASM International, Materials Park, OH. 2001. 